\title{
Granulocyte transfusions for preventing infections in people with neutropenia or neutrophil dysfunction (Review)
}

Estcourt LJ, Stanworth S, Doree C, Blanco P, Hopewell S, Trivella M, Massey E
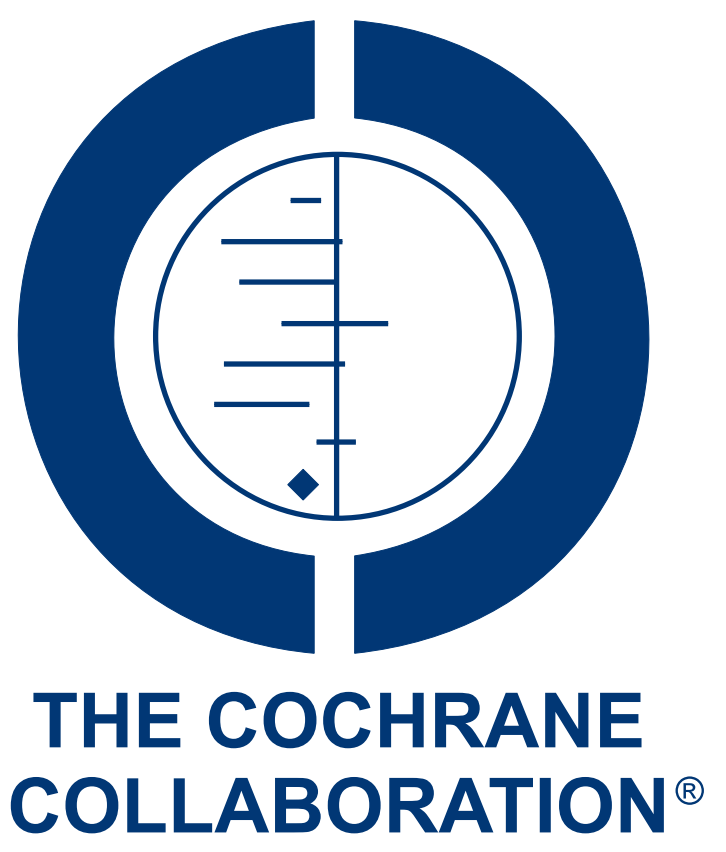

This is a reprint of a Cochrane review, prepared and maintained by The Cochrane Collaboration and published in The Cochrane Library 2015, Issue 6

http://www.thecochranelibrary.com

\section{WILEY}

Granulocyte transfusions for preventing infections in people with neutropenia or neutrophil dysfunction (Review)

Copyright $\odot 2015$ The Cochrane Collaboration. Published by John Wiley \& Sons, Ltd. 
TABLE OF CONTENTS

HEADER . . . . . . . . . . . . . . . . . . . . . . . . . . . . . . . . . . . . 1

ABSTRACT . . . . . . . . . . . . . . . . . . . . . . . . . . . . . . . . . . . . . . . . . . . . . . .

PLAIN LANGUAGE SUMMARY . . . . . . . . . . . . . . . . . . . . . . . . . . . . . . . . . . . .

SUMMARY OF FINDINGS FOR THE MAIN COMPARISON $\quad$. . . . . . . . . . . . . . . . . . . . . . . . . . . 4

BACKGROUND . . . . . . . . . . . . . . . . . . . . . . . . . . . . . . . . . . . . . . . . . . . . . .

OBJECTIVES . . . . . . . . . . . . . . . . . . . . . . . . . . . . . . . . . . . . . . . . . . . . .

METHODS . . . . . . . . . . . . . . . . . . . . . . . . . . . . . . . . . . . . . .

RESUlTS . . . . . . . . . . . . . . . . . . . . . . . . . . . . . . . . . . . . . 11

Figure 1. . . . . . . . . . . . . . . . . . . . . . . . . . . . . . . . . . . . 12

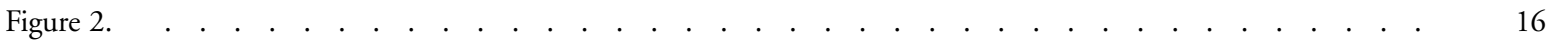

Figure $3 . \quad$. . . . . . . . . . . . . . . . . . . . . . . . . . . . . . . . . . . . . 17

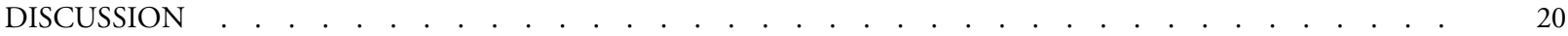

AUTHORS' CONCLUSIONS . . . . . . . . . . . . . . . . . . . . . . . . . . . . . . . . .

ACKNOWLEDGEMENTS . . . . . . . . . . . . . . . . . . . . . . . . . . . . . . . . . . . .

REFERENCES . . . . . . . . . . . . . . . . . . . . . . . . . . . . . . . . . . . . . . 23

CHARACTERISTICS OF STUDIES . . . . . . . . . . . . . . . . . . . . . . . . . . . . . . 27

DATA AND ANALYSES . . . . . . . . . . . . . . . . . . . . . . . . . . . . . . . . . . . 53

ADDITIONAL TABLES . . . . . . . . . . . . . . . . . . . . . . . . . . . . . . . . . . . 54

WHAT'S NEW . . . . . . . . . . . . . . . . . . . . . . . . . . . . . . . . . . . . . 61

HISTORY . . . . . . . . . . . . . . . . . . . . . . . . . . . . . . . . . . . . . . . 61

CONTRIBUTIONS OF AUTHORS . . . . . . . . . . . . . . . . . . . . . . . . . . . . . . . . . . . . . . . . . .

DECLARATIONS OF INTEREST . . . . . . . . . . . . . . . . . . . . . . . . . . . . . . . . . . . . . . . . . 62

SOURCES OF SUPPORT . . . . . . . . . . . . . . . . . . . . . . . . . . . . . . . . . . 62

DIFFERENCES BETWEEN PROTOCOL AND REVIEW . . . . . . . . . . . . . . . . . . . . . . 63

INDEX TERMS . . . . . . . . . . . . . . . . . . . . . . . . . . . . . . . . . . . . . 63

Granulocyte transfusions for preventing infections in people with neutropenia or neutrophil dysfunction (Review)

Copyright $\odot 2015$ The Cochrane Collaboration. Published by John Wiley \& Sons, Ltd. 


\title{
[Intervention Review] \\ Granulocyte transfusions for preventing infections in people with neutropenia or neutrophil dysfunction
}

\author{
Lise J Estcourt ${ }^{1}$, Simon Stanworth ${ }^{2}$, Carolyn Doree ${ }^{3}$, Patricia Blanco ${ }^{3}$, Sally Hopewell ${ }^{4}$, Marialena Trivella ${ }^{4}$, Edwin Massey $^{5}$ \\ ${ }^{1}$ Haematology/Transfusion Medicine, NHS Blood and Transplant, Oxford, UK. ${ }^{2}$ National Institute for Health Research (NIHR) \\ Oxford Biomedical Research Centre, Oxford University Hospitals and the University of Oxford, Oxford, UK. ${ }^{3}$ Systematic Review \\ Initiative, NHS Blood and Transplant, Oxford, UK. ${ }^{4}$ Centre for Statistics in Medicine, University of Oxford, Oxford, UK. ${ }^{5}$ NHS \\ Blood and Transplant, Bristol, UK \\ Contact address: Lise J Estcourt, Haematology/Transfusion Medicine, NHS Blood and Transplant, Level 2, John Radcliffe Hospital, \\ Headington, Oxford, OX3 9BQ, UK. lise.estcourt@nhsbt.nhs.uk. lise.estcourt@ndcls.ox.ac.uk.
}

Editorial group: Cochrane Gynaecological Cancer Group.

Publication status and date: New search for studies and content updated (no change to conclusions), published in Issue 6, 2015.

Review content assessed as up-to-date: 20 April 2015.

Citation: Estcourt LJ, Stanworth S, Doree C, Blanco P, Hopewell S, Trivella M, Massey E. Granulocyte transfusions for preventing infections in people with neutropenia or neutrophil dysfunction. Cochrane Database of Systematic Reviews 2015, Issue 6. Art. No.: CD005341. DOI: 10.1002/14651858.CD005341.pub3.

Copyright (C) 2015 The Cochrane Collaboration. Published by John Wiley \& Sons, Ltd.

\begin{abstract}
A B S T R A C T
Background

Despite modern antimicrobials and supportive therapy, bacterial and fungal infections are still major complications in people with prolonged disease-related or therapy-related neutropenia. Since the late 1990s there has been increasing demand for donated granulocyte transfusions to treat or prevent severe infections in people who lack their own functional granulocytes. This is an update of a Cochrane review first published in 2009.
\end{abstract}

\section{Objectives}

To determine the effectiveness and safety of prophylactic granulocyte transfusions compared with a control population not receiving this intervention for preventing all-cause mortality, mortality due to infection, and evidence of infection due to infection or due to any other cause in people with neutropenia or disorders of neutrophil function.

\section{Search methods}

We searched for randomised controlled trials (RCTs) and quasi-RCTs in the Cochrane Central Register of Controlled Trials (Cochrane Library 2015, Issue 3), MEDLINE (from 1946), EMBASE (from 1974), CINAHL (from 1937), theTransfusion Evidence Library (from 1980) and ongoing trial databases to April 202015.

\section{Selection criteria}

Randomised controlled trials (RCTs) and quasi-RCTs comparing people receiving granulocyte transfusions to prevent the development of infection with a control group receiving no granulocyte transfusions. Neonates are the subject of another Cochrane review and were excluded from this review. There was no restriction by outcomes examined, but this review focuses on mortality, mortality due to infection and adverse events.

\section{Data collection and analysis}

We used standard methodological procedures expected by The Cochrane Collaboration.

Granulocyte transfusions for preventing infections in people with neutropenia or neutrophil dysfunction (Review)

Copyright $\odot 2015$ The Cochrane Collaboration. Published by John Wiley \& Sons, Ltd. 


\section{Main results}

Twelve trials met the inclusion criteria. One trial is still ongoing, leaving a total of 11 trials eligible involving 653 participants. These trials were conducted between 1978 and 2006 and enrolled participants from fairly comparable patient populations. None of the studies included people with neutrophil dysfunction. Ten studies included only adults, and two studies included children and adults. Ten of these studies contained separate data for each arm and were able to be critically appraised. One study re-randomised people and therefore quantitative analysis was unable to be performed.

Overall, the quality of the evidence was very low to low across different outcomes according to GRADE methodology. This was due to many of the studies being at high risk of bias, and many of the outcome estimates being imprecise.

All-cause mortality was reported for nine studies (609 participants). There was no difference in all-cause mortality over 30 days between people receiving prophylactic granulocyte transfusions and those that did not (seven studies; 437 participants; RR 0.92, 95\% CI 0.63 to 1.36 , very low-quality evidence).

Mortality due to infection was reported for seven studies (398 participants). There was no difference in mortality due to infection over 30 days between people receiving prophylactic granulocyte transfusions and those that did not (six studies; 286 participants; RR 0.69 , $95 \%$ CI 0.33 to 1.44 , very low-quality evidence).

The number of people with localised or systemic bacterial or fungal infections was reported for nine studies (609 participants). There were differences between the granulocyte dose subgroups (test for subgroup differences $\mathrm{P}=0.01$ ). There was no difference in the number of people with infections over 30 days between people receiving prophylactic granulocyte transfusions and those that did not in the low-dose granulocyte group $\left(<1.0 \times 10^{10}\right.$ granulocytes per day) (four studies, 204 participants; RR 0.84, 95\% CI 0.58 to 1.20; very low-quality evidence). There was a decreased number of people with infections over 30 days in the people receiving prophylactic granulocyte transfusions in the intermediate-dose granulocyte group $\left(1.0 \times 10^{10}\right.$ to $4.0 \times 10^{10}$ granulocytes per day) (4 studies; 293 participants; RR $0.40,95 \%$ CI 0.26 to 0.63 , low-quality evidence).

There was a decreased number of participants with bacteraemia and fungaemia in the participants receiving prophylactic granulocyte transfusions (nine studies; 609 participants; RR 0.45, 95\% CI 0.30 to 0.65 , low-quality evidence).

There was no difference in the number of participants with localised bacterial or fungal infection in the participants receiving prophylactic granulocyte transfusions (six studies; 296 participants; RR 0.75, 95\% CI 0.50 to 1.14; very low-quality evidence).

Serious adverse events were only reported for participants receiving granulocyte transfusions and donors of granulocyte transfusions.

\section{Authors' conclusions}

In people who are neutropenic due to myelosuppressive chemotherapy or a haematopoietic stem cell transplant, there is low-grade evidence that prophylactic granulocyte transfusions decrease the risk of bacteraemia or fungaemia. There is low-grade evidence that the effect of prophylactic granulocyte transfusions may be dose-dependent, a dose of at least $10 \times 10^{10}$ per day being more effective at decreasing the risk of infection. There is insufficient evidence to determine any difference in mortality rates due to infection, all-cause mortality, or serious adverse events.

\section{PLAIN LANGUAGESUMMARY}

\section{Transfusions of white blood cells called granulocytes for preventing infections in people who lack functioning granulocytes}

\section{Review question}

We evaluated the evidence about whether granulocyte transfusions given to prevent infection are safe and decrease the risk of infection. Our target population was people with neutropenia (a very low count of a type of white blood cell (neutrophil), or white blood cells that did not function properly (neutrophil dysfunction).

\section{Background}

Functioning white blood cells, in particular granulocytes, are important for fighting life-threatening bacterial and fungal infections. For many years, some hospital physicians have been giving granulocyte transfusions to people who lack white cells as a result of disease and/or treatment that has reduced their number or function.

Granulocyte transfusions for preventing infections in people with neutropenia or neutrophil dysfunction (Review) 
The demand for granulocytes for transfusion has shown a steady increase since the 1990s mainly as a result of the introduction of a drug called granulocyte colony-stimulating factor (G-CSF) which, if given to donors, leads to increased granulocyte numbers in the donor's blood and the collection of a larger dose of granulocytes than was previously possible.

\section{Study characteristics}

The evidence is current to April 2015. In this update, 12 trials were identified that compared giving granulocyte transfusions to prevent infections compared to not giving granulocytes to prevent infection. One trial has not yet been completed. Eleven trials containing a total of 653 participants were reviewed. These trials were conducted between 1978 and 2006. Data from one trial were not included in the analyses because patients were included within the trial more than once. Ten studies included only adults, and two studies included children and adults.

Six studies reported their funding sources, and all were funded by charities or governments.

\section{Key results}

Giving granulocyte transfusions to prevent infections did not affect the risk of death due to infection, or the risk of death due to any cause.

Giving granulocyte transfusions to prevent infections decreased the number of people who had a bacterial or fungal infection in the blood, but did not decrease the number of people having a localised bacterial or fungal infection.

It is unknown whether granulocyte transfusions increased the risk of having a serious adverse event because adverse events were only reported in people receiving granulocyte transfusions.

\section{Quality of the evidence}

The evidence for most of the findings was of very low or low quality. This was because patients and their doctors knew which study arm the patient had been allocated to and two of the studies were not true randomised studies (patients were allocated to the granulocyte transfusion arm if they had a suitable granulocyte donor). 


\section{SUMMARY OF FINDINGSFOR THE MAIN COMPARISON [Explanation]}

Prophylactic granulocytes compared with no prophylactic granulocytes for preventing infection in people with neutropenia or neutrophil dysfunction

Patient or population: people with neutropenia or neutrophil dysfunction

Settings: Hospital

Intervention: prophylactic granulocytes

Comparison: no prophylactic granulocytes

\begin{tabular}{|c|c|c|c|c|c|c|}
\hline \multirow[t]{3}{*}{ Outcomes } & \multicolumn{2}{|c|}{ Illustrative comparative risks* (95\% CI) } & \multirow{3}{*}{$\begin{array}{l}\text { Relative effect } \\
(95 \% \mathrm{CI})\end{array}$} & \multirow{3}{*}{$\begin{array}{l}\text { No of Participants } \\
\text { (studies) }\end{array}$} & \multirow{3}{*}{$\begin{array}{l}\text { Quality of the evidence } \\
\text { (GRADE) }\end{array}$} & \multirow[t]{3}{*}{ Comments } \\
\hline & Assumed risk & Corresponding risk & & & & \\
\hline & Control & $\begin{array}{l}\text { Prophylactic granulo- } \\
\text { cytes }\end{array}$ & & & & \\
\hline $\begin{array}{l}\text { All-cause mortality up to } \\
\mathbf{3 0} \text { days } \\
\text { Follow-up: median } 30 \\
\text { days }\end{array}$ & 145 per 1000 & $\begin{array}{l}134 \text { per } 1000 \\
(91 \text { to } 198)\end{array}$ & $\begin{array}{l}\text { RR } \mathbf{0 . 9 2} \\
\text { (0.63 to } 1.36)\end{array}$ & $\begin{array}{l}437 \\
\text { (7 studies) }\end{array}$ & $\begin{array}{l}\oplus \bigcirc \bigcirc \bigcirc \\
\text { very low }\end{array}$ & \\
\hline $\begin{array}{l}\text { Mortality due to infection } \\
\text { up to } 30 \text { days } \\
\text { Follow-up: median } 30 \\
\text { days }\end{array}$ & 98 per 1000 & $\begin{array}{l}68 \text { per } 1000 \\
(32 \text { to } 141)\end{array}$ & $\begin{array}{l}\text { RR } 0.69 \\
(0.33 \text { to } 1.44)\end{array}$ & $\begin{array}{l}286 \\
\text { (6 studies) }\end{array}$ & $\begin{array}{l}\oplus \bigcirc \bigcirc \bigcirc \\
\text { very low }\end{array}$ & \\
\hline $\begin{array}{l}\text { People with localised } \\
\text { or systemic bacterial or } \\
\text { fungal infections - low- } \\
\text { dose granulocyte trans- } \\
\text { fusions } \\
\text { Follow-up: median } 30 \\
\text { days }\end{array}$ & 374 per 1000 & $\begin{array}{l}314 \text { per } 1000 \\
(217 \text { to } 141)\end{array}$ & $\begin{array}{l}\text { RR } \mathbf{0 . 8 4} \\
(0.58 \text { to } 1.2)\end{array}$ & $\begin{array}{l}204 \\
\text { (4 studies) }\end{array}$ & $\begin{array}{l}\oplus \bigcirc \bigcirc \bigcirc \\
\text { very low } 1,2,3\end{array}$ & \\
\hline
\end{tabular}




\begin{tabular}{|c|c|c|c|c|c|c|}
\hline $\begin{array}{l}\text { People with localised } \\
\text { or systemic bacterial or } \\
\text { fungal infections - In- } \\
\text { termediate-dose granu- } \\
\text { locyte transfusions } \\
\text { Follow-up: median } 30 \\
\text { days }\end{array}$ & 376 per 1000 & $\begin{array}{l}150 \text { per } 1000 \\
\text { (98 to } 237)\end{array}$ & $\begin{array}{l}\text { RR } 0.4 \\
(0.26 \text { to } 0.63)\end{array}$ & $\begin{array}{l}293 \\
\text { (4 studies) }\end{array}$ & $\begin{array}{l}\oplus \oplus \bigcirc \bigcirc \\
\mathbf{l}_{\mathbf{0}} \mathbf{w}^{1,2}\end{array}$ & \\
\hline $\begin{array}{l}\text { People with bacteraemia } \\
\text { or fungaemia } \\
\text { Follow-up: median } 30 \\
\text { days }\end{array}$ & 249 per 1000 & $\begin{array}{l}112 \text { per } 1000 \\
\text { (75 to } 162)\end{array}$ & $\begin{array}{l}\text { RR } 0.45 \\
(0.3 \text { to } 0.65)\end{array}$ & $\begin{array}{l}609 \\
\text { (9 studies) }\end{array}$ & $\begin{array}{l}\oplus \oplus \bigcirc \bigcirc \\
\mathbf{l}_{\mathbf{0}} \mathbf{w}^{1,2}\end{array}$ & \\
\hline $\begin{array}{l}\text { People with localised } \\
\text { bacterial or fungal infec- } \\
\text { tion } \\
\text { Follow-up: median } 30 \\
\text { days }\end{array}$ & 271 per 1000 & $\begin{array}{l}204 \text { per } 1000 \\
(136 \text { to } 309)\end{array}$ & $\begin{array}{l}\text { RR } 0.75 \\
(0.50 \text { to } 1.14)\end{array}$ & $\begin{array}{l}296 \\
\text { (6 studies) }\end{array}$ & $\begin{array}{l}\oplus \bigcirc \bigcirc \bigcirc \\
\text { very low } 1,2,3\end{array}$ & \\
\hline $\begin{array}{l}\text { People with serious ad- } \\
\text { verse events }\end{array}$ & See comment & See comment & See comment & See comment & See comment & $\begin{array}{l}\text { Adverse events were } \\
\text { only reported for the } \\
\text { groups receiving granulo- } \\
\text { cyte transfusions } \\
\text { See Table } 7 \& \text { Table } 8\end{array}$ \\
\hline
\end{tabular}

*The basis for the assumed risk (e.g. the median control group risk across studies) is provided in footnotes. The corresponding risk (and its $95 \%$ confidence interval) is based on the assumed risk in the comparison group and the relative effect of the intervention (and its $95 \% \mathrm{Cl}$ ).

Cl: Confidence interval; RR: Risk Ratio

GRADE Working Group grades of evidence

High quality: Further research is very unlikely to change our confidence in the estimate of effect.

Moderate quality: Further research is likely to have an important impact on our confidence in the estimate of effect and may change the estimate.

Low quality: Further research is very likely to have an important impact on our confidence in the estimate of effect and is likely to change the estimate.

Very low quality: We are very uncertain about the estimate.

${ }^{1}$ Owing to the nature of the intervention (granulocyte transfusion) and difficulty blinding participants, physicians and outcome assessors

studies were at high risk of performance and detection bias. We downgraded the evidence by 1 for risk of bias 


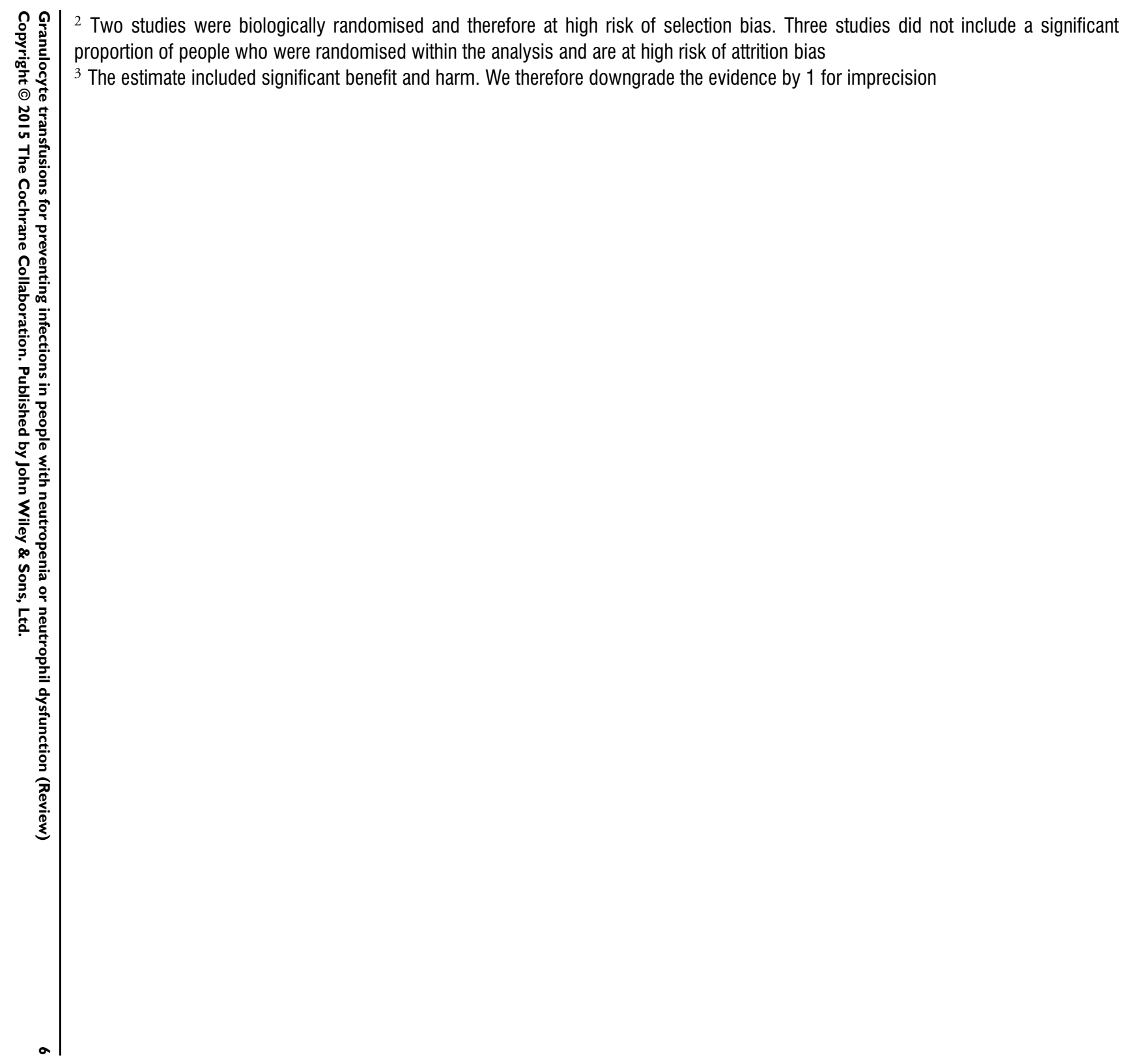




\section{B A C K G R O U N D}

\section{Description of the condition}

Functioning white blood cells are a vital component of the defence system against infection in humans. There are a variety of different white blood cells that work together and perform complementary roles. Granulocytes are white blood cells that contain granules which are directly visible when viewed through a light microscope. Neutrophils are a subtype of granulocytes and are the most numerous circulating white blood cells in healthy adults. Granulocytes in general and neutrophils in particular are crucial in protecting against bacterial and fungal infection. A persisting reduction in neutrophil numbers is called neutropenia, the severity of which has been classified by the World Health Organization (WHO 1992): when the peripheral blood count of neutrophils is below a level of $0.5 \times 10^{9} / \mathrm{L}$ there is an increased risk of severe infection (the normal neutrophil count ranges from 2 to $7.5 \times 10$ $9 / \mathrm{L}$ in adults). Idiosyncratic neutropenia occurs in the population with a frequency of 120 per million people per year (van Staa 2003), but neutropenia is also an inevitable complication of chemotherapy for malignant diseases, as well as a presenting feature of many haematological disorders. Infection in people with neutropenia is associated with hospital admission, organ damage, and a significant number of deaths, despite the use of specific and appropriate antibiotic and antifungal drugs (Klastersky 2001). Even with a normal number of neutrophils, other patients may suffer from a similar inability to fight infections adequately if there is an impairment in the function of their neutrophils (Kuijpers 1999).

\section{Description of the intervention}

Published reviews have suggested that the efficacy of granulocyte transfusions in neutropenic people is proportional to the dose of granulocytes transfused, with an optimal level being at least 10 ${ }^{10}$ granulocytes or at least $10^{10}$ granulocytes per metre squared of recipient body surface area per transfusion (Engelfriet 2000; Vamvakas 1996). However, there are a number of technical problems that make it difficult to collect adequate granulocyte doses for transfusion. Granulocytes are difficult to separate from other blood cells, and in addition healthy donors do not have very high levels of circulating granulocytes in their peripheral blood. There are a number of different methods for collecting granulocytes for transfusion in humans. Apheresis is a favoured technique utilising equipment incorporating a centrifuge or filter to selectively remove white blood cells from the donor whilst returning other cellular and liquid components to the donor (Freireich 1964). In the early 1990s, growth factors such as granulocyte colony-stimulating factor (G-CSF) that stimulate the bone marrow to produce more white blood cells (particularly granulocytes) were developed for therapeutic use. These drugs allowed high peripheral blood white cell counts to be achieved in healthy donors. Steroids can also increase the white cell count, but alone they are not as effective as G-CSF. Using this method, adequate doses of granulocytes can be produced for adults. The exposure of a healthy volunteer donor to any form of medication with potential side effects does however present ethical and safety issues (Gutierrez 2001; Strauss 2003).

\section{How the intervention might work}

There is limited evidence by laboratory testing that donated granulocytes are functional (Bashir 2003; Dale 1998). The ability to collect greater numbers of granulocytes has however generated renewed interest in the potential role of granulocyte transfusions, either as additional therapy for people with neutropenia and established infections or when given as prophylaxis to prevent severe or life-threatening infections (Dale 2000; Hubel 2001; Illerhaus 2002; Kerr 2003; Peters 1999; Price 2000). These advances have occurred in conjunction with advances in anti-microbial therapy, including antifungal drugs, but the exact relative contributions of these agents in the context of more aggressive chemotherapy regimens and bone marrow transplants remains unclear.

\section{Why it is important to do this review}

This systematic review aimed to assess the effectiveness and safety of prophylactic granulocyte transfusions in people with neutropenia or neutrophil dysfunction. Previous Cochrane reviews have been performed with specific reference to neonatal practice and therapeutic granulocyte transfusion in adults (Pammi 2011; Stanworth 2005). Using granulocyte transfusion as part of a strategy for prevention of infection in neutropenic people may be more effective than therapeutic transfusions in response to established infection. This systematic review would therefore complement the previous Cochrane reviews.

This is an update of a previous Cochrane review (Massey 2009).

\section{O B J E C T I VES}

To determine the effectiveness and safety of prophylactic granulocyte transfusions compared with a control population not receiving this intervention for preventing all-cause mortality, mortality due to infection, and evidence of infection due to infection or due to any other cause in people with neutropenia or disorders of neutrophil function.

\section{METHODS}




\section{Criteria for considering studies for this review}

\section{Types of studies}

Randomised controlled trials (RCTs) and quasi-RCTs. QuasiRCTs included those in which allocation to receive granulocyte transfusion was dependent upon the availability of suitablymatched donors; this form of randomisation was referred to as quasi-randomisation in the text.

\section{Types of participants}

People with neutropenia (whether due to treatment or disease, or whether reversible or irreversible) were considered. People with inherited disorders of neutrophil dysfunction were also eligible for inclusion. Studies with neonates were excluded as these trials have been appraised in another Cochrane Review (Pammi 2011).

\section{Types of interventions}

\section{Intervention}

Granulocyte transfusions given as prophylaxis, prior to the development of documented infection. All sources of granulocytes, all doses, and different methods of collection were included.

\section{Control}

Prophylactic granulocyte transfusions not administered.

\section{Types of outcome measures}

\section{Primary outcomes}

- Death (from all causes)

\section{Secondary outcomes}

- Death due to infection

- Number of infections (whether systemic or at specific loci or microbiologically proven, with details of pathogens isolated)

- Numbers of days with fever

- Number of days on treatment with antimicrobials (or courses of treatment with antibiotics/antifungals)

- Increment of neutrophil count $\left(\times 10^{9} / \mathrm{L}\right)$

- Duration of neutropenia reversal after transfusion (neutropenia defined as count below $0.5 \times 10^{9} / \mathrm{L}$ ).

- Serious adverse events: resulting in death, requiring or prolonging hospitalisation, resulting in persistent or significant disability/incapacity, or life-threatening

- Adverse events requiring discontinuation of intervention
Other factors which may influence the outcome of neutropenia were extracted and reported in Characteristics of included studies and discussed in Overall completeness and applicability of evidence. These included the following.

- Use of therapeutic granulocyte transfusion

- Use of colony-stimulating factors in recipients, particularly G-CSF

- Policies and use of prophylactic antibiotics and antifungals

- Method of preparation and source of granulocytes for transfusion

\section{Search methods for identification of studies}

\section{Electronic searches}

\section{Bibliographic databases}

We searched for randomised controlled trials (RCTs) in the following databases.

- CENTRAL (Cochrane Library 2014, Issue 3) (Appendix 1)

- MEDLINE (Ovid, 1946 to April 20 2015) (Appendix 2)

- EMBASE (Ovid, 1974 to April 20 2015) (Appendix 3)

- CINAHL (EBSCOhost, 1937 to April 20 2015) (Appendix 4)

- Lilacs (BIREME/PAHO/WHO, 1982 to April 20 2015) (Appendix 5)

- KoreaMed (KAMJE, 1997 to April 20 2015) (Appendix 6)

- PakMediNet (2001 to April 20 2015) (Appendix 6)

- IndMed (ICMR-NIC, 1986 to April 20 2015) (Appendix

7)

- Transfusion Evidence Library ( www.transfusionevidencelibrary.com) (1980 to April 20 2015) (Appendix 8)

We updated searches from the original search in October 2008 (Massey 2009). Searches in MEDLINE, EMBASE and CINAHL were combined with adaptations of the Cochrane RCT search filters, as detailed in the Cochrane Handbook for Systematic Reviews of Interventions (Lefebvre 2011).

\section{Databases of ongoing trials}

We also searched ClinicalTrials.gov (http://clinicaltrials.gov/ct2/ search) (Appendix 9), the WHO International Clinical Trials Registry (ICTRP) (http://apps.who.int/trialsearch/) (Appendix 9), and the ISRCTN Register (http://www.controlled-trials.com/ isrctn/) (Appendix 10), in order to identify ongoing trials. All new search strategies are presented as indicated in Appendices 1-10. Search strategies for the original (2008) searches are presented in Appendix 11. 


\section{Searching other resources}

We augmented database searching with the following methods.

\section{Handsearching of reference lists}

We checked references of all included trials, relevant review articles and current treatment guidelines for further literature. These searches were limited to the 'first generation' reference lists.

\section{Personal contacts}

We contacted authors of relevant studies, study groups and experts worldwide known to be active in the field for unpublished material or further information on ongoing studies.

\section{Data collection and analysis}

\section{Selection of studies}

We updated the selection of studies from the selection of studies performed for the previous version of this review (Massey 2009). One review author (CD) excluded all duplicates and studies that were clearly irrelevant (e.g. non-human) that had been identified by the review search strategy. Two review authors (LE, PB) independently screened all remaining electronically-derived citations and abstracts of papers identified by the review search strategy for relevance. We excluded studies that were clearly irrelevant at this stage based on a review of the abstract. Two review authors (LE, $\mathrm{PB}$ ) independently formally assessed the full texts of all potentiallyrelevant trials for eligibility against the criteria outlined above. All disagreements were resolved by discussion without the need for a third review author (SS). We sought further information from study authors if the article contained insufficient data to make a decision about eligibility. A study eligibility form was designed for trials of granulocyte transfusion to help in the assessment of relevance, which included ascertaining whether the participants were neonates, and whether the two groups could be defined in the trial on the basis of a therapeutic-only versus prophylactic granulocyte transfusion strategy. We recorded the reasons why potentially-relevant studies failed to meet the eligibility criteria.

\section{Data extraction and management}

We updated the data extraction from the one used to extract data for the previous version of this review (Massey 2009). This included data extraction for all new studies that have been included since the previous review and an updated 'Risk of bias' assessment for all included studies.

Two review authors (LE, PB) conducted the data extraction according to the guidelines proposed by The Cochrane Collaboration (Higgins 2011a). We resolved potential disagreements between the review authors by consensus. The review authors were not blinded to names of authors, institutions, journals, or the outcomes of the trials. Due to minor changes in the format, the data extraction forms were piloted on a further study, thereafter the two authors (LE, PB) extracted data independently for all the studies. The following data were extracted.

\section{General information}

Review author's name, date of data extraction, study ID, first author of study, author's contact address (if available), citation of paper, objectives of the trial.

\section{Trial details}

Trial design, location, setting, sample size, power calculation, treatment allocation, inclusion and exclusion criteria, reasons for exclusion, comparability of groups, length of follow-up, stratification, stopping rules described, statistical analysis, results, conclusion, and funding.

\section{Characteristics of participants}

Age, gender, ethnicity, total number recruited, total number randomised, total number analysed, types of underlying disease, lost to follow-up numbers, drop outs (percentage in each arm) with reasons, protocol violations, previous treatments, current treatment, prognostic factors.

\section{Interventions}

Experimental and control interventions, method of preparation and source of granulocytes for transfusion, timing of intervention, dosage of granulocyte given, compliance to interventions, any differences between interventions, and any additional interventions given, especially in relation to the use of therapeutic granulocyte transfusions, the use of colony-stimulating factors in recipients, particularly G-CSF and the use of prophylactic and therapeutic antibiotics and antifungals.

\section{Assessment of bias}

Sequence generation, allocation concealment, blinding (participants, personnel, and outcome assessors), incomplete outcome data, selective outcome reporting, other sources of bias.

\section{Outcomes measured}

Death (from all causes). Death due to infection. Number of infections (whether systemic or at specific loci or microbiologically proven, with details of pathogens isolated). Numbers of days with fever. Number of days on treatment with antimicrobials (or courses of treatment with antibiotics/antifungals). Increment of neutrophil count $\left(\times 10^{9} / \mathrm{L}\right)$. Duration of neutropenia reversal after transfusion (neutropenia defined as count below $0.5 \times 10^{9} / \mathrm{L}$ ). 
Serious adverse events: resulting in death, requiring or prolonging hospitalisation, resulting in persistent or significant disability/incapacity, or life-threatening. Adverse events requiring discontinuation of intervention.

We used both full-text versions and abstracts to retrieve the data. For publications reporting on more than one trial, we used one data extraction form for each trial. For trials reported in more than one publication, we extracted data using one form only. Where these sources did not provide sufficient information, we contacted authors and study groups for additional details.

One review author entered data into the software and a second review author checked for accuracy.

\section{Assessment of risk of bias in included studies}

We updated the 'Risk of bias' assessment from the 'Risk of bias' assessment performed for the previous version of this review ( Massey 2009).

Two review authors (LE, PB) assessed all included studies for possible risk of bias (as described in the Cochrane Handbook for Systematic Reviews of Interventions (Higgins 2011c). The assessment included information about the design, conduct and analysis of the trial. Each criterion was evaluated on a three-point scale: low risk of bias, high risk of bias, or unclear. To assess risk of bias, the following questions were included in the 'Risk of bias' table for each included study.

- Was the allocation sequence adequately generated?

- Was allocation adequately concealed?

- Was knowledge of the allocated intervention adequately prevented during the study (including an assessment of blinding of participants, personnel, and outcome assessors)?

- Were incomplete outcome data adequately addressed (for every outcome separately)?

- Are reports of the study free of selective outcome reporting?

- Was the study apparently free of other problems that could put it at risk of bias?

\section{Measures of treatment effect}

For dichotomous outcomes, we recorded the number of outcomes in the treatment and control groups and we estimated the treatment effect measures across individual studies as the relative effect measures (risk ratio (RR) with $95 \%$ confidence intervals (CIs)). For continuous outcomes, we recorded the mean and standard deviations (SDs). For continuous outcomes measured using the same scale, the effect measure was the mean difference (MD) with 95\% CIs, or the standardised mean difference (SMD) for outcomes measured using different scales.

For time-to-event outcomes, we planned to extract the hazard ratio (HR) from published data according to Parmar 1998 and Tierney 2007. However, no time to event data were reported.

If the data available could not be reported in any of the formats described above, we reported the results narratively.

\section{Unit of analysis issues}

We did not pre-specify in the protocol how we would deal with any unit of analysis issues. There were unit of analyses issues. In Mannoni 1979 participants were randomised more than once, 44 participants were included within the study but six participants were re-randomised. Data for the first randomisation could not be extracted from the report, and further information from the authors was not available. Data from this study were therefore not incorporated into any meta-analysis.

\section{Dealing with missing data}

We dealt with missing data according to the recommendations in the Cochrane Handbook for Systematic Reviews of Interventions (Higgins 2011b). We contacted authors in order to obtain information that was missing or unclear in the published report. We contacted the authors of the Vij 2003 study, but no further analyses had been performed apart from the analyses in the primary paper.

Within an outcome, the preferred analysis was an intention-totreat analysis (ITT). Where data were missing, we recorded the number of participants lost to follow-up for each trial.

\section{Assessment of heterogeneity}

If studies were considered sufficiently homogenous in their study design, we conducted a meta-analysis and assessed the statistical heterogeneity (Deeks 2011). We assessed statistical heterogeneity of treatment effects between trials using a $\mathrm{Chi}^{2}$ test with a significance level at $\mathrm{P}<0.1$. We used the $\mathrm{I}^{2}$ statistic to quantify possible heterogeneity $\left(\mathrm{I}^{2}>50 \%\right.$ moderate heterogeneity, $\mathrm{I}^{2}>80 \%$ considerable heterogeneity). We explored potential causes of heterogeneity by sensitivity and subgroup analyses if possible.

\section{Assessment of reporting biases}

We did not perform a formal assessment of potential publication bias (small trial bias) by generating a funnel plot and statistically test using a linear regression test (Sterne 2011) as no meta-analysis contained 10 or more studies.

\section{Data synthesis}

We performed analyses according to the recommendations of The Cochrane Collaboration (Deeks 2011). We used aggregated data for analysis. For statistical analysis, we entered data into Review Manager 5.3.

Where meta-analysis was feasible, we used the fixed-effect model for pooling the data. We used the Mantel-Haenszel method for dichotomous outcomes or Peto method as necessary, and the inverse variance method for continuous outcomes. Even in the absence of statistical heterogeneity, we explored the robustness of any summary measures, particularly with respect to study methodological quality. 
We planned to use the random-effects model for sensitivity analyses as part of the exploration of heterogeneity. However, none of the analyses performed reported heterogeneity, as expressed by the $I^{2}$ above $50 \%$, therefore only the fixed-effect model was reported. If heterogeneity was found to be above $80 \%$, we did not perform a meta-analysis and results were commented on as a narrative.

\section{'Summary of findings' table}

We used GRADE to build a 'Summary of findings' table as suggested in the Cochrane Handbook for Systematic Reviews of Interventions (Schünemann 2011). This included the following.

- Death from all causes

- Death due to infection

- Number of infections (localised or systemic)

- Number of infections (bacteraemia or fungaemia)

- Number of infections (localised)

- Number of serious adverse events

A GRADE assessment had not been pre-specified in the protocol.

\section{Subgroup analysis and investigation of heterogeneity}

The only subgroup analysis pre-specified in the previous version of this review (Massey 2009), was granulocyte dose.

We performed a subgroup analysis on granulocyte dose, classifying studies in to low dose (mean granulocyte dose less than $1 \times 10^{10}$ per day for an adult patient), intermediate dose (mean granulocyte dose $1 \times 10^{10}$ to $4 \times 10^{10}$ per day for an adult patient), and high dose (mean granulocyte dose greater than $4 \times 10^{10}$ per day for an adult patient).
We commented on differences between subgroups as a narrative. Investigation of heterogeneity between studies also included, if appropriate, age of the study (as the treatment of neutropenic people has changed over the last 40 years).

\section{Sensitivity analysis}

We intend to assess the robustness of our findings by the following two sensitivity analyses.

- Including only those trials at low risk of bias

- Including only those trials in which $20 \%$ participants or less were lost to follow-up.

A sensitivity analysis including only those studies at low risk of bias was not performed because none of the studies were at low risk of bias.

\section{R E S U L T S}

\section{Description of studies}

See Characteristics of included studies; Characteristics of excluded studies.

\section{Results of the search}

See PRISMA Flow Diagram Figure 1. 
Figure I. Study flow diagram.

Granulocyte transfusions for preventing infections in people with neutropenia or neutrophil dysfunction (Review) Copyright $\odot 2015$ The Cochrane Collaboration. Published by John Wiley \& Sons, Ltd. 
The original search (conducted 1st January 2009) identified a total of 1253 potentially relevant citations. There were 701 citations after duplicates were removed, 676 records were excluded on the basis of the abstract. The original systematic review identified 25 studies which appeared relevant on the basis of the their full text or abstract.

This updated search (conducted 20th April 2015) identified a total of 2188 potentially relevant citations. There were 1910 citations after duplicates were removed. We were able to exclude 1893 citations on the basis of the abstract by two out of three review authors (LE, CD, and PB). Two review authors (LE, PB) retrieved and assessed 10 full-text articles for relevance.

The previous systematic review (Massey 2009), identified 12 trials that compared prophylactic granulocyte transfusions versus no prophylactic platelet transfusions; 10 completed trials (Clift 1978; Ford 1982; Gomez-Villagran 1984; Mannoni 1979; Oza 2006; Petersen 1987; Schiffer 1979; Strauss 1981; Sutton 1982; Winston 1980), and two ongoing studies (Price 2014; Seidel 2008), which are now excluded. This updated search identified two additional studies (Vij 2003; NCT01204788). The study by Vij 2003 was not identified in the previous systematic review (Massey 2009). This was because the search strategy we used for this update of the review was much more extensive than the previous search strategy (see Search methods for identification of studies).

In total, we assessed 12 studies and deemed them eligible for inclusion (Clift 1978; Ford 1982; Gomez-Villagran 1984; Mannoni 1979; NCT01204788; Oza 2006; Petersen 1987; Schiffer 1979; Strauss 1981; Sutton 1982; Vij 2003; Winston 1980), however the NCT01204788 study is still ongoing.

\section{Included studies}

See Characteristics of included studies for full details of each study. Twelve studies were eligible for inclusion in this review. Eleven studies have been completed (Clift 1978; Ford 1982; GomezVillagran 1984; Mannoni 1979; Oza 2006; Petersen 1987; Schiffer 1979; Strauss 1981; Sutton 1982; Vij 2003; Winston 1980), and one study has been stopped early due to poor recruitment (NCT01204788) but results have not been published.

Of the 11 completed studies, nine studies were randomly controlled studies (Clift 1978; Ford 1982; Gomez-Villagran 1984; Mannoni 1979; Petersen 1987; Schiffer 1979; Strauss 1981; Sutton 1982; Winston 1980), and two studies allocated participants to the intervention arm on the basis of a suitable available granulocyte donor (Oza 2006; Vij 2003).

\section{Ongoing Studies}

This updated review identified one ongoing study that was eligible for inclusion (NCT01204788). This study has been completed but has not been published. The previous systematic review
(Massey 2009) identified two potentially relevant studies that have since been excluded because they were studying the wrong intervention (Price 2014; Seidel 2008).

See Characteristics of ongoing studies for further details.

\section{Studies contributing to this review}

See Characteristics of included studies for full details of each study.

\section{Study Design}

There were five single-centre parallel randomised controlled trials (RCTs) (Clift 1978; Ford 1982; Gomez-Villagran 1984; Schiffer 1979; Winston 1980); two single centre quasi-randomised studies (Oza 2006; Vij 2003); three multicentre parallel RCTs (Petersen 1987; Strauss 1981; Sutton 1982) and one parallel RCT where the number of centres was unclear (Mannoni 1979).

\section{Study Size}

The number of participants enrolled in all studies was small, ranging between 18 (Schiffer 1979) and 225 (Vij 2003) participants analysed. Most of the studies presented no or little information on sample sizes required to power the trial around a main outcome, and only one study made any attempt to justify the statistical analysis of the required size (Oza 2006). All other trials should probably be considered more as hypothesis generating in respect of design.

\section{Setting}

The nine RCTs were published between 1978 and 1987 (Clift 1978; Ford 1982; Gomez-Villagran 1984; Mannoni 1979; Petersen 1987; Schiffer 1979; Strauss 1981; Sutton 1982; Winston 1980), the two quasi-randomised studies were published between 2003 and 2006 (Oza 2006; Vij 2003). Seven studies were based in the United States (Clift 1978; Oza 2006; Petersen 1987; Schiffer 1979; Strauss 1981; Vij 2003; Winston 1980); one study was based in Canada (Sutton 1982); one study was based in France (Mannoni 1979); one study was based in Spain (Gomez-Villagran 1984); and one study was based in the United Kingdom (Ford 1982).

\section{Participants}

The majority of participants were people with haematological malignancies receiving intensive chemotherapy or a haematopoietic stem cell transplant (HMST). Most studies included only adults. Two studies included children and adults (Clift 1978; Gomez-Villagran 1984). 


\section{Intervention}

\section{Average dose and range}

The dose of granulocytes transfused varied between studies (Table 1). The mean dose varied from $0.6 \times 10^{10}$ (Strauss 1981) to $5.9 \mathrm{x}$ $10^{10}$ (Oza 2006) (Table 1). No dose was reported by two studies (Petersen 1987; Vij 2003).

\section{Schedule for transfusion}

Granulocyte transfusions were commenced when the recipient's neutrophil count fell below a pre-defined value in eight of the 11 studies. This "trigger" neutrophil count was $0.2 \times 10^{9} / \mathrm{L}$ for two studies (Clift 1978; Petersen 1987), and $0.5 \times 10^{9} / \mathrm{L}$ for six studies (Ford 1982; Gomez-Villagran 1984; Schiffer 1979; Strauss 1981; Sutton 1982; Winston 1980). In the Schiffer study, the granulocyte component contained a significant number of platelets and was therefore commenced if the patient needed platelet transfusion, even if the defined neutrophil count trigger had not been met Schiffer 1979.

The other three studies started granulocyte transfusions at prespecified time points after treatment (Mannoni 1979; Oza 2006; Vij 2003).

Once prophylactic granulocyte transfusions had commenced, daily transfusions were given in seven of the 11 studies (Clift 1978; Gomez-Villagran 1984; Mannoni 1979; Petersen 1987; Strauss 1981; Sutton 1982; Winston 1980) (Table 1). Granulocyte transfusions were given on alternate days by one study (Ford 1982), and for four days out of seven by one study (Schiffer 1979). Two studies gave granulocyte transfusions on two occasions at fixed time points after HSCT (Oza 2006; Vij 2003).

Granulocyte transfusions were discontinued when the recipient's neutrophil count rose above a pre-defined value in eight of the 11 studies. This "trigger" neutrophil count was $0.2 \times 10^{9} / \mathrm{L}$ for two studies (Clift 1978; Petersen 1987), and $0.5 \times 10^{9} / \mathrm{L}$ for six studies (Ford 1982; Gomez-Villagran 1984; Schiffer 1979; Strauss 1981; Sutton 1982; Winston 1980). Mannoni gave transfusions for a set period of 12 days but continued for 15 days in one case as there was evidence of infection at 12 days (Mannoni 1979). Two studies gave granulocyte transfusions on two occasions at fixed time points after HSCT (Oza 2006; Vij 2003).

\section{Method of collection of granulocytes}

The method of collection of granulocytes varied between trials. Nine studies used either intermittent or continuous flow centrifugation (Ford 1982; Gomez-Villagran 1984; Mannoni 1979; Oza 2006; Petersen 1987; Schiffer 1979; Strauss 1981; Sutton 1982;
Vij 2003). One study used both filtration leucapheresis and continuous flow centrifugation (Clift 1978). One study only used filtration leucapheresis (Winston 1980). Methods of collection have developed considerably since these publications. Filtration leucapheresis is rarely used now, as despite possibly higher yields compared to continuous flow centrifugation, there are concerns about toxicity to the donor and recipient, in addition to evidence of poor increments and functionality of transfused granulocytes.

\section{Premedication of donors}

Four studies did not administer any form of medication to the donors to increase the granulocyte yield (Clift 1978; Petersen 1987; Strauss 1981; Winston 1980).

Five studies gave donors steroids, either dexamethasone, hydrocortisone or prednisolone (Ford 1982; Gomez-Villagran 1984; Mannoni 1979; Schiffer 1979; Sutton 1982).

Two studies gave donors G-CSF (Oza 2006; Vij 2003).

\section{Donor selection}

Human leucocyte (HLA)-matched and ABO matched the granulocyte donor in two studies (Oza 2006; Vij 2003); one study ensured that donor and recipient were HLA and ABO compatible (Mannoni 1979). One study stated that family members were used as granulocyte donors and the HLA-matched sibling donor was used whenever possible (Petersen 1987).

Two studies used serological compatibility based upon leucocyte crossmatch (rather than HLA matching) (Clift 1978; GomezVillagran 1984), in which donor leucocytes were crossmatched against recipient serum/plasma by lymphocytotoxic (LCT) techniques prior to transfusion, and donors were $\mathrm{ABO}$ and Rh compatible.

Four studies did not HLA-match the granulocyte donor (Ford 1982; Schiffer 1979; Strauss 1981; Winston 1980). Schiffer 1979 discontinued unmatched transfusions if transfusion reactions or refractoriness to platelet transfusions occurred, at which point HLA-matched donors were used if available. One study did not report whether any assessment of leucocyte compatibility was assessed (Sutton 1982).

\section{Co-interventions and/or alternative interventions}

Differences between the studies were also identified in the co-interventions provided to participants. Specifically, this would include the diagnostic and therapeutic options available for antimicrobial practice.

One study (Petersen 1987) had an important difference in that there was an alternative intervention. Petersen 1987 randomised participants between two study arms. One arm received prophylactic granulocyte transfusions, the other arm received prophylac- 
tic broad-spectrum antibiotics (vancomycin $2 \mathrm{~g} / 24$ hours, ticarcillin $300 \mathrm{mg} / \mathrm{kg} / 24$ hours (cefotaxime if allergic) and tobramycin $5 \mathrm{mg} / \mathrm{kg} / 24$ hours) (Petersen 1987).

Four studies gave prophylactic antibiotics to all participants (Ford 1982; Gomez-Villagran 1984; Schiffer 1979; Winston 1980). Three studies did not give prophylactic antibiotics (Mannoni 1979; Oza 2006; Strauss 1981). Three studies did not report whether prophylactic antibiotics were given (Clift 1978; Sutton 1982; Vij 2003).

Five studies defined the empirical antibiotic treatment to be given if a patient had a febrile episode (Ford 1982; Gomez-Villagran 1984; Oza 2006; Strauss 1981; Winston 1980). Five studies did not specify the antibiotics to be given (Clift 1978; Mannoni 1979; Schiffer 1979; Sutton 1982; Vij 2003).

Six studies gave therapeutic granulocyte transfusions to control participants (Clift 1978; Mannoni 1979; Petersen 1987; Strauss 1981; Sutton 1982; Winston 1980). Two studies did not give therapeutic granulocyte transfusions to control participants (Ford 1982; Gomez-Villagran 1984). Three studies did not report whether therapeutic granulocyte transfusions were given $(\mathrm{Oza}$ 2006; Schiffer 1979).

Specific regimens for antifungal diagnosis and therapy were not stated in any trial except for Oza 2006 who stated that Amphotericin B was used as therapy and Winston 1980 who stated that people remaining febrile for seven days and people with surveillance cultures that were positive for Candida orAspergillus were eligible to receive amphotericin. Amphotericin B was the most widely used antifungal agent at the time of the other included studies.

\section{Funding Sources}

Six studies reported their funding sources, and all were funded by charities or governments (Clift 1978; Ford 1982; Petersen 1987; Strauss 1981; Sutton 1982; Winston 1980).

\section{Definition of infection (used to recruit uninfected people or identify those who became infected)}

Studies also applied different criteria for definition of infection although defined in all studies on the basis of temperature, clinical signs and isolation of organisms.

Seven studies stated that patients with infections were excluded from the studies (Ford 1982; Gomez-Villagran 1984; Mannoni
1979; Petersen 1987; Schiffer 1979; Strauss 1981; Winston 1980); the specific exclusion definitions varied (See Characteristics of included studies).

Four studies did not specifically state whether infected patients were excluded from the studies (Clift 1978; Oza 2006; Sutton 1982; Vij 2003), and in the Clift 1978 study it is clear in the analysis that some patients were on systemic antibiotics at enrolment.

\section{Outcomes}

Although few studies examined exactly the same range of outcomes, most trials reported mortality and survival (at different time points), information on fever (or days with fever), and information on episodes of infection (however defined), together with a measure of antibiotic use. (See Characteristics of included studies).

\section{Excluded studies}

Twenty-three studies within 27 citations did not meet the inclusion criteria for this review (See Characteristics of excluded studies).

- Twelve studies were excluded because they evaluated the therapeutic use of granulocyte transfusions (Alavi 1977; Bow 1984; DRKS00000218; Herzig 1977; Higby 1975; Klastersky 2001; Price 2014; Scali 1978; Seidel 2008; Vogler 1977; Wheeler 1987; Winston 1982)

- Two studies evaluated the prophylactic use of granulocyte transfusions in neonates (Baley 1987; Christensen 1982)

- Two studies compared two different types of granulocyte transfusions (Ambinder 1981; Freireich 2013)

- Five studies were not randomised (Altrichter 2011; Atay 2011; Ikemoto 2012; NCT01932710; UMIN000014777)

- One study included both randomised and allocated people, and the results of the study did not separate out these categories of enrolled participants.(Buckner 1983)

- One article study was a review (Pammi 2011)

\section{Risk of bias in included studies}

See Figure 2 and Figure 3 for visual representations of the assessments of risk of bias across all studies and for each item in the included studies. See the Characteristics of included studies section 'Risk of bias' table for further information about the bias identified within the individual studies. 
Figure 2. 'Risk of bias' graph: review authors' judgements about each risk of bias item presented as percentages across all included studies.

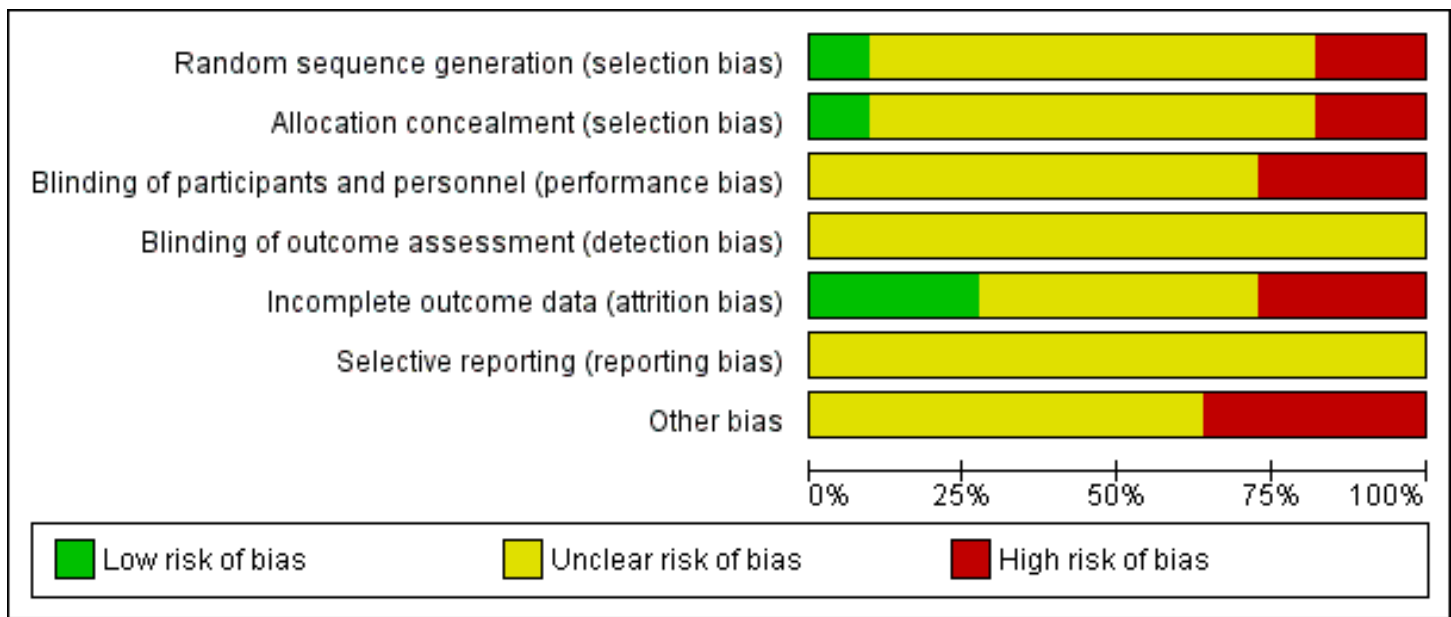


Figure 3. 'Risk of bias' summary: review authors' judgements about each risk of bias item for each included study.

\begin{tabular}{|c|c|c|c|c|c|c|c|}
\hline & 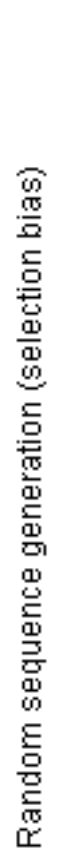 & 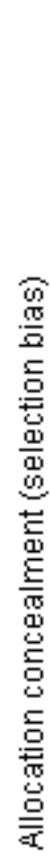 & 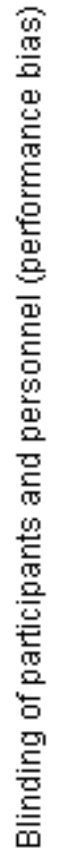 & 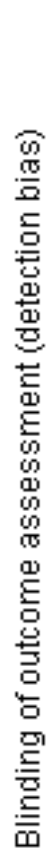 & 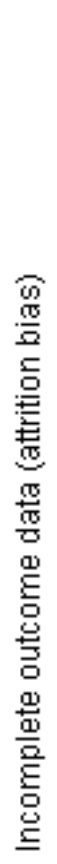 & 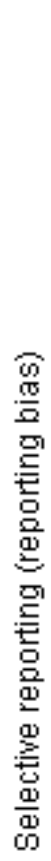 & 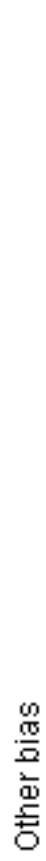 \\
\hline Clift 1978 & $?$ & $?$ & $?$ & $?$ & & $?$ & $?$ \\
\hline Ford 1982 & $?$ & $?$ & & $?$ & & $?$ & $?$ \\
\hline Gomez-Villagran 1984 & $?$ & $?$ & & $?$ & & $?$ & $?$ \\
\hline Mannoni 1979 & $?$ & $?$ & - & $?$ & $?$ & $?$ & \\
\hline Oza 2006 & & & $?$ & $?$ & $?$ & $?$ & \\
\hline Petersen 1987 & $?$ & $?$ & $?$ & $?$ & & $?$ & \\
\hline Schiffer 1979 & $?$ & ? & $?$ & $?$ & $?$ & $?$ & $?$ \\
\hline Strauss 1981 & + & + & $?$ & $?$ & $?$ & $?$ & $?$ \\
\hline Sutton 1982 & $?$ & $?$ & $?$ & $?$ & + & $?$ & $?$ \\
\hline Vij 2003 & & & $?$ & $?$ & $?$ & $?$ & \\
\hline Winston 1980 & $?$ & $?$ & $?$ & $?$ & + & $?$ & $?$ \\
\hline
\end{tabular}


Although nine of the 11 included studies were RCTs (Clift 1978; Ford 1982; Gomez-Villagran 1984; Mannoni 1979; Petersen 1987; Schiffer 1979; Strauss 1981; Sutton 1982; Winston 1980), many of the studies had some threats to validity. The majority of these potential risks were due to a lack of detail on the specific criteria and were judged as "unclear risk" according to the Cochrane grading system. Two studies were quasi-randomised studies that allocated participants to the intervention arm if they had a suitable donor (Oza 2006; Vij 2003).

\section{Allocation}

We considered two studies to be at high risk of selection bias (Oza 2006; Vij 2003). In Oza 2006 and Vij 2003 the recipient was "randomised" to the prophylactic granulocyte group if the donor who donated stem cells for the transplant was ABO-matched and able to donate. Eight studies were at an unclear risk of bias because they did not report the methods of sequence generation or allocation concealment (Clift 1978; Ford 1982; Gomez-Villagran 1984; Mannoni 1979; Petersen 1987; Schiffer 1979; Sutton 1982; Winston 1980). We considered one study (Strauss 1981) to be at low risk of selection bias because it reported that separate randomisation schedules were prepared for each institute and stratum. An algorithm that ensured an approximate balance between treatment groups was used to generate each schedule. Participants were randomly assigned to receive daily granulocyte transfusions or not to receive them by a telephone call to the co-ordinating centre.

\section{Blinding}

None of the studies provided any details on whether participants, investigators or outcome assessors were blinded to the intervention. For all subjective outcomes (all secondary outcomes of this review), we considered three studies to be at high risk of bias because they noted that the participants receiving prophylactic granulocyte transfusions did not require prophylactic platelet transfusions because of the number of platelets contained within the granulocyte transfusion (Ford 1982; Gomez-Villagran 1984; Mannoni 1979). Investigators would have been able to identify which participants were receiving prophylactic granulocyte transfusion even if they had been blinded to the intervention. We considered the other eight studies to be at an unclear risk of bias (Clift 1978; Oza 2006; Petersen 1987; Schiffer 1979; Strauss 1981; Sutton 1982; Vij 2003; Winston 1980).

\section{Incomplete outcome data}

We considered three studies to be at high risk of attrition bias due to the large number of participants who were randomised but not included in the final analysis (Clift 1978; Ford 1982; Petersen
1987). Between 16\% (Petersen 1987) and 50\% (Ford 1982) of participants were randomised but not included within the analysis. In Clift 1978 and Petersen 1987 there was also a significant imbalance between the number of participants randomised and included within the study between those participants in the prophylactic granulocyte transfusion group and those in the control group.

\section{Selective reporting}

We could not assess this for any of the studies because protocols were not available to assess whether any pre-specified outcomes were not reported or outcomes were reported that were not prespecified. We therefore classified all studies as at unclear risk of bias.

\section{Other potential sources of bias}

One study publication (Vij 2003) was classified as an "advertisement" in accordance with 18 USC section 1734 because the publication costs of the article were defrayed in part by part charge payment, this study was classified as high risk because of this.

We classified the Mannoni 1979 study at high risk of bias because six participants had been re-randomised within the study. We classified the Oza 2006 study at high risk of bias because people who were cytomegalovirus (CMV) mis-matched with their donor were excluded from being in the prophylactic granulocyte transfusion group. This mis-match may have increased the risk of CMV viraemia within the control group. We classified the Petersen 1987 study at high risk of bias because of the number of deviations from the original study design in the prophylactic granulocyte arm of the study.

The small numbers of participants in all the studies compromised the likelihood that there was equivalence in baseline and prognostic parameters. We therefore classified the seven other studies at unclear risk of bias (Clift 1978; Ford 1982; Gomez-Villagran 1984; Schiffer 1979; Strauss 1981; Sutton 1982; Winston 1980).

\section{Effects of interventions}

See: Summary of findings for the main comparison See Summary of findings for the main comparison.

The Vij 2003 study reported none of the outcomes pre-specified in our review. We contacted the study authors who were unable to provide any additional data not reported in the original paper. Therefore, data were available for only 10 of the 11 included studies (Clift 1978; Ford 1982; Gomez-Villagran 1984; Mannoni 1979; Oza 2006; Petersen 1987; Schiffer 1979; Strauss 1981; Sutton 1982; Winston 1980). 


\section{All-cause mortality (10 studies)}

All-cause mortality was reported by 10 studies (Clift 1978; Ford 1982; Gomez-Villagran 1984; Mannoni 1979; Oza 2006; Petersen 1987; Schiffer 1979; Strauss 1981; Sutton 1982; Winston 1980) (Table 2). The time points for assessment of mortality varied between studies. Eight studies reported mortality up to 30 days (Clift 1978; Ford 1982; Gomez-Villagran 1984; Mannoni 1979; Oza 2006; Schiffer 1979; Strauss 1981; Winston 1980); one study reported mortality up to 100 days (Petersen 1987); and one study reported mortality over 100 days (Sutton 1982).

The Mannoni 1979 study re-randomised six participants and the information was therefore not included within the meta-analysis. Information on overall mortality was available and extracted from nine studies (Clift 1978; Ford 1982; Gomez-Villagran 1984; Oza 2006; Petersen 1987; Schiffer 1979; Strauss 1981; Sutton 1982; Winston 1980).

Seven studies (437 participants) reported mortality up to 30 days ( Clift 1978; Ford 1982; Gomez-Villagran 1984; Oza 2006; Schiffer 1979; Strauss 1981; Winston 1980). A meta-analysis showed no difference between participants receiving prophylactic granulocyte transfusions and those that did not (risk ratio (RR) 0.92; 95\% confidence interval (CI) 0.63 to 1.36) (Analysis 1.1), nor was any difference seen if only studies that gave a median granulocyte dose of over $1 \times 10^{10} / \mathrm{L}$ per day were included (four studies (Clift 1978; Gomez-Villagran 1984; Oza 2006; Winston 1980); 293 participants; RR 0.74; 95\% CI 0.47 to 1.16 ) (Analysis 1.1).

One study reported all-cause mortality up to 100 days (Petersen 1987). There was no difference in all-cause mortality between participants receiving prophylactic granulocyte transfusions and those that did not (112 participants; RR 1.28; $95 \%$ CI 0.69 to 2.39) (Analysis 1.2).

One study reported all-cause mortality over 100 days (Sutton 1982). There was no difference in all-cause mortality between participants receiving prophylactic granulocyte transfusions and those that did not (65 participants; RR $0.94 ; 95 \%$ CI 0.67 to 1.33) (Analysis 1.3).

\section{Mortality due to infection (eight studies)}

Mortality due to infection was reported by eight studies (Clift 1978; Gomez-Villagran 1984; Mannoni 1979; Oza 2006; Petersen 1987; Strauss 1981; Sutton 1982; Winston 1980) (Table 3). The Mannoni 1979 study re-randomised six participants and the information was therefore not included within the meta-analysis. Six studies (286 participants) reported mortality due to infection up to 30 days (Clift 1978; Gomez-Villagran 1984; Oza 2006; Schiffer 1979; Strauss 1981; Winston 1980). A meta-analysis showed no difference between participants receiving prophylactic granulocyte transfusions and those that did not (RR 0.69; 95\% CI 0.33 to 1.44 ) (Analysis 1.4), nor was any difference seen if only studies that gave a median granulocyte dose of over $1 \times 10^{10} / \mathrm{L}$ per day were included (three studies (Clift 1978; Gomez-Villagran
1984; Winston 1980); 142 participants; RR 0.25; 95\% CI 0.06 to 1.10 ) (Analysis 1.4).

One study reported mortality due to infection up to 100 days (Petersen 1987). There was no difference in mortality due to infection between participants receiving prophylactic granulocyte transfusions and those that did not (112 participants; RR 1.01; 95\% CI 0.18 to 5.79 ) (Analysis 1.5 ).

\section{Number of infection episodes ( 10 studies)}

The numbers of localised or systemic bacterial or fungal infections were reported by 10 studies. (Clift 1978; Ford 1982; Gomez-Villagran 1984; Mannoni 1979; Oza 2006; Petersen 1987; Schiffer 1979; Strauss 1981; Sutton 1982; Winston 1980) (Table 4). The Mannoni 1979 study re-randomised six participants and the information was therefore not included within the meta-analysis.

Nine studies (609 participants) reported localised or systemic infections up to 30 days (Clift 1978; Gomez-Villagran 1984; Oza 2006; Petersen 1987; Schiffer 1979; Strauss 1981; Sutton 1982; Winston 1980). A meta-analysis showed that there were significant differences between the granulocyte dose subgroups (test for subgroup differences: $\left.\mathrm{Chi}^{2}=8.54, \mathrm{df}=2(\mathrm{P}=0.01), \mathrm{I}^{2}=76.6 \%\right)$ (Analysis 1.6). We therefore did not perform an overall analysis. In the intermediate granulocyte dose group, participants receiving prophylactic granulocyte transfusions had fewer infections (four studies (Clift 1978; Gomez-Villagran 1984; Oza 2006; Winston 1980); 293 participants; RR 0.40; 95\% CI 0.26 to 0.63) (Analysis 1.6). In the low-dose subgroup no difference was seen between those participants who received prophylactic granulocytes and those that did not (four studies (Ford 1982; Schiffer 1979; Strauss 1981; Sutton 1982); 204 participants; RR 0.84; 95\% CI 0.58 to 1.20 ) (Analysis 1.6).

As there was clinical heterogeneity between studies in the types of infections reported, we performed separate meta-analyses for systemic infections (bacteraemia and fungaemia) and localised infections (bacterial or fungal infections excluding oral candidaemia). Nine studies (609 participants) reported systemic infections (Clift 1978; Ford 1982; Gomez-Villagran 1984; Oza 2006; Petersen 1987; Schiffer 1979; Strauss 1981; Sutton 1982; Winston 1980). A meta-analysis showed that overall, there was a reduction in the number of bacteraemias and fungaemias in the participants receiving granulocyte transfusions (RR $0.45 ; 95 \%$ CI 0.30 to 0.65 ) (Analysis 1.7); this effect was most marked in those studies giving an intermediate dose of granulocytes (four studies (Clift 1978; Gomez-Villagran 1984; Oza 2006; Winston 1980); 293 participants; RR 0.28 ; 95\% CI 0.14 to 0.55 ) (Analysis 1.7).

Excluding the data for the study that compared prophylactic granulocyte transfusions versus prophylactic antibiotics from the analysis had no effect on the overall result (Petersen 1987), (RR 0.37; $95 \%$ CI 0.23 to 0.59 ) (Analysis 1.8 ).

Six studies (296 participants) reported localised infections (Clift 
1978; Ford 1982; Gomez-Villagran 1984; Petersen 1987; Schiffer 1979; Winston 1980). A meta-analysis showed that overall, there was no difference in the number of localised infections between participants receiving prophylactic granulocyte transfusions and those that did not (RR $0.75 ; 95 \%$ CI 0.50 to 1.14 ) (Analysis 1.9). There was also no difference seen when only those studies giving an intermediate dose of granulocytes were included in the analysis (three studies (Clift 1978; Gomez-Villagran 1984; Winston 1980); 142 participants; RR $0.71 ; 95 \%$ CI 0.38 to 1.31) (Analysis 1.9).

Excluding the data for the study that compared prophylactic granulocyte transfusions versus prophylactic antibiotics from the analysis had no effect on the overall result (Petersen 1987), (RR 0.62; 95\% CI 0.37 to 1.02 ) (Analysis 1.10).

\section{Number of days with fever (five studies)}

Five studies reported the number of days with fever (Ford 1982; Gomez-Villagran 1984; Oza 2006; Schiffer 1979; Winston 1980). These data were reported in different ways and could not be incorporated in to a meta-analysis (Table 5). There was no obvious trend in the number of days with fever between studies.

\section{Number of days on treatment with antimicrobials (courses of treatment with antibiotics/antifungals) (five studies)}

Five studies reported the number of days on treatment with antibiotics (Ford 1982; Gomez-Villagran 1984; Oza 2006; Schiffer 1979; Winston 1980). these data were reported in different ways and could not be incorporated in to a meta-analysis (Table 5). Three of the five studies showed a slightly lower number of days on antibiotics in the prophylactic granulocyte arm of the study (Ford 1982; Gomez-Villagran 1984; Oza 2006); one study showed no difference (Schiffer 1979); and one study showed an increased number of days on antibiotics (Winston 1980).

\section{Increment of neutrophil count ( $\left.x 10^{9} / L\right)$ (six studies)}

Neutrophil increments were reported as an absolute rise in the peripheral blood neutrophil count, known as the count increment, or as a corrected count increment see Table 6 . The data could not be incorporated in to a meta-analysis because of the different ways the data had been reported.

Six studies report the count increment or corrected count increment (Clift 1978; Ford 1982; Gomez-Villagran 1984; Mannoni 1979; Schiffer 1979; Winston 1980). Two studies reported the count increment, and it varied from a median of $<0.15 \times 10^{9} / \mathrm{L}$ to $0.32 \times 10^{9} / \mathrm{L}$ (Ford 1982; Schiffer 1979). Four studies reported the corrected count increment (Clift 1978; Gomez-Villagran 1984; Mannoni 1979; Winston 1980), and it varied from a median of $0.06 \times 10^{9} / \mathrm{L}$ (Clift 1978) to a mean of $0.5 \times 10^{9} / \mathrm{L}$ (Gomez-Villagran 1984).

\section{Duration of neutropenia reversal after transfusion (neutropenia defined as count below $0.5 \times 10^{9} / \mathrm{L}$ )}

None of the studies reported the duration of neutropenia reversal after transfusion.

Serious adverse events: resulting in death, requiring or prolonging hospitalisation, resulting in persistent or significant disability/incapacity, or life-threatening (four studies)

Serious adverse events were reported by four studies (Table 7). One study reported a donor event (Clift 1978), and three studies reported recipient events (Ford 1982; Gomez-Villagran 1984; Sutton 1982).

Clift 1978 described an episode of haemodynamic compromise due to loss of blood after a section of tubing was accidentally disconnected.

Ford 1982 described one death due to transfusion-associated graft versus host disease in a participant who had received 10 granulocyte transfusions that had not been irradiated from related donors. Gomez-Villagran 1984 described one case of haemolysis due to passive transfer of anti-A, and six pulmonary reactions (dyspnoea, cyanosis, but no pulmonary infiltrates on chest X-ray).

Sutton 1982 described severe dyspnoea and wheezing in three participants.

\section{Adverse events requiring discontinuation of intervention (six studies)}

Adverse events requiring discontinuation of the granulocyte transfusions were reported for six studies (Clift 1978; Petersen 1987; Schiffer 1979; Strauss 1981; Sutton 1982; Winston 1980) (See Table 8). Two studies reported donor events (Clift 1978; Petersen 1987) and six studies reported recipient events (Clift 1978; Petersen 1987; Schiffer 1979; Strauss 1981; Sutton 1982; Winston 1980).

\section{DISCUSSION}

\section{Summary of main results}

This Cochrane review aimed to evaluate the literature on the effectiveness and safety of prophylactic granulocyte transfusions. This review should be read in conjunction with another review undertaken to evaluate the randomised trial evidence base for the use of therapeutic granulocyte transfusions (Stanworth 2005).

We identified 12 randomised and quasi-randomised trials that met our inclusion criteria; one of which is still ongoing ( 
NCT01204788). Eleven trials were included in this review containing a total of 653 participants. These trials were conducted between 1978 and 2006 and enrolled participants from fairly comparable patient populations. None of the studies included people with neutrophil dysfunction. Ten of these studies contained separate data for each arm and were able to be critically appraised. One study re-randomised participants and therefore quantitative analysis was unable to be performed.

The findings of the review led to the following main conclusions.

- There was insufficient evidence to detect a difference in allcause mortality between people receiving prophylactic granulocyte transfusions and those that did not. This was measured over 30 days in seven studies (437 participants; RR $0.92,95 \%$ CI 0.63 to 1.36 ).

- There was insufficient evidence to detect a difference in mortality due to infection between people receiving prophylactic granulocyte transfusions and those that did not. This was measured over 30 days in six studies (286 participants; RR 0.69, 95\% CI 0.33 to 1.44 ).

- There were differences between the granulocyte dose subgroups (test for subgroup differences $P=0.01$ ) in the number of people with localised or systemic bacterial or fungal infections. There was no difference in the number of people with infections in the low-dose granulocyte group $\left(<1.0 \times 10^{10}\right.$ granulocytes per day) between people receiving prophylactic granulocyte transfusions and those that did not (four studies, 204 participants; RR $0.84,95 \%$ CI 0.58 to 1.20 ). There was a decreased number of people with infections over 30 days in the people receiving prophylactic granulocyte transfusions in the intermediate-dose granulocyte group $\left(1.0 \times 10^{10}\right.$ to $4.0 \times 10^{10}$ granulocytes per day) (4 studies; 293 participants; RR 0.4, 95\% CI 0.26 to 0.63$)$. There was a decreased number of people with bacteraemia and fungaemia in the people receiving prophylactic granulocyte transfusions (nine studies; 609 participants; RR $0.45,95 \%$ CI 0.30 to 0.65 ). There was no difference in the number of people with localised bacterial or fungal infection in the people receiving prophylactic granulocyte transfusions (six studies; 296 participants; RR 0.75 , 95\% CI 0.50 to 1.14 ).

- There was insufficient evidence to detect a difference in the number of serious adverse events between people receiving prophylactic granulocyte transfusions and those that did not. This was because serious adverse events were only reported for people receiving granulocyte transfusions and donors of granulocyte transfusions.

- There was no obvious trend in the number of days with fever, or number of days with antibiotics between people receiving prophylactic granulocyte transfusions and those that did not.

- None of the studies reported the duration of neutropenia reversal.

\section{Overall completeness and applicability of evidence}

This review provides the most up-to-date assessment of the effectiveness and safety of a prophylactic granulocyte transfusion policy compared with not administering prophylactic granulocyte transfusions. This updated review identified one additional quasi-randomised trial (Vij 2003). This review provides some low-quality evidence that prophylactic granulocytes decrease the risk of developing a bacterial or fungal infection.

However, the results of this review should not be interpreted without considering the impact of the following factors.

- The studies included in this review range over a 28 -year period (1978 to 2006) during which chemotherapy protocols, predicted survival rates, supportive care, including antibiotics and antifungal medication, have changed substantially. Newer less toxic antifungal drug options are now available.

- None of the studies reported on quality control measures operating for blood components, including granulocytes, and current blood components may be manufactured to a higher specification than in the time period of these studies.

- Only two of the studies gave granulocyte colony-stimulating factor (G-CSF) to the granulocyte donors (Oza 2006; Vij 2003).

- None of the studies assessed the use of granulocytes derived from whole blood donations (Bashir 2008). This component has been assessed in a small safety study (Massey 2012). The process of obtaining granulocyte collections from directed G-CSF and/ or steroid-stimulated donors who are 'family and friends' of patients or unrelated donors involves multiple steps. It is important that family and 'friends' of patients are given time and adequate explanation of the small risks to which they are exposed by both taking specific drugs (steroids or G-CSF, or both) to mobilise granulocytes into the peripheral blood and by undergoing an apheresis procedure. To date, most of these risks have been theoretical or weak associations only but posterior capsular cataracts, splenic rupture and venous thrombosis have been described (Bennett 2006; Ghodsi 2001; Goldman 2006; Gutierrez 2001). There are also a number of potentially important constraints that can limit provision of apheresis products on a regular and timely basis; e.g. hospitals in Europe managing granulocyte collections by apheresis now have a requirement for meeting 'blood establishment status' according to EU legislation.

- One study (Petersen 1987), compared prophylactic granulocyte transfusions with prophylactic broad-spectrum antibiotics. Data from this study were only incorporated into meta-analyses for two outcomes, people with bacteraemia of fungaemia and people with localised bacterial or fungal infection. There was no significant difference to the overall analysis when results from this study were excluded.

- Not all end points from the studies could be analysed due to varying methods of reporting the outcomes. This was true for: numbers of days with fever; number of days on treatment with 
antimicrobials (or courses of treatment with antibiotics/ antifungals); and increment of neutrophil count $\left(\times 10^{9} / \mathrm{L}\right)$.

- In three of the studies many of the participants enrolled were not included in the final analysis (Clift 1978; Ford 1982; Petersen 1987). Between 16\% (Petersen 1987) and 50\% (Ford 1982) of participants were randomised but not included within the analysis.

\section{Quality of the evidence}

Overall, the quality of the evidence was rated as very low to low across different outcomes according to GRADE methodology ( Summary of findings for the main comparison). This was due to many of the studies being at high risk of bias, and many of the outcome estimates being imprecise.

Two outcomes were considered low-grade quality evidence according to GRADE methodology due to the very serious risk of bias of the included studies.

- People with localised or systemic bacterial or fungal infections - Intermediate-dose granulocyte transfusions.

- People with bacteraemia or fungaemia.

This was because of: a high risk of selection bias because two studies were quasi-randomised; a high risk of attrition bias because three studies did not include a significant proportion of randomised people in the analysis; and a high risk of performance bias and detection bias due to the nature of the intervention (granulocyte transfusion) and difficulty blinding participants, physicians and outcome assessors.

Four outcomes were considered very low-grade quality evidence according to GRADE methodology due to the very serious risk of bias of the included studies (see above) and the serious imprecision of the estimates.

- All-cause mortality.

- Mortality due to infection.

- People with localised or systemic bacterial or fungal infections - low-dose granulocyte transfusions.

- People with localised bacterial or fungal infection.

The reason for the imprecision is because of the small number of participants within the trials and the low number of events. For example, if we assume an all-cause mortality rate of $14.5 \%$ (overall rate within the included studies within this review up to 30 days), we need a sample size of approximately 15,000 participants to be able to detect with $90 \%$ power the ability to save two extra lives per 100 people within a 30-day period.

See Figure 2 and Figure 3 for visual representations of the assessments of risk of bias across all studies and for each item in the individual studies.

\section{Potential biases in the review process}

To our knowledge, our review process is free from bias. We conducted a comprehensive search; searching data sources (including multiple databases, and clinical trial registries) to ensure that all relevant trials would be captured. There were no restrictions for the language in which the paper was originally published. The relevance of each paper was carefully assessed and all screening and data extractions were performed in duplicate. We pre-specified all outcomes and subgroups prior to analysis. There were insufficient numbers of included studies within the meta-analyses for us to use a funnel plot to examine the risk of publication bias.

\section{Agreements and disagreements with other studies or reviews}

We know of no other recent systematic reviews on the use of prophylactic granulocyte transfusions in people with neutropenia or neutrophil dysfunction. The last review on this subject was the previous version of this review (Massey 2009). Although the methodology of the review has changed in this update of the review to conform to current Cochrane Collaboration recommendations, the overall message of the review is unaltered.

\section{A U THORS, CONCLUSIONS}

\section{Implications for practice}

The review has identified low-quality evidence that prophylactic granulocyte transfusion lead to a reduction in the number of people developing a bacterial or fungal infection, especially if the dose is at least $1.0 \times 10^{10}$ per day. It would however, be premature to conclude that the use of granulocytes as prophylaxis in people with neutropenia would improve outcomes and prove cost-effective as the potential harms of the intervention could not be fully assessed. Supportive therapy in this setting has changed since most of the reviewed studies were performed. None of the studies in this review specifically evaluated people with congenital disorders of neutrophil function or production. None of the studies in this review assessed the use of blood product-derived granulocytes. In keeping with the conclusions from the systematic review of the use of granulocyte transfusions for therapeutic indications, the use of granulocyte transfusions should still be regarded as investigational and should ideally be conducted in the context of ongoing prospective trials designed to answer the question of effectiveness.

\section{Implications for research}

Contemporary well-designed prospective trials of sufficient power are required to evaluate the effectiveness of granulocyte transfusions as prophylaxis. The design of trials needs to consider multiple factors. Most importantly, the power calculations should be based upon the outcome measures currently encountered with standard 
therapy in the population selected. If mortality rate is to be used as an outcome measure that may be improved by granulocyte transfusion then populations with a higher mortality rate may be more amenable to show evidence of benefit.

All systematic reviews performed to date have suggested that the dose transfused is important although the exact minimal effective dose remains uncertain. Such a dose could be consistently obtained by secondary processing of "buffy coat" granulocytes or by administering G-CSF and steroids to ABO-compatible apheresis donors. The schedule for administration of granulocyte transfusions in the identified studies varied considerably, and would need to be standardised. However, the frequency of transfusion is to a major part also governed by logistical issues and therefore it is likely that the schedule will continue to be dictated by availability of donors and facilities.

\section{ACKNOWLEDGEMENTS}

The protocol for this review was initially developed within the Infectious Diseases Group, supported by a grant from the De- partment for International Development, UK. The protocol was transferred to the Cochrane Gynaecological, Neuro-oncology and Orphan Cancer Group in March 2005. The authors and the Cochrane Gynaecological, Neuro-oncology and Orphan Cancer Group would like to thank and acknowledge the assistance of the Cochrane Infectious Diseases Group.

We wish to acknowledge Ulrike Paulus who was an author of the previous review (Massey 2009), and was involved in protocol development, searching, selection of studies, data extraction and analysis, and was also a content expert.

We wish to acknowledge the input and comments from Susan Brunskill and Chris Hyde on protocol development.

This project was supported by the National Institute for Health Research, via Cochrane Infrastructure, Cochrane Programme Grant or Cochrane Incentive funding to the Cochrane Gynaecological, Neuro-oncology and Orphan Cancer Group. This project was also supported by the National Institute for Health Research (NIHR) Oxford Biomedical Research Centre Programme. The views and opinions expressed therein are those of the authors and do not necessarily reflect those of the Systematic Reviews Programme, NIHR, NHS or the Department of Health.

\section{R E F E R N C E S}

\section{References to studies included in this review}

\section{Clift 1978 \{published data only\}}

Clift RA, Sanders JE, Thomas ED, Williams B, Buckner

$\mathrm{CD}$. Granulocyte transfusions for the prevention of infection in patients receiving bone-marrow transplants. New England Journal of Medicine 1978;298(19):1052-7. [MEDLINE: 417248]

Ford 1982 \{published data only\}

* Ford JM, Cullen MH, Roberts MM, Brown LM, Oliver RTD, Lister TA. Prophylactic granulocyte transfusions: results of a randomized controlled trial in patients with acute myelogenous leukemia. Transfusion 1982;22(4):311-6. Ford JM, Lucey JJ, Cullen MH, Tobias JS, Lister TA. Fatal graft-versus-host disease following transfusion of granulocytes from normal donors. Lancet 1976;2:837-40.

Gomez-Villagran 1984 \{published data only\}

Gomez-Villagran JL, Torres-Gomez A, Gomez-Garcia P, Martinez-Guibelalde F, Velasco-Jimena F. A controlled trial of prophylactic granulocyte transfusions during induction chemotherapy for acute nonlymphoblastic leukemia. Cancer 1984;54(4):734-8. [MEDLINE: 6378355]

Mannoni 1979 \{published data only\}

Mannoni P, Rodet M, Vernant JP, Brun B, Coquin-Radeau EI, Bracq C, et al. Efficiency of prophylactic granulocyte transfusions in preventing infections in acute leukaemia. Blood Transfusion and Immunohaematology 1979;22(5): 503-17.
Oza 2006 \{published data only\}

Oza A, Hallemeier C, Goodnough L, Khoury H, Shenoy

$S$, Devine $S$, et al. Granulocyte-colony-stimulating factor-mobilized prophylactic granulocyte transfusions given after allogeneic peripheral blood progenitor cell transplantation result in a modest reduction of febrile days and intravenous antibiotic usage. Transfusion 2006;46(1): 14-23. [MEDLINE: 16398726]

Petersen 1987 \{published data only\}

Petersen FB, Buckner CD, Clift RA, Nelson N, Counts GW, Meyers JD, et al. Prevention of nosocomial infections in marrow transplant patients: a prospective randomized comparison of systemic antibiotics versus granulocyte transfusions. Infection Control 1987;7(12):586-92.

Schiffer 1979 \{published data only\} Schiffer CA, Aisner J, Daly PA, Schimpff SC, Wiernik $\mathrm{PH}$. Alloimmunization following prophylactic granulocyte transfusion. Blood 1979;54(4):766-74. [MEDLINE: 476300]

Strauss 1981 \{published data only\} NCT00000581. Granulocyte Transfusion Study. Clinical.Trials.gov 1999:[Accessed 21st April 2015]. * Strauss RG, Connett JE, Gale RP, Bloomfield CD, Herzig GP, McCullough, et al. A controlled trial of prophylactic granulocyte transfusions during initial induction chemotherapy for acute myelogenous leukemia. New England Journal of Medicine 1981;305(11):597-603. [MEDLINE: 6790985] 
Sutton 1982 \{published data only\}

Sutton DMC, Shumak KH, Baker MA. Prophylactic granulocyte transfusions in acute leukemia. Plasma Therapy 1982;3(1):45-9.

\section{Vij 2003 \{published data only\}}

Vij R, DiPersio JF, Venkatraman P, Trinkaus K, Goodnough LT, Brown RA, et al. Donor CMV serostatus has no impact on $\mathrm{CMV}$ viraemia or disease when prophylactic granulocyte transfusions are given following allogeneic peripheral blood stem cell transplantation. Blood 2003;101(5):2067-9.

Winston 1980 \{published data only\}

NCT00000581. Granulocyte Transfusion Study. Clinical.Trials.gov 1999:[Accessed 21st April 2015].

* Winston DJ, Ho WG, Young LS, Gale RP. Prophylactic granulocyte transfusions during human bone marrow transplantation. American Journal of Medicine 1980;68(6): 893-7. [MEDLINE: 6247910]

\section{References to studies excluded from this review}

\section{Alavi 1977 \{published data only\}}

Alave JB, Roor RK, Djerassi I, Evans AE, Gluckman SJ, MacGregor RR, et al. A randomised clinical trial of granulocyte transfusions for infection in acute leukemia. New England Journal of Medicine 1977;296(13):706-11. [MEDLINE: 320477]

\section{Altrichter 2011 \{published data only\}}

Altrichter J, Sauer M, Kaftan K, Birken T, Gloger D, Gloger M, et al. Extracorporeal cell therapy of septic shock patients with donor granulocytes: a pilot study. Critical Care 2011; 15(2):R82.

\section{Ambinder 1981 \{published data only\}}

Ambinder EP, Button GR, Cheung T, Goldberg JD, Holland JF. Filtration versus gravity leukapheresis in febrile granulocytopenic patients: a randomized prospective trial. Blood 1981;57:836-41.

Atay 2011 \{published data only\}

Atay D, Ozturk G, Akcay A, Yanasik M, Anak S, Devecioglu O. Effect and safety of granulocyte transfusions in pediatric patients with febrile neutropenia or defective granulocyte functions. Journal of Pediatric Hematology/ Oncology: Official Journal of the American Society of Pediatric Hematology/Oncology 2011;33(6):e220-5.

Baley 1987 \{published data only\}

Baley JE, Stork EK, Warkentin PI, Shurin SB. Buffy coat transfusions in neutropenic neonates with presumed sepsis: A prospective randomised trial. Pediatrics 1987;80:712-9.

Bow 1984 \{published data only\}

Bow EJ, Schroeder ML, Louie TJ. Pulmonary complications in patients receiving granulocyte transfusions and amphotericin B. Canadian Medical Association Journal 1984; 130:593-5.

Buckner 1983 \{published data only\} Buckner CD, Clift RA, Thomas ED, Hersman J, Sanders JE, Stewart PS, et al. Early infectious complications in allogeneic marrow transplant recipients with acute leukemia: effects of prophylactic measures. Infection 1983;11(5): 243-50. [MEDLINE: 6417027]

Christensen 1982 \{published data only\}

Christensen RD, Rothstein G, Anstall HB, Bybee B.

Granulocyte transfusions in neonates with bacterial

infection, neutropenia and depletion of mature marrow neutrophils. Pediatrics 1982;70:1-6.

\section{DRKS00000218 \{published data only\}}

DRKS00000218. Transfusion of granulocytes for patients with febrile neutropenia (GRANITE). Deutsche Forschungsgemeinschaft 2011:[Accessed 24th April 2015].

Freireich 2013 \{published data only\}

* Freireich EJ, Lichtiger B, Mattiuzzi G, Martinez F, Reddy V, Kyle WJ. A prospective, randomized, double-blind study, comparing unirradiated to irradiated white blood cell transfusions in acute leukemia patients. Leukemia 2013;27 (4):861-5.

NCT00968838. A study for leukemia patients with life-threatening infections. www.clinicaltrials.gov 2008 [Accessed 17th February 2015].

Herzig 1977 \{published data only\}

Herzig R, Herzig GP, Graw RG, Bull MJ, Ray KK. Successful granulocyte transfusion therapy for gramnegative septicemia. New England Journal of Medicine 1977; 296(13):701-5.

Higby 1975 \{published data only\}

Higby DJ, Yates JW, Henderson ES, Holland JF. Filtration leukapheresis for granulocyte transfusion therapy. New England Journal of Medicine 1975;292(15):762-6.

Ikemoto 2012 \{published data only\} Ikemoto J, Yoshihara S, Fujioka T, Ohtsuka Y, Fujita N, Kokubunji A, et al. Impact of the mobilization regimen and the harvesting technique on the granulocyte yield in healthy donors for granulocyte transfusion therapy. Transfusion 2012;52(12):2646-52.

Klastersky 1983 \{published data only\} Klastersky J. EORTC International Antimicrobial Therapy Project Group. Early granulocyte transfusions in high risk febrile neutropenic patients. Schweizerische Medizinische Wochenschrift 1983;113(Suppl 14):46-8.

\section{NCT01932710 \{published data only\}} NCT01932710. A feasibility study of prophylactic white blood cell transfusions. Clinical.Trials.gov 2013: [Accessed 21st April 2015].

\section{Pammi 2011 \{published data only\}}

Pammi M, Brocklehurst P. Granulocyte transfusions for neonates with confirmed or suspected sepsis and neutropenia. Cochrane Database of Systematic Reviews 2011, Issue 10. [DOI: 10.1002/14651858.CD003956.pub2]

Price 2014 \{published data only\} NCT00627393. Safety and effectiveness of granulocyte transfusions in resolving infection in people With 
neutropenia (The RING Study). www.Clinical Trials.gov 2008 [Accessed 17th February 2015].

Price TH. The RING study: a randomized controlled trial of GCSF stimulated granulocytes in granulocytopenic patients. Blood 2014;124(21):SCI-16.

* Price TH, McCullough J, Ness P, Strauss RG, Pulkrabek SM, Harrison R, et al. A randomized controlled trial on the efficacy of high-dose granulocyte transfusion therapy in neutropenic patients with infection. Blood 2014;124(21): 597.

Scali 1978 \{published data only\}

Scali G, von Felten A, Fehr J, Sasuter C, Gmür J. Granulocyte substitution in febrile leukemia patients with bone marrow aplasia. 1. Results of a prospective study [Granulozytensubstitution bei febrilen leukamiepatienten in knochenmarkaplasie]. Schweizerische Medizinische Wochenschrift 1978;108(41):1583-5.

Seidel 2008 \{published data only\} Peters C, Seidel MG, Northoff H, Moog R, Boehme A, Silling G, et al. Granulocyte transfusions for treatment or prophylaxis of severe infections in immunocompromized neutropenic patients - a randomized clinical trial. $A S H$ Annual Meeting Abstracts 2006;108(11):2934.

* Seidel MG, Peters C, Wacker A, Northoff H, Moog R, Boehme A, et al. Randomized phase III study of granulocyte transfusions in neutropenic patients. Bone Marrow Transplantation 2008;42(10):679-84.

UMIN000014777 \{published data only\}

UMIN000014777. Study on safety and efficacy of granulocyte transfusion mobilized with G-CSF in related donor. UMIN Clinical Trials Registry 2014: [Accessed 24th April 2015].

Vogler 1977 \{published data only\}

Vogler WR, Winton EF. A controlled study of the efficacy of granulocyte transfusions in patients with neutropenia. American Journal of Medicine 1977;63:548-55.

Wheeler 1987 \{published data only\}

Wheeler JG, Chauvenet AR, Johnson CA, Block SM, Dillard R, Abramson JS. Buffy coat transfusions in neonates with sepsis and neutrophil storage pool depletion. Pediatrics 1982;79:422-5.

Winston 1982 \{published data only\}

Winston DJ, Winston G, Gale RP. Therapeutic granulocyte transfusions for documented infections - A controlled trial in ninety-five infectious granulocytopenic episodes. Annals of Internal Medicine 1982;97:509-15.

\section{References to ongoing studies}

NCT01204788 \{published data only\}

NCT01204788. Prophylactic white cell transfusions versus therapeutic white cell transfusions in patients with leukemia. www.Clinicaltrials.gov 2010 [Accessed 17th February 2015].

\section{Additional references}

Bashir 2003

Bashir S, Cardigan R. Granulocyte concentrates: how can we assess their quality?. Transfusion Medicine 2003;13:245.

Bashir 2008

Bashir S, Stanworth S, Massey E, Goddard F, Cardigan R. Neutrophuil function is preserved in a pooled granulocyte component prepared from whole blood donations. British Journal of Haematology 2008;140:701-11.

\section{Bennett 2006}

Bennett CL, Evens AM, Andritsos LA. Haematological malignancies developing in previously healthy individuals who received haematopoietic growth factors: report from the Research on Adverse Drug Events and Reports (RADAR) project. British Journal of Haematology 2006;135 (5):642-50.

\section{Dale 1998}

Dale DC, Liles WC, Llewelyn C, Rodger E, Price TH. Neutrophil transfusions: kinetics and functions of neutrophils mobilized with granulocyte colony-stimulating factor and dexamethasone. Transfusion 1998;38:713-21.

Dale 2000

Dale DC, Liles WC. Return of granulocyte transfusions. Current Opinion in Pediatrics 2000;12:18-22.

\section{Deeks 2011}

Deeks JJ, Higgins JPT, Altman DG (editors). Chapter 9: Analysing data and undertaking meta-analyses. In: Higgins JPT, Green S (editors). Cochrane Handbook for Systematic Reviews of Interventions Version 5.1.0 (updated March 2011). The Cochrane Collaboration, 2011. Available from www.cochrane-handbook.org.

\section{Engelfriet 2000}

Engelfriet CO, Reesink HW. Granulocyte transfusions. Vox Sanguinis 2000;79:59-96.

\section{Freireich 1964}

Freireich EJ, Levin RH, Whang J, Carbone PP, Bronson W, Morse EE. The function and fate of transfused leukocytes from donors with chronic myelocytic leukemia in leukopenic recipients. Annals of the New York Academy of Sciences 1964;113:1081-90.

\section{Ghodsi 2001}

Ghodsi Z, Strauss RG. Cataracts in neutrophil donors stimulated with adrenal corticosteroids. Transfusion 2001; 41:1464-8.

\section{Goldman 2006}

Goldman JM, Madrigal JA, Pamphilon D. Possible harmful effects of short course granulocyte colony-stimulating factor in normal donors. British Journal of Haematology 2006 December;8: 155-60.

\section{Gutierrez 2001}

Gutierrez-Delgado F, Bensigner W. Safety of granulocyte colony-stimulating factor in normal donors. Current Opinion in Haematology 2001;8:155-60.

\section{Higgins 2011a}

Higgins JPT, Deeks JJ (editors). Chapter 7: Selecting studies and collecting data. In: Higgins JPT, Green S 
(editors), Cochrane Handbook for Systematic Reviews of Interventions Version 5.1.0 (updated March 2011). The Cochrane Collaboration, 2011. Available from www.cochrane-handbook.org.

\section{Higgins 2011b}

Higgins JPT, Deeks JJ, Altman DG (editors). Chapter 16: Special topics in statistics. In: Higgins JPT, Green $S$ (editors), Cochrane Handbook for Systematic Reviews of Interventions Version 5.1.0 (updated March 2011). The Cochrane Collaboration, 2011. Available from www.cochrane-handbook.org.

Higgins 2011c

Higgins JPT, Altman DG, Sterne JAC (editors). Chapter 8: Assessing risk of bias in included studies. In: Higgins JPT, Green S (editors). Cochrane Handbook for Systematic Reviews of Interventions Version 5.1.0 (updated March 2011). The Cochrane Collaboration, 2011. Available from www.cochrane-handbook.org.

\section{Hubel 2001}

Hubel K, Dale D C, Engert A, Liles WC. Current status of granulocyte (neutrophil) transfusion therapy for infectious diseases. Journal of Infectious Diseases 2001;183:321-8.

\section{Illerhaus 2002}

Illerhaus G, Wirth K, Dwenger A, Waller CF, Garbe A, Brass $\mathrm{V}$, et al. Treatment and prohylaxis of severe infections in neutropenic patients by granulocyte transfusions. Annals of Hematology 2002;81:273-81.

\section{Kerr 2003}

Kerr JP, Liakopolou E, Brown J, Cornish JM, Fleming D, Massey E, et al. The use of stimulated granulocyte transfusions to prevent recurrence of past severe infections after allogeneic stem cell transplantation. British Journal of Haematology 2003;123:114-8.

\section{Klastersky 2001}

Klastersky J. Empirical treatment of sepsis in neutropenic patients. Hospital Medicine (London) 2001;62:101-3.

\section{Kuijpers 1999}

Kuijpers TW, Weening RS, Roos D. Clinical and laboratory work-up of patients with neutrophil shortage or dysfunction. Journal of Immunological Methods 1999;232: 211-29.

\section{Lefebvre 2011}

Lefebvre C, Manheimer E, Glanville J. Chapter 6: Searching for studies. In: Higgins JPT, Green S (editors). Cochrane Handbook for Systematic Reviews of Interventions Version 5.1.0 (updated March 2011). The Cochrane Collaboration, 2011. Available from www.cochrane-handbook.org.

Massey 2012

Massey E, Harding K, Kahan BC, Llewelyn C, Wynn R, Moppett J, et al. The granulocytes in neutropenia 1 (GIN 1) study: a safety study of granulocytes collected from whole blood and stored in additive solution and plasma. Transfusion Medicine 2012;22(4):277-84.

\section{Parmar 1998}

Parmar MK, Torri V, Stewart L. Extracting summary statistics to perform meta-analyses of the published literature for survival endpoints. Statistics in Medicine 1998;17(24): 2815-34.

\section{Peters 1999}

Peters C, Minkov M, Matthes-Martin S, Potschger U, Witt $\mathrm{V}$, Mann G, et al. Leucocyte transfusions from rhG-CSF or prednisolone stimulated donors for treatment of severe infections in immunocompromised neutropenic patients. British Journal of Haematology 1999;106:689-96.

\section{Price 2000}

Price TH, Bowden RA, Beockh M, Bux J, Nelson K, Liles WC, et al. Phase 1/ll trial of neutrophil transfusions from donors stimulated with G-CSF and dexamethasone for treatment of patients with infections in hematopoietic stem cell transplantation. Blood 2000;95:3302-9.

\section{Review Manager 5.3}

The Nordic Cochrane Centre. Review Manager (RevMan). Version 5.3. Copenhagen: The Cochrane Collaboration, 2014.

\section{Schünemann 2011}

Schünemann HJ, Oxman AD, Higgins JPT, Vist GE, Glasziou P, Guyatt GH. Chapter 11: Presenting results and 'Summary of findings' tables. In: Higgins JPT, Green $S$ (editors), Cochrane Handbook for Systematic Reviews of Interventions Version 5.1.0 (updated March 2011). The Cochrane Collaboration, 2011. Available from www.cochrane-handbook.org.

\section{Stanworth 2005}

Stanworth S, Massey E, Brunskill S, Hyde C, Lucas G, Marks D, et al. Granulocyte transfusions for treating infections in patients with neutropenia or neutrophil dysfunction. Cochrane Database of Systematic Reviews 2005, Issue 3. [DOI: 10.1002/14651858.CD005339]

\section{Sterne 2011}

Sterne JAC, Egger M, Moher D (editors). Chapter 10: Addressing reporting biases. In: Higgins JPT, Green $S$ (editors). Cochrane Handbook for Systematic Reviews of Intervention. Version 5.1.0 (updated March 2011). The Cochrane Collaboration, 2011. Available from www.cochrane-handbook.org.

\section{Storring 1977}

Storring RA, Jameson B, McElwain TJ, Wiltshaw E. Oral non-absorbed antibiotics prevent infection in acute nonlymphoblastic leukaemia. Lancet 1977;2(8043):837-40. [MEDLINE: 72192]

\section{Stovold 2014}

Stovold E, Beecher D, Foxlee R, Noel-Storr A. Study flow diagrams in Cochrane systematic review updates: an adapted PRISMA flow diagram. Systematic Reviews 2014;3 (1):54.

\section{Strauss 2003}

Strauss RG. Granulocyte (neutrophil) transfusion. Apheresis: Principles and Practice. Bethesda: AABB Press, 2003: 237-52. 
Tierney 2007

Tierney JF, Stewart LA, Ghersi D, Burdett S, Sydes MR. Practical methods for incorporating summary time-to-event data into meta-analysis. Trials 2007; Vol. 8, issue 16 . [DOI: $10.1186 / 1745-6215-8-16]$

Vamvakas 1996

Vamvakas EC, Pineda AA. Meta-analysis of clinical studies of the efficacy of granulocyte transfusions in the treatment of bacterial sepsis. Journal of Clinical Apheresis 1996;11:1-9.

van Staa 2003

van Staa TP, Boulton F, Cooper C, Hagenbeek A, Inskip H, Leufkens HG. Neutropenia and agranulocytosis in England and Wales: incidence and risk factors. American Journal of Hematology 2003;72(4):248-54.

WHO 1992

World Health Organization. International statistical classification of diseases and related health problems. 10th edition. Vol. 1. Geneva 1992.

\section{References to other published versions of this review}

\section{Massey 2009}

Massey E, Paulus U, Doree C, Stanworth S. Granulocyte transfusions for preventing infections in patients with neutropenia or neutrophil dysfunction. Cochrane Database of Systematic Reviews 2009, Issue 1. [DOI: 10.1002/ 14651858.CD005341.pub2]

Paulus 2005

Paulus U, Massey E, Doree C, Brunskill S, Hyde C, Lucas $\mathrm{G}$, et al. Granulocyte transfusions for preventing infections in patients with neutropenia or neutrophil dysfunction. Cochrane Database of Systematic Reviews 2005, Issue 3. [DOI: 10.1002/14651858.CD005341]

* Indicates the major publication for the study 


\section{CHARACTERISTICS OF STUDIES}

\section{Characteristics of included studies [ordered by study ID]}

\section{Clift 1978}

Methods

Parallel RCT (conducted from February 1974 to September 1977). Single centre. Country: USA

Participants

Inclusion criteria: Adults and children with acute leukaemia and aplastic anaemia undergoing related HLA-matched allogeneic haematopoietic stem cell transplantation

Exclusion criteria: Infection criteria for excluding people from the study was not reported

Total randomised $\mathrm{N}=86$

Total analysed $\mathrm{N}=69$

Arm 1 (Granulocyte transfusions): randomised $=41$, analysed $=29$; Acute leukaemia $=$ 17 , Aplastic anaemia $=12$

Arm 2 (Control): randomised $=45$, analysed $=40:$ Acute leukaemia $=27$, Aplastic anaemia $=13$

Interventions

Comparison between standard treatment and prophylactic granulocyte transfusions

Granulocyte dose: mean $2.22 \times 10^{10}$ (leucofiltration) $1.57 \times 10^{10}$ (centrifugation)

Granulocyte method of collection: by either continuous flow centrifugation or reversible leukoadhesion to nylon columns

Donor premedication: None

Initiation of granulocyte transfusions: 1 st post-transplant day neutrophil count $\leq 0$. $2 \times 10^{9} / \mathrm{L}$

Frequency of granulocyte transfusions: Daily

Termination of granulocyte transfusions: Neutrophil count $>0.2 \times 10^{9} / \mathrm{L}$ [not clearly stated]

Outcomes

Primary Outcome: The effectiveness of granulocytes in reducing the acquisition of bacterial or fungal infection during the first 21 post-transplant days

Secondary Outcomes:

Mortality/survival, fever (days or episodes), infection (days or episodes), antibiotic use, adverse events

Definition of infection

Febrile day - two temperatures greater than $38.3^{\circ} \mathrm{C}$ in 24 hours.

Febrile episode - not defined

Proven infection: subdivided in to:-

Septicaemia - at least one positive blood culture with appropriate symptoms, or two consecutive blood cultures growing the same organism (daily surveillance blood cultures were performed)

Local infection - lesions with symptoms or signs of infection and isolation of causative bacterial or fungal organisms 
Clift 1978 (Continued)

$\begin{array}{ll}\text { Co-interventions } & \text { Prophylactic antibiotics: not reported } \\ \text { Therapeutic antibiotics: no restrictions on type of systemic antibiotic treatment given } \\ \text { Therapeutic granulocyte transfusions: participants in the control group were eligible } \\ \text { for granulocyte transfusions as clinically indicated for the treatment of established infec- } \\ \text { tion }\end{array}$

Notes

Funding Sources: Grants CA18579, CA18029, CA17117 and CA15704 from the National Cancer Institute. Dr Thomas is the recipient of a research career award (AI 02425) from the National Institute for Allergy and Infectious Diseases

Conflict of Interests: Not reported

Risk of bias

\begin{tabular}{lll}
\hline Bias & Authors' judgement & Support for judgement \\
\hline $\begin{array}{l}\text { Random sequence generation (selection } \\
\text { bias) }\end{array}$ & Unclear risk & $\begin{array}{l}\text { Method of sequence generation was not re- } \\
\text { ported }\end{array}$ \\
\hline Allocation concealment (selection bias) & Unclear risk & $\begin{array}{l}\text { Method of allocation concealment was not } \\
\text { reported }\end{array}$ \\
\hline
\end{tabular}

Blinding of participants and personnel Unclear risk (performance bias)

All outcomes

It was not reported whether participants were blinded to the intervention. It was not reported whether clinicians or investigators were blinded to the intervention

Blinding of outcome assessment (detection Unclear risk bias)

It was not reported whether outcome asses-

All outcomes sors were blinded to the intervention

Incomplete outcome data (attrition bias) High risk All outcomes

Only 40 of the 45 participants randomised to the control group were included in the analysis. Only 29 of the 41 participants randomised to the intervention group were included in the analysis

Five randomised participants were not included in the control group:

- One patient was not eligible for treatment with the marrow transplantation protocol

- Three participants could not be evaluated because the decision was made to transplant them elsewhere

- One patient died of cardiac failure on the 11th day after transplantation. This patient was not receiving antibiotics before the first day but antibiotics were initiated on the second day because of 
Clift 1978 (Continued)

fever without documented infection.

There was no autopsy evidence of an infective process

Twelve randomised participants were not included in the intervention group:

- Three participants were withdrawn because the potential granulocyte donors were unacceptable for medical reasons

- Three participants the granulocyte transfusions were abandoned because of donor complications

- Three participants the granulocyte transfusions were abandoned because their HLA-matched granulocyte donors were the only source of effective platelets and granulocyte collections were jeopardising the recipients' platelet support

- One participant did not receive a transplant in accordance with the protocol

- One participant died on the 10th post-transplant day after receiving nine daily granulocyte transfusions

- One participant reason not given

Selective reporting (reporting bias) Unclear risk

The protocol was not available to assess whether any pre-specified outcomes were not reported or outcomes were reported that were not pre-specified

Other bias

Unclear risk

Although none identified, it is difficult to rule out any significant bias due to insufficient reporting of the study. More control participants had relapsed disease $(16 /$ 40 compared to $8 / 29$ )

Ford 1982

Methods

Participants
Parallel RCT (recruitment period not reported). Single centre. Country: England

Inclusion criteria: People over 15 years old with acute myeloid leukaemia undergoing induction chemotherapy

Exclusion criteria: "afebrile, free of infection and not receiving antibiotics". Microbiological proof of absence of infection was required prior to commencing granulocyte transfusion therapy

Total randomised: $\mathrm{N}=49$

Total analysed: $\mathrm{N}=24$

Arm 1 (Granulocyte transfusions): randomised = 26, analysed $=13$ with acute myeloid leukaemia 
Ford 1982 (Continued)

Arm 2 (Control): randomised $=23$, analysed $=11$ with acute myeloid leukaemia

\begin{tabular}{ll}
\hline Interventions & Comparison between standard treatment and prophylactic granulocyte transfusions \\
& Granulocyte dose: $1.45 \times 10^{10}(0.28$ to 3.45$)$ \\
& Granulocyte method of collection: intermittent flow centrifugation \\
& Donor premedication: dexamethasone \\
& Initiation of granulocyte transfusions: Day after the neutrophil count $<0.5 \times 10^{9} / \mathrm{L}$ \\
& Frequency of granulocyte transfusions: Alternate days \\
& Termination of granulocyte transfusions: Neutrophil count $>0.5 \times 10^{9} / \mathrm{L}$ \\
\hline
\end{tabular}

Outcomes

Primary Outcome: Not reported

Other Outcomes:

Mortality/survival, fever (days or episodes), infection (days or episodes), antibiotic use, adverse events

Definition of infection

Febrile day - two temperatures greater than $38.0^{\circ} \mathrm{C}$ in 24 hours.

Febrile episode - a temperature greater than or equal to $38^{\circ} \mathrm{C}$ for greater than or equal to 4 hours in the absence of blood transfusion

Proven infection - a causative organism was cultured either from blood or infected site or there were clinical signs strongly suggestive of infection or pneumonia was identified by chest X-ray changes and clinical signs or symptoms

Definition of neutropenia

Co-interventions
Not reported but the 'trigger' neutrophil count was $0.5 \times 10^{9} / \mathrm{L}$

Prophylactic antibiotics: all participants received oral, non-absorbable antibiotics ( Storring 1977).

Therapeutic antibiotics: if a fever occurred lasting more than 4 hours intravenous tobramycin and carbenicillin (or flucloxacillin for identified skin sepsis) were administered Therapeutic granulocyte transfusions: not given to control participants

Notes

Funding Sources: Imperial Cancer Research Fund, Department of Medical Oncology and Department of Haematology, St Bertholomew Hospital, London

Conflict of Interests: Not reported

\section{Risk of bias}

\begin{tabular}{l|ll}
\hline Bias & Authors' judgement & Support for judgement \\
\hline $\begin{array}{l}\text { Random sequence generation (selection } \\
\text { bias) }\end{array}$ & Unclear risk & $\begin{array}{l}\text { Method of sequence generation was not re- } \\
\text { ported }\end{array}$ \\
\hline Allocation concealment (selection bias) & Unclear risk & $\begin{array}{l}\text { Method of allocation concealment was not } \\
\text { reported }\end{array}$ \\
\hline
\end{tabular}

Blinding of participants and personnel High risk (performance bias)

All outcomes
It was not reported whether participants were blinded to the intervention If participants received granulocyte transfusions, "patients needed no platelet sup- 
Ford 1982 (Continued)

port because of the coincidentally transfused platelets". Clinicians and investigators would therefore be able to tell whether patients were receiving granulocyte transfusions

Blinding of outcome assessment (detection Unclear risk bias)

All outcomes

Incomplete outcome data (attrition bias) High risk All outcomes
It was not reported whether outcome assessors were blinded to the intervention

49 participants were randomised, of whom 26 received granulocyte transfusions 25 of the 49 participants were excluded from the analysis because they did not meet the criteria for study entry

- 12 participants were randomised but excluded from the study because fever or infection developed either before their neutrophil count fell below 0.5 (eight participants) or before the first granulocyte transfusion (4 participants)

- 13 participants were randomised but excluded, the specific reason for not meeting the study criteria was not reported

Selective reporting (reporting bias) Unclear risk

The protocol was not available to assess whether any pre-specified outcomes were not reported or outcomes were reported that were not pre-specified

Other bias

Unclear risk

Although none identified, it is difficult to rule out any significant bias due to insufficient reporting of the study

Gomez-Villagran 1984

Methods

Participants
Parallel RCT (conducted from January 1981 to June 1982 ). Single centre. Country Spain

Inclusion criteria: Adults and children with acute myeloid leukaemia (AML) undergoing induction chemotherapy

Exclusion criteria: had to have no evidence of infection or fever

Total randomised: $\mathrm{N}=35$

Total analysed: $\mathrm{N}=35$

Arm 1 (Granulocyte transfusions): N = 19; Acute myeloid leukaemia = 19

Arm 2 (Control): $\mathrm{N}=16$, Acute myeloid leukaemia $=16$ 


\begin{tabular}{l} 
Interventions \\
$\begin{array}{l}\text { Comparison between standard treatment and prophylactic granulocyte transfusions } \\
\text { Granulocyte dose: } 1.24 \times 10^{10}(0.55 \text { to } 4.2)\end{array}$ \\
$\begin{array}{l}\text { Granulocyte method of collection: intermittent flow centrifugation } \\
\text { Donor premedication: dexamethasone } \\
\text { Initiation of granulocyte transfusions: Neutrophil count }<0.5 \times 10^{9} / \mathrm{L} \\
\text { Frequency of granulocyte transfusions: Daily } \\
\text { Termination of granulocyte transfusions: Until } \\
\circ \text { The neutrophil count was greater than } 0.5 \times 10^{9} / \mathrm{L}, \text { or } \\
\circ 21 \text { days of granulocyte transfusion had been given. } \\
\circ \text { There were no donors available or } \\
\circ \text { There were "other signs of bone marrow recovery" }\end{array}$ \\
\hline
\end{tabular}

\begin{tabular}{ll} 
Outcomes & $\begin{array}{l}\text { Primary Outcome: Not reported } \\
\text { Other Outcomes: } \\
\text { Mortality/survival, fever (days or episodes), infection (days or episodes), antibiotic use, } \\
\text { adverse events }\end{array}$ \\
\hline Definition of infection & $\begin{array}{l}\text { Febrile day: Not reported } \\
\text { Febrile episode: Temperature } \geq 38^{\circ} \mathrm{C} \text { in the absence of a recent blood product trans- } \\
\text { fusion } \\
\text { Proven infection: Not reported }\end{array}$ \\
\hline Definition of neutropenia & \begin{tabular}{l} 
Not reported but the 'trigger' neutrophil count was $0.5 \times 10^{9} / \mathrm{L}$ \\
\hline Co-interventions
\end{tabular} \\
\hline $\begin{array}{l}\text { Prophylactic antibiotics: oral non-absorbable drugs neomycin, colimycin and nystatin } \\
\text { Therapeutic antibiotics: cephalosporin, tobramycin and carbenicillin as empirical treat- } \\
\text { ment of infection } \\
\text { Therapeutic granulocyte transfusions: participants in the control group were not eli- } \\
\text { gible for granulocyte transfusions during the on-study period (21 days), even if a docu- } \\
\text { mented infection developed }\end{array}$ \\
\hline
\end{tabular}

\begin{tabular}{l|l} 
Notes & Funding Sources: Not reported \\
Conflict of Interests: Not reported
\end{tabular}

Risk of bias

\begin{tabular}{l|ll}
\hline Bias & Authors' judgement & Support for judgement \\
\hline $\begin{array}{l}\text { Random sequence generation (selection } \\
\text { bias) }\end{array}$ & Unclear risk & $\begin{array}{l}\text { Method of sequence generation was not re- } \\
\text { ported }\end{array}$ \\
\hline Allocation concealment (selection bias) & Unclear risk & $\begin{array}{l}\text { Method of allocation concealment was not } \\
\text { reported }\end{array}$ \\
\hline
\end{tabular}

Blinding of participants and personnel High risk (performance bias)

All outcomes
It was not reported whether participants were blinded to the intervention "The patients under prophylactic transfusions did not require isolated platelet trans- 
fusions during pancytopenic episodes because of the high contaminating level of platelets in the granulocyte concentrate" Therefore medical staff would have been aware of whether patients were in the intervention arm

Blinding of outcome assessment (detection Unclear risk bias)

All outcomes

Incomplete outcome data (attrition bias) Low risk All outcomes

Selective reporting (reporting bias) Unclear risk

It was not reported whether outcome assessors were blinded to the intervention
All participants either died or remission status was assessed after the chemotherapy

The protocol was not available to assess whether any pre-specified outcomes were not reported or outcomes were reported that were not pre-specified
Other bias

Unclear risk
The median age of participants was higher in the control group 35 years versus 27.5 years. Three of the participants in the control group had AML M3, and none of the participants in the intervention group had AML M3. Participants were receiving induction chemotherapy and therefore participants with AML M3 would have had a higher risk or early death due to bleeding or disseminated intravascular coagulation There were also more AML M1 cases in the transfused arm (14/19) when compared with controls $(6 / 16)$
Methods

Participants
Parallel RCT (recruitment period not reported). Number of centres unclear. Country: France

Inclusion criteria: Adults ( $>16$ years old) with acute myeloid leukaemia receiving standardised chemotherapy inducing profound bone marrow depression

Exclusion criteria: "not severely infected", severe infection being defined as pulmonary or perineal localisation or diarrhoea with abdominal distension

Total randomised: $\mathrm{N}=44$ participants and 50 episodes of aplasia

Arm 1 (Granulocyte transfusions): randomised $=20$, Acute myeloid leukaemia $=20(22$ separate episodes of aplasia)

Arm 2 (Control): randomised $=26^{*}$, Acute myeloid leukaemia $=26$ (28 separate episodes of aplasia)

Acute leukaemia (myeloid)

* Six participants may have been re-randomised but this is not clear in the text. Ran- 
domisation occurred at the onset of 50 episodes of aplasia

\begin{tabular}{|c|c|}
\hline Interventions & $\begin{array}{l}\text { Comparison between standard treatment and prophylactic granulocyte transfusions } \\
\text { Granulocyte dose: } 2.1 \times 10^{10}(1.3 \text { to } 3.7) \\
\text { Granulocyte method of collection: intermittent flow centrifugation } \\
\text { Donor premedication: dexamethasone or hydrocortisone } \\
\text { Initiation of granulocyte transfusions: Fourth day of chemotherapy } \\
\text { Frequency of granulocyte transfusions: Daily } \\
\text { Termination of granulocyte transfusions: After approximately } 12 \text { days in the absence } \\
\text { of fever or infection }\end{array}$ \\
\hline Outcomes & $\begin{array}{l}\text { Primary Outcome: Not reported } \\
\text { Other Outcomes: } \\
\text { Mortality/survival, infection (days or episodes), adverse events }\end{array}$ \\
\hline Definition of infection & $\begin{array}{l}\text { Febrile day - Not reported } \\
\text { Febrile episode - temperature elevation alone of } 38^{\circ} \mathrm{C} \text { for at least } 24 \text { hours excluding } \\
\text { febrile reactions to blood products or administration of chemotherapy } \\
\text { Minor infection: Bacteraemia alone, with at least } 2 \text { positive blood cultures, or local skin } \\
\text { or mucocutaneous infection, or in case of diarrhoea without abdominal distension } \\
\text { Major infection: Any life-threatening infection or the associations of septicaemia and } \\
\text { local infections were considered as major infections }\end{array}$ \\
\hline Definition of neutropenia & Neutrophils $<0.5 \times 10^{9} / \mathrm{L}$ \\
\hline Co-interventions & $\begin{array}{l}\text { Prophylactic antibiotics: non absorbable antibiotics } \\
\text { Therapeutic antibiotics: combination of two systemic antibiotics if the patient was } \\
\text { febrile for } 24 \text { hours } \\
\text { Therapeutic granulocyte transfusions: given to the control group if participants had } \\
\text { a severe infection or in the case of refractoriness to antibiotics in minor infections }\end{array}$ \\
\hline Notes & $\begin{array}{l}\text { Funding Sources: Not reported } \\
\text { Conflict of Interests: Not reported }\end{array}$ \\
\hline
\end{tabular}

\section{Risk of bias}

\begin{tabular}{lll}
\hline Bias & Authors' judgement & Support for judgement \\
\hline $\begin{array}{l}\text { Random sequence generation (selection } \\
\text { bias) }\end{array}$ & Unclear risk & $\begin{array}{l}\text { Method of sequence generation was not re- } \\
\text { ported }\end{array}$ \\
\hline Allocation concealment (selection bias) & Unclear risk & $\begin{array}{l}\text { Method of allocation concealment was not } \\
\text { reported }\end{array}$ \\
\hline
\end{tabular}

Blinding of participants and personnel High risk (performance bias)

All outcomes
It was not reported whether participants were blinded to the intervention

In the intervention group "the number of platelets contaminating the leucocyte transfusions was usually enough to main- 
tain the platelet count" above 20. Therefore clinicians would be able to tell whether patient was receiving prophylactic granulocyte transfusions

Blinding of outcome assessment (detection Unclear risk bias)

All outcomes
Clinical data were collected and re-examined by two different persons who had not been in charge of the participants, in order to determine the diagnosis and severity of infection. However it was not reported whether these outcome assessors were blinded to the intervention

It was unclear whether any participants were lost to follow-up

The protocol was not available to assess whether any pre-specified outcomes were not reported or outcomes were reported that were not pre-specified

Study funding and any conflicts of interest were not reported. Baseline characteristics of the participants were not reported It appeared that at least six participants had been re-randomised, 44 participants and 50 episodes of aplasia

Oza 2006

Methods

Participants
Biologically randomised study (recruitment period not reported). Single centre. Country: USA

Inclusion criteria: People aged at least 15 years of age undergoing related HLA-matched allogeneic haematopoietic stem cell transplantation

Exclusion criteria: infection criteria for excluding people from the study was not reported

Total cohort $\mathrm{N}=151$

Arm 1 (Granulocyte transfusions): Allocated and analysed $\mathrm{N}=53$ Leukemia = 38; Lymphoroliferative disorders $=15$

Arm 2 (Control): Allocated and analysed $=98$; Leukaemia $=59$, Lymphoroliferative disorders $=39$

Allograft BMT, acute leukaemia
Comparison between standard treatment and prophylactic granulocyte transfusions Granulocyte dose: participants received two granulocyte transfusions. The mean dose and range were given separately for the first dose, $5.9 \times 10^{10}(0.02$ to 15.5$)$ and the second dose $5.2 \times 10^{10}(0.02$ to 21.0$)$

Granulocyte method of collection: intermittent flow centrifugation 
Donor premedication: G-CSF

Initiation of granulocyte transfusions: Day plus 3 or 5 (depending on protocol)

Frequency of granulocyte transfusions: Twice during neutropenic interval

Termination of granulocyte transfusions: Day plus 6 or 7 (depending on protocol)

Outcomes

Primary Outcomes: The number of febrile days and days of intravenous antibiotic use during the initial transplant hospitalisation period

Secondary Outcomes:

Mortality/survival, fever (episodes), antibiotic use, adverse events

Definition of infection

Febrile day - Any day during the initial hospitalisation that the recipient's temperature was $38.3^{\circ} \mathrm{C}$

Febrile episode - Temperature of at least $38.3^{\circ} \mathrm{C}$

Proven infection: Documented bacteraemia included only culture-proven systemic blood infections for either gram-positive or gram-negative bacteria

Definition of neutropenia

Co-interventions
Neutrophil count $<0.5 \times 10^{9} / \mathrm{L}$

Prophylactic antibiotics: not given

Therapeutic antibiotics: IV vancomycin and imipenem as empirical treatment for infection

Therapeutic granulocyte transfusions: not reported.

$\begin{array}{ll}\text { Notes } & \text { Funding Sources: Not reported } \\ & \text { Conflict of Interests: Not reported }\end{array}$

\section{Risk of bias}

\begin{tabular}{|c|c|c|}
\hline Bias & Authors' judgement & Support for judgement \\
\hline $\begin{array}{l}\text { Random sequence generation (selection } \\
\text { bias) }\end{array}$ & High risk & $\begin{array}{l}\text { Participants were allocated to the inter- } \\
\text { vention arm dependent on ABO-matching } \\
\text { and donor's ability to donate granulocytes. } \\
\text { "Donor-recipient pairs that were ABO- } \\
\text { matched were assigned as potential candi- } \\
\text { dates for Cohort G (Granulocyte transfu- } \\
\text { sions), whereas those that were not ABO- } \\
\text { matched were assigned to Cohort C (con- } \\
\text { trol). Donor-recipient pairs assigned as po- } \\
\text { tential candidates for Cohort G remained } \\
\text { in Cohort G if the donors also satisfied the } \\
\text { criteria to donate granulocytes. Otherwise, } \\
\text { these donors were reassigned to Cohort C. } \\
\text { ABO mismatch included major (donor-re- } \\
\text { cipient ABO typing of A-O, B-O, AB-O, } \\
\text { AB-B, and AB-A, respectively) and bidirec- } \\
\text { tional (donor-recipient ABO typing of A- } \\
\text { B and B-A, respectively) mismatches." }\end{array}$ \\
\hline
\end{tabular}




\section{Oza 2006 (Continued)}

\begin{tabular}{|c|c|c|}
\hline Allocation concealment (selection bias) & High risk & $\begin{array}{l}\text { Treatment allocation was dependent on } \\
\text { availability of an appropriate granulocyte } \\
\text { donor }\end{array}$ \\
\hline $\begin{array}{l}\text { Blinding of participants and personnel } \\
\text { (performance bias) } \\
\text { All outcomes }\end{array}$ & Unclear risk & $\begin{array}{l}\text { It was not reported whether participants } \\
\text { were blinded to the intervention. It was not } \\
\text { reported whether clinicians or investigators } \\
\text { were blinded to the intervention }\end{array}$ \\
\hline $\begin{array}{l}\text { Blinding of outcome assessment (detection } \\
\text { bias) } \\
\text { All outcomes }\end{array}$ & Unclear risk & $\begin{array}{l}\text { It was not reported whether outcome asses- } \\
\text { sors were blinded to the intervention }\end{array}$ \\
\hline $\begin{array}{l}\text { Incomplete outcome data (attrition bias) } \\
\text { All outcomes }\end{array}$ & Unclear risk & $\begin{array}{l}\text { It was unclear whether any participants } \\
\text { were lost to follow-up }\end{array}$ \\
\hline Selective reporting (reporting bias) & Unclear risk & $\begin{array}{l}\text { The protocol was not available to assess } \\
\text { whether any pre-specified outcomes were } \\
\text { not reported or outcomes were reported } \\
\text { that were not pre-specified }\end{array}$ \\
\hline Other bias & High risk & $\begin{array}{l}\text { In the control group } 26 \text { participants were } \\
\mathrm{ABO} \text { mis-matched, } 14 \text { participants had } \\
\mathrm{CMV} \text { mis-match with their donors. CMV } \\
\text { mis-match could have increased the risk of } \\
\mathrm{CMV} \text { infection in the recipient. } 17 \text { donors } \\
\text { underwent more than } 1 \text { PBSC collection } \\
\text { and were therefore not eligible as granulo- } \\
\text { cyte donors }\end{array}$ \\
\hline
\end{tabular}

Petersen 1987

Methods

Participants
Parallel RCT (2:1 ratio) (conducted from February 1981 to March 1984). Multicentre (2 sites). Country USA

Inclusion criteria: people with a haematological malignancy admitted to the Fred Hutchinson Cancer Research Center or the

Swedish Hospital Medical Center for marrow transplantation from HLA-matched sibling donors

Exclusion criteria: people on broad-spectrum antibiotics and those with a "documented major infection"

Total randomised: $\mathrm{N}=134$

Total analysed: $\mathrm{N}=112$

Arm 1 (Granulocyte transfusions): randomised $=87$, analysed $=67$. Acute myeloid leukaemia $=32$, Acute lymphocytic leukaemia $=14$, Chronic myeloid leukaemia $=19$, Myelodysplasia $=2$

Arm 2 (Control): randomised $=47$, analysed $=45$, Acute myeloid leukaemia $=15$, Acute lymphocytic leukaemia $=12$, Chronic myeloid leukaemia $=17$, Myelodysplasia $=1$ 
Petersen 1987 (Continued)

\begin{tabular}{ll} 
Interventions & Comparison between prophylactic broad-spectrum antibiotics and prophylactic granu- \\
locyte transfusions & Granulocyte dose: Not reported \\
Granulocyte method of collection: continuous flow centrifugation \\
Donor premedication: not reported \\
Initiation of granulocyte transfusions: Neutrophil count $<0.2 \times 10^{9} / \mathrm{L}$ \\
Frequency of granulocyte transfusions: Daily \\
Termination of granulocyte transfusions: Neutrophil count "self-sustaining" $>0.2 \times$ \\
$10^{9} / \mathrm{L}$ \\
\hline
\end{tabular}

Outcomes

Primary Outcome: Major infectious complications occurring in patients treated in conventional rooms

Other Outcomes:

Mortality/survival, infection (days or episodes)

Definition of infection

Febrile day - Not reported

Febrile episode - Fever was defined as an oral temperature $>38.3^{\circ} \mathrm{C}$.

Proven infection:

Septicaemia: single positive blood culture associated with signs and symptoms of infection (documented local site and/or fever) or two consecutive positive blood cultures of the same organism

Major localised infection: potentially life-threatening infection requiring systemic antibiotic therapy and/or surgical intervention

Definition of neutropenia

Not reported but the 'trigger' neutrophil count was $0.2 \times 10^{9} / \mathrm{L}$

Co-interventions

Prophylactic antibiotics: broad-spectrum antibiotics given to the study arm not receiving prophylactic granulocyte transfusions

Therapeutic antibiotics: no restrictions were imposed on the attending physician.

Therapeutic granulocyte transfusions: were given if a patient in the prophylactic broadspectrum antibiotic arm had a major infectious episode with deterioration of the clinical condition despite appropriate antibiotics and a granulocyte donor was available

Notes

Funding Sources: PHS Grant Numbers CA 15704, CA

18029, CA 18221, and CA 18579, awarded by the National Cancer Institute, DHHS. Dr. Petersen is the recipient of a grant (12-5057) from the Danish Medical Research Council.

Dr. Thomas is the recipient of a Research Career Award (AI 02425) from the National Institute of Allergy and Infectious Diseases

Conflict of Interests: Not reported

Risk of bias

\begin{tabular}{|c|c|c|}
\hline Bias & Authors' judgement & Support for judgement \\
\hline $\begin{array}{l}\text { Random sequence generation (selection } \\
\text { bias) }\end{array}$ & Unclear risk & $\begin{array}{l}\text { Method of sequence generation was not re- } \\
\text { ported }\end{array}$ \\
\hline
\end{tabular}

Granulocyte transfusions for preventing infections in people with neutropenia or neutrophil dysfunction (Review) 
Petersen 1987 (Continued)

\begin{tabular}{|c|c|c|}
\hline Allocation concealment (selection bias) & Unclear risk & $\begin{array}{l}\text { Method of allocation concealment was not } \\
\text { reported }\end{array}$ \\
\hline
\end{tabular}

Blinding of participants and personnel Unclear risk (performance bias)

All outcomes

It was not reported whether participants were blinded to the intervention. It was not reported whether clinicians or investigators were blinded to the intervention

Blinding of outcome assessment (detection Unclear risk

It was not reported whether outcome assesbias) All outcomes
Incomplete outcome data (attrition bias) High risk All outcomes sors were blinded to the intervention

87 participants were randomised to receive granulocyte transfusions and 47 to receive prophylactic broad-spectrum antibiotics. Twenty participants in the granulocyte transfusions group did not receive granulocyte transfusions and were excluded from the study because of problems related to using the proposed granulocyte donor or because the granulocyte donor was found to have antibodies to cytomegalovirus (CMV) while the recipient was negative

Two participants in the prophylactic broadspectrum antibiotics group were excluded because of delay of the transplant and subsequent placement into laminar air flow isolation
Selective reporting (reporting bias) Unclear risk

High risk

The protocol was not available to assess whether any pre-specified outcomes were not reported or outcomes were reported that were not pre-specified

Other bias
Only 42 (63\%) participants received granulocyte transfusions according to the study's protocol (as reported in final report of study, initial protocol not available. Granulocyte transfusions were stopped in $25(37 \%)$ participants, 19 permanently and six temporarily. Ten $(40 \%)$ of the 25 protocol violations were caused by complications in the donor, and in four of these cases the transfusions were resumed after one to three days. Eight (32\%) of the protocol violations were due to complications in the patient, five of which were transfusion reactions involving pulmonary symptoms 
Petersen 1987 (Continued)

in four. All five transfusion reactions occurred in participants receiving granulocyte transfusions from a parent (three from the mother and two from the father), and none were observed following transfusions from HLA-matched donors. Seven (28\%) protocol violations were caused by the donor being needed for platelet transfusion

Schiffer 1979

\begin{tabular}{ll}
\hline Methods & Parallel RCT (recruitment period not reported). Single centre. Country: USA \\
\hline Participants & Inclusion criteria: Previously untreated adults $(>18$ years) with acute myeloid leukaemia \\
& Exclusion criteria: excluded infected patients and patients on systemic antibiotics \\
& Total randomised: $\mathrm{N}=22$ \\
& Total analysed: $\mathrm{N}=18$ \\
& Arm $\mathbf{1}(\mathrm{Granulocyte}$ transfusions): randomised $=12$, analysed $=9$, Acute myeloid \\
& leukaemia $=12$ \\
& Arm $\mathbf{2}$ (Control): randomised $=10$, analysed $=9$, Acute myeloid leukaemia $=10$ \\
\hline
\end{tabular}

Interventions

Comparison between prophylactic platelet transfusions on alternate days (3 to 4 out of 7 days) versus prophylactic granulocyte and platelet transfusions on alternate days (4 out of 7 days)

Granulocyte dose: $1.15 \times 10^{10}$ (0.34 to 2.4$)$

Granulocyte method of collection: intermittent flow centrifugation

Donor premedication: dexamethasone

Initiation of granulocyte transfusions: Neutrophil count $<0.5 \times 10^{9} / \mathrm{L}$ or platelet count $<20 \times 10^{9} / \mathrm{L}$

Frequency of granulocyte transfusions: Four days out of seven each week

Termination of granulocyte transfusions: Until recovery (or rising neutrophil count > $0.5 \times 10^{9} / \mathrm{L}$ with no dependence on platelet transfusions

Outcomes

Primary Outcomes: Microbiologically or clinically documented severe infection and detected alloimmunisation

Other Outcomes:

Mortality/survival, fever (days or episodes), infection (days or episodes), antibiotic use, adverse events

Definition of infection

Febrile day - not reported

Febrile episode - temperature $>38.3^{\circ} \mathrm{C}$

Proven infection: - not reported

Definition of neutropenia

Not reported but the 'trigger' neutrophil count was $0.5 \times 10^{9} / \mathrm{L}$

Co-interventions

Prophylactic antibiotics: all participants received oral non-absorbable antibiotics Therapeutic antibiotics: empirical systemic antibiotics were started if the temperature was $>38.3^{\circ} \mathrm{C}$ and / or there was clinical evidence of infection but the nature of these 
Schiffer 1979 (Continued)

antibiotics were not stated

Therapeutic granulocyte transfusions: not reported

$\begin{array}{ll}\text { Notes } & \text { Funding Sources: Not reported } \\ & \text { Conflict of Interests: Not reported }\end{array}$

Risk of bias

\begin{tabular}{|c|c|c|}
\hline Bias & Authors' judgement & Support for judgement \\
\hline $\begin{array}{l}\text { Random sequence generation (selection } \\
\text { bias) }\end{array}$ & Unclear risk & $\begin{array}{l}\text { Method of sequence generation was not re- } \\
\text { ported }\end{array}$ \\
\hline
\end{tabular}

Allocation concealment (selection bias) Unclear risk

Method of allocation concealment was not reported

Blinding of participants and personnel Unclear risk (performance bias)

All outcomes

It was not reported whether participants were blinded to the intervention. It was not reported whether clinicians or investigators were blinded to the intervention

Blinding of outcome assessment (detection Unclear risk bias)

It was not reported whether outcome assessors were blinded to the intervention

All outcomes

Incomplete outcome data (attrition bias) Unclear risk

All outcomes

Unclear risk

Selective reporting (reporting bias) Unclear risk

Ten participants were randomised to the control. One participant developed alloimmunisation after her first platelet transfusion and was not continued in the study. 12 participants were randomised to receive granulocyte transfusions. Two participants developed infections prior to receiving their first granulocyte transfusion and were excluded from the study. A third participant refused further granulocyte transfusions after two severe transfusion reactions

\begin{tabular}{|c|c|c|}
\hline serective reporting (Ieporting Dias) & 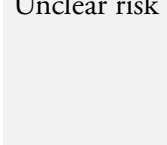 & $\begin{array}{l}\text { whether any pre-specified outcomes were } \\
\text { not reported or outcomes were reported } \\
\text { that were not pre-specified }\end{array}$ \\
\hline Other bias & Unclear risk & $\begin{array}{l}\text { Two participants in the control group had } \\
\text { acute promyelocytic leukaemia and devel- } \\
\text { oped disseminated intravascular coagula- } \\
\text { tion. This could have increased the risk of } \\
\text { mortality in the control arm }\end{array}$ \\
\hline
\end{tabular}


Methods

Participants
Parallel RCT (recruitment period not reported). Multicentre, four clinical centres. Country: USA

Inclusion criteria: people with untreated acute leukaemia who were at least 12 years old, and were "found by examination, chest roentgenography, urinalysis and cultures of blood and urine to be free of infection"

Exclusion criteria: people with an infection

Total randomised: $\mathrm{N}=102$

Total analysed: $\mathrm{N}=102$

Arm 1 (Granulocyte transfusions): randomised and analysed $=54$, Acute myeloid leukaemia $=54$

Arm 2 (Control): randomised and analysed $=48$, Acute myeloid leukaemia $=48$

Interventions

Comparison between standard treatment and prophylactic granulocyte transfusions

Granulocyte dose: Median dose 0.34 x $10^{10} / \mathrm{m}^{2}$

Granulocyte method of collection: intermittent flow centrifugation

Donor premedication: none

Initiation of granulocyte transfusions: Neutrophil count $<0.5 \times 10^{9} / \mathrm{L}$

Frequency of granulocyte transfusions: Daily

Termination of granulocyte transfusions: For 28 days, or until bone marrow recovery defined as a neutrophil count above $0.5 \times 10^{9} / \mathrm{L}$ for 48 hours. death, a severe transfusion reaction, withdrawal of the patient's consent, or gram negative septicaemia

Outcomes

Primary Outcome: Documented infection

Other Outcomes:

Mortality/survival, infection (days or episodes), antibiotic use, adverse events

Definition of infection

Febrile day - not reported

Febrile episode - fever was defined as an oral temperature above $38^{\circ} \mathrm{C}$, unrelated to transfusions, that was recorded on two separate occasions separated by at least four hours during a 24 hour period

Septicaemia: culture of an organism from the blood of patients with fever

Pneumonia: fever plus either a localised infiltrate or cavity seen on chest X-ray

Urinary tract infection: fever and the isolation of a single pathogenic organism $(\geq 100$, 000 colonies per millilitre)

Cellulitis: fever plus and inflammatory lesion $\geq 9 \mathrm{~cm}$ in diameter

Abscess: $\geq 4 \mathrm{~cm}$ in diameter with either a fluctuant mass or drainage from which a single organism was cultured

Definition of neutropenia

Not reported but the 'trigger' neutrophil count was $0.5 \times 10^{9} / \mathrm{L}$

Co-interventions

Prophylactic antibiotics: not given

Therapeutic antibiotics: systemic carbenicillin or ticarcillin plus an aminoglycoside if a participant suffered two temperatures $>38.5^{\circ} \mathrm{C}$ in 24 hours.

Therapeutic granulocyte transfusions: if participants in the control group acquired gram-negative septicaemia 
Strauss 1981 (Continued)

$\begin{array}{ll}\text { Fotes } & \text { Funding Sources: National Heart, Lung and Blood Institute; the National Cancer } \\ \text { Institute; Masonic Hospital Fund Incorporated; the Minessota Medical Foundation } \\ \text { Conflict of Interests: Not reported }\end{array}$

\section{Risk of bias}

\begin{tabular}{l|l|l} 
Bias & Authors' judgement & Support for judgement \\
\hline $\begin{array}{l}\text { Random sequence generation (selection } \\
\text { bias) }\end{array}$ & Low risk & $\begin{array}{l}\text { Separate randomisation schedules were } \\
\text { prepared for each institute and stratum. An } \\
\text { algorithm that ensured an approximate bal- } \\
\text { ance between treatment groups was used to } \\
\text { generate each schedule }\end{array}$ \\
\hline
\end{tabular}

\begin{tabular}{|l|l} 
Allocation concealment (selection bias) $\quad$ Low risk & $\begin{array}{l}\text { By a telephone call to the co-ordinat- } \\
\text { ing centre, participants were randomly as- } \\
\text { signed to receive daily granulocyte transfu- } \\
\text { sions or not to receive them }\end{array}$
\end{tabular}

Blinding of participants and personnel Unclear risk (performance bias)

All outcomes

Blinding of outcome assessment (detection Unclear risk bias)

All outcomes

Incomplete outcome data (attrition bias) Unclear risk All outcomes

Selective reporting (reporting bias) Unclear risk

Other bias

Unclear risk
It was not reported whether participants were blinded to the intervention. It was not reported whether clinicians or investigators were blinded to the intervention

Participants were monitored and data were collected daily by personnel trained by the co-ordinating centre but it was unclear whether these outcome assessors were blinded to the intervention

Loss to follow-up was not reported

The protocol was not available to assess whether any pre-specified outcomes were not reported or outcomes were reported that were not pre-specified

A policy and data-monitoring board, composed of scientists from institutions not participating in the trial was appointed by the NHLBI to review the study results periodically. Randomisation into the study was terminated in the basis of this review by recommendation of the policy board, but the reason for the recommendation was not reported 
Inclusion criteria: Adults with acute myeloid leukaemia

Exclusion criteria: infection criteria for excluding people from the study not reported

Total randomised: $\mathrm{N}=67$

Total analysed: $\mathrm{N}=65$

Arm 1 (Granulocyte transfusions): randomised and analysed = 29, Acute myeloid leukaemia $=29$

Arm 2 (Control): randomised $=38$, analysed $=36$, Acute myeloid leukaemia $=36$

Interventions

Comparison between standard treatment and prophylactic granulocyte transfusions Granulocyte dose: $0.9 \times 10^{10}(0.2$ to 0.5$)$

Granulocyte method of collection: intermittent flow centrifugation

Donor premedication: prednisolone

Initiation of granulocyte transfusions: Neutrophil count $<0.5 \times 10^{9} / \mathrm{L}$

Frequency of granulocyte transfusions: Daily

Termination of granulocyte transfusions: until neutrophil count above $0.5 \times 10^{9} / \mathrm{L}$

Outcomes

Primary Outcome: Not reported

Other Outcomes:

Mortality/survival, infection (days or episodes), adverse events

Definition of infection

Febrile day - Not reported

Febrile episode - Not reported

Proven infection: Not reported

Definition of neutropenia

Not reported but the 'trigger' neutrophil count was $0.5 \times 10^{9} / \mathrm{L}$

Co-interventions

Prophylactic antibiotics: not reported

Therapeutic antibiotics: participants received broad-spectrum antibiotics as indicated

Therapeutic granulocyte transfusions: for documented bacterial septicaemia

Notes

Funding Sources: Grant \#384 from the Ontario Cancer Treatment and Research foundation

Conflict of Interests: Not reported

\section{Risk of bias}

\begin{tabular}{lll} 
Bias & Authors' judgement & Support for judgement \\
\hline $\begin{array}{l}\text { Random sequence generation (selection } \\
\text { bias) }\end{array}$ & Unclear risk & $\begin{array}{l}\text { Method of sequence generation was not re- } \\
\text { ported }\end{array}$ \\
\hline Allocation concealment (selection bias) & Unclear risk & $\begin{array}{l}\text { Method of allocation concealment was not } \\
\text { reported }\end{array}$
\end{tabular}


Blinding of participants and personnel Unclear risk (performance bias)

All outcomes

Blinding of outcome assessment (detection Unclear risk bias)

All outcomes

Incomplete outcome data (attrition bias) Low risk All outcomes
It was not reported whether participants were blinded to the intervention. It was not reported whether clinicians or investigators were blinded to the intervention

It was not reported whether outcome assessors were blinded to the intervention

\begin{tabular}{|l|l|l} 
& & $\begin{array}{l}\text { analysis, one because the records were lost } \\
\text { and the other because the diagnosis was } \\
\text { changed to acute lymphoblastic leukaemia. } \\
\text { One participant in the control group was } \\
\text { discharged with resistant disease and was } \\
\text { lost to follow-up }\end{array}$ \\
\hline Selective reporting (reporting bias) & Unclear risk & $\begin{array}{l}\text { The protocol was not available to assess } \\
\text { whether any pre-specified outcomes were } \\
\text { not reported or outcomes were reported } \\
\text { that were not pre-specified }\end{array}$ \\
\hline Other bias & Unclear risk & $\begin{array}{l}\text { Although none were identified, it is diffi- } \\
\text { cult to rule out any significant bias due to } \\
\text { insufficient reporting of the study }\end{array}$ \\
\hline
\end{tabular}

Vij 2003

Methods

Participants
Biologically randomised study (recruitment period not reported). Single centre. Country: USA

Inclusion criteria: people receiving an allogeneic peripheral blood stem cell transplant Exclusion criteria: infection criteria for excluding people from the study not reported Total allocated: $\mathrm{N}=225$

Total analysed: $\mathrm{N}=225$

Arm 1 (Granulocyte transfusions): allocated and analysed $=83$, Acute leukaemia $=36$, Non Hodgkins lymphoma $=17$, Chronic myeloid leukaemia $=17$, other $=13$

Arm 2 (Control): allocated and analysed $=142$, Acute leukaemia $=61$, Non Hodgkins lymphoma $=37$, Chronic myeloid leukaemia $=18$, other $=26$

Interventions

Comparison between standard treatment and prophylactic granulocyte transfusions Granulocyte dose: participants received two granulocyte transfusions. The mean dose and range were not reported

Granulocyte method of collection: continuous flow apheresis

Donor premedication: G-CSF

Initiation of granulocyte transfusions: Day plus 3 or 5 (depending on protocol)

Frequency of granulocyte transfusions: Twice during neutropenic interval 
Vij 2003 (Continued)

Termination of granulocyte transfusions: Day plus 6 or 7 (depending on protocol)

\begin{tabular}{ll}
\hline Outcomes & $\begin{array}{l}\text { Primary Outcome: Not reported } \\
\text { Other Outcomes: } \\
\text { Incidence of CMV viraemia; median time to detection of CMV viraemia }\end{array}$ \\
\hline Definition of infection & $\begin{array}{l}\text { Febrile day - Not reported } \\
\text { Febrile episode - Not reported } \\
\text { Proven infection: Not reported }\end{array}$ \\
\hline Definition of neutropenia & Not reported \\
\hline Co-interventions & $\begin{array}{l}\text { Prophylactic antibiotics: not reported } \\
\text { Therapeutic antibiotics: not reported } \\
\text { Therapeutic granulocyte transfusions: not reported }\end{array}$ \\
\hline Notes & $\begin{array}{l}\text { Funding Sources: the publication costs of the article were defrayed in part by part } \\
\text { charge payment. Therefore and solely to indicate this fact, this article is hereby marked } \\
\text { "advertisement" in accordance with } 18 \text { USC section } 1734 \\
\text { Conflict of Interests: Not reported }\end{array}$ \\
\hline
\end{tabular}

Risk of bias

\begin{tabular}{l|l|l}
\hline Bias & Authors' judgement & Support for judgement \\
\hline $\begin{array}{l}\text { Random sequence generation (selection } \\
\text { bias) }\end{array}$ & High risk & $\begin{array}{l}\text { Randomisation was biological, determined } \\
\text { by the availability of an ABO-compatible } \\
\text { allogeneic peripheral blood stem cell donor. } \\
\text { The same donor served as both the stem } \\
\text { cell and granulocyte donor }\end{array}$ \\
\hline $\begin{array}{l}\text { Allocation concealment (selection bias) } \\
\text { Blinding of participants and personnel } \\
\text { (performance bias) } \\
\begin{array}{l}\text { All outcomes } \\
\text { Unclear risk }\end{array}\end{array}$ & High risk & $\begin{array}{l}\text { Treatment allocation was dependent on } \\
\text { availability of an appropriate granulocyte } \\
\text { donor }\end{array}$ \\
\hline $\begin{array}{l}\text { Blinding of outcome assessment (detection } \\
\text { bias) } \\
\text { All outcomes }\end{array}$ & Unclear risk & $\begin{array}{l}\text { It was not reported whether participants } \\
\text { were blinded to the intervention. It was not } \\
\text { reported whether clinicians or investigators } \\
\text { were blinded to the intervention }\end{array}$ \\
\hline
\end{tabular}

Incomplete outcome data (attrition bias) Unclear risk Loss to follow-up was not reported All outcomes 
Vij 2003 (Continued)

\begin{tabular}{l|l|l}
\hline Selective reporting (reporting bias) & Unclear risk & $\begin{array}{l}\text { The protocol was not available to assess } \\
\text { whether any pre-specified outcomes were } \\
\text { not reported or outcomes were reported } \\
\text { that were not pre-specified }\end{array}$ \\
\hline Other bias & High risk & $\begin{array}{l}\text { The publication costs of the article were de- } \\
\text { frayed in part by part charge payment, this } \\
\text { article was marked as an "advertisement" in } \\
\text { accordance with 18 USC section 1734 }\end{array}$ \\
\hline
\end{tabular}

Winston 1980

Methods

Participants

Interventions
Parallel RCT (recruitment period not reported). Single centre Country: USA

Inclusion criteria: people received high-dose chemotherapy and/or radiation therapy followed by the intravenous infusion of bone marrow from an HLA identical sibling; neutrophil count $\leq 0.5 \times 10^{9} / \mathrm{L}$; no systemic antibiotic therapy within the preceding 72 hours; no signs or symptoms of infection:

and; negative blood cultures before randomisation.

Exclusion criteria: excluded people with an infection

Total randomised: $\mathrm{N}=38$

Arm 1 (Granulocyte transfusions): randomised and analysed $=19$, Acute leukaemia $=$ 13 , Aplastic anaemia $=6$

Arm 2 (Control): randomised and analysed $=19$, Acute leukaemia $=12$, Aplastic anaemia $=7$

Allograft BMT, aplastic anaemia, acute leukaemia

Granulocyte transfusions

Granulocyte dose: $1.2 \times 10^{10}$ (0.3 to 3.5)

Granulocyte method of collection: continuous flow centrifugation

Donor premedication: none

Initiation of granulocyte transfusions: Neutrophil count $<0.5 \times 10^{9} / \mathrm{L}$

Frequency of granulocyte transfusions: Daily

Termination of granulocyte transfusions:

Outcomes

Primary Outcome: Not reported

Other Outcomes:

Mortality/survival, fever (days or episodes), infection (days or episodes), antibiotic use, adverse events

Definition of infection

Febrile day - not reported

Febrile episode - temperature $\geq 38.0^{\circ} \mathrm{C}$ on two or more occasions within 24 hours in the absence of blood product transfusions

Septicemia: one or more blood cultures were positive for a pathogenic organism in a clinical setting compatible with septicaemia

Pneumonia: signs and symptoms of pulmonary infection with a lobar or diffuse infiltrate evident on chest film 
Winston 1980 (Continued)

\begin{tabular}{l|l}
\hline Definition of neutropenia & Not reported but the 'trigger' neutrophil count was $0.5 \times 10^{9} / \mathrm{L}$ \\
\hline Co-interventions & $\begin{array}{l}\text { Prophylactic antibiotics: oral non-absorbable antibiotics to all participants (van- } \\
\text { comycin, colistin and nystatin) } \\
\text { Therapeutic antibiotics: if a participant suffered two fevers }>38^{\circ} \mathrm{C} \text { in } 24 \text { hours they } \\
\text { were treated systemically with carbenicillin (or cefazolin if allergic) and either amikacin } \\
\text { or netilmicin } \\
\text { Therapeutic granulocyte transfusions: if a participant remained febrile after } 96 \text { hours }\end{array}$ \\
\hline Notes & $\begin{array}{l}\text { Funding Sources: National Heart, Lung and Blood Institute, the National Cancer } \\
\text { Institute and the U.S Public Health Service } \\
\text { Conflict of Interests: Not reported }\end{array}$ \\
\hline
\end{tabular}

\section{Risk of bias}

\begin{tabular}{lll}
\hline Bias & Authors' judgement & Support for judgement \\
\hline $\begin{array}{l}\text { Random sequence generation (selection } \\
\text { bias) }\end{array}$ & Unclear risk & $\begin{array}{l}\text { Method of sequence generation was not re- } \\
\text { ported }\end{array}$ \\
\hline Allocation concealment (selection bias) & Unclear risk & $\begin{array}{l}\text { Method of allocation concealment was not } \\
\text { reported }\end{array}$ \\
\hline
\end{tabular}

Blinding of participants and personnel Unclear risk (performance bias)

It was not reported whether participants All outcomes were blinded to the intervention. It was not reported whether clinicians or investigators were blinded to the intervention

Blinding of outcome assessment (detection Unclear risk bias)

It was not reported whether outcome assessors were blinded to the intervention

All outcomes

Incomplete outcome data (attrition bias) Low risk

All outcomes

Selective reporting (reporting bias)

Unclear risk
All participants randomised were included within the analysis

The protocol was not available to assess whether any pre-specified outcomes were not reported or outcomes were reported that were not pre-specified

Other bias $\quad$ Unclear risk

$\mathrm{AML}=$ acute myeloid leukaemia

$\mathrm{BMT}=$ bone marrow therapy

$\mathrm{CMV}=$ cytomegalovirus
Although none were identified, it is difficult to rule out any significant bias due to insufficient reporting of the study 
G-CSF = granulocyte colony-stimulating factor

HLA = human leucocyte antigen

$\mathrm{IV}=$ intravenous

PBSC $=$ peripheral blood stem cell

$\mathrm{RCT}=$ randomised controlled trial

Characteristics of excluded studies [ordered by study ID]

\begin{tabular}{|c|c|}
\hline Study & Reason for exclusion \\
\hline Alavi 1977 & Trial of therapeutic granulocytes \\
\hline Altrichter 2011 & Non-randomised study \\
\hline Ambinder 1981 & Evaluation of different methods \\
\hline Atay 2011 & Non-randomised study \\
\hline Baley 1987 & Trial of neonates \\
\hline Bow 1984 & Trial of therapeutic granulocytes \\
\hline Buckner 1983 & Combined data for randomised and non-randomised participants \\
\hline Christensen 1982 & Trial of neonates \\
\hline DRKS00000218 & Trial of therapeutic granulocytes \\
\hline Freireich 2013 & Comparing irradiated versus non-irradiated granulocytes \\
\hline Herzig 1977 & Trial of therapeutic granulocytes \\
\hline Higby 1975 & Trial of therapeutic granulocytes \\
\hline Ikemoto 2012 & Non-randomised study assessing granulocyte yield in donors \\
\hline Klastersky 1983 & Trial of therapeutic granulocytes \\
\hline NCT01932710 & Non-randomised study \\
\hline Pammi 2011 & Systematic review \\
\hline Price 2014 & Trial of therapeutic granulocytes \\
\hline Scali 1978 & Trial of therapeutic granulocytes \\
\hline Seidel 2008 & Trial of therapeutic granulocytes \\
\hline
\end{tabular}


(Continued)

\begin{tabular}{ll}
\hline UMIN000014777 & Non-randomised study \\
\hline Vogler 1977 & Trial of therapeutic granulocytes \\
\hline Wheeler 1987 & Trial of therapeutic granulocytes \\
\hline Winston 1982 & Trial of therapeutic granulocytes \\
\hline
\end{tabular}

Characteristics of ongoing studies [ordered by study ID]

\section{NCT01204788}

Trial name or title A prospective randomized comparative study of the effect on infections of radiated prophylactic white cell transfusions versus therapeutic radiated white cell transfusions (NCT01204788)

$\begin{array}{ll}\text { Methods } & \text { Allocation: Randomised. First } 60 \\ & \text { Endpoint Classification: Efficacy study } \\ & \text { Intervention Model: Parallel assignment } \\ \text { Masking: Open label } \\ \text { Primary Purpose: Prevention }\end{array}$

Participants

Inclusion Criteria: Aged 2 years or older with a diagnosis of acute myelogenous leukaemia (including undifferentiated and bi-phenotypic leukaemia), or high-risk myelodysplastic syndrome, or chronic myelogenous leukaemia in blast crisis who will receive first or second anti-leukaemia therapeutic intent with chemotherapy, targeted therapy or hypomethylating agents

\section{Exclusion Criteria:}

Patients with baseline (at start leukaemia treatment) infection, defined as patients with:

1. fever and known positive cultures at the time of randomisation; or

2. chest or sinus computed tomography with findings suggestive of pneumonia or sinusitis; or

3. one positive galactomannan test $>/=1$ or two positive galactomannan text $>/=0.5$ to 1

Patients with Zubrod performance status $>/=3$

Interventions $\quad$ Prophylactic Arm - Prophylactic Treatment (standard of care prophylactic antibiotics) + Prophylactic White Cell Transfusion

Therapeutic Arm - Prophylactic Treatment (standard of care prophylactic antibiotics) + Therapeutic White Cell Transfusion

Outcomes

Primary Outcome Measures: Number of patients with Infection (yes/no) where patient without infection found by day 42 patient are counted as 'No' to infection

Secondary outcomes not reported on clinical trials website

Starting date September 2010

Contact information University of Texas MD Anderson Cancer Center

Emil J Freireich 


\section{NCT01204788 (Continued)}


DATA AND ANALYSES

Comparison 1. Prophylactic granulocytes versus no prophylactic granulocytes

\begin{tabular}{|c|c|c|c|c|}
\hline Outcome or subgroup title & $\begin{array}{l}\text { No. of } \\
\text { studies }\end{array}$ & $\begin{array}{c}\text { No. of } \\
\text { participants }\end{array}$ & Statistical method & Effect size \\
\hline 1 All-cause mortality up to 30 days & 7 & 437 & Risk Ratio (M-H, Fixed, 95\% CI) & $0.92[0.63,1.36]$ \\
\hline 1.1 Low-dose granulocytes & 3 & 144 & Risk Ratio (M-H, Fixed, 95\% CI) & $1.32[0.64,2.72]$ \\
\hline $\begin{array}{l}1.2 \text { Intermediate-dose } \\
\text { granulocytes }\end{array}$ & 4 & 293 & Risk Ratio (M-H, Fixed, 95\% CI) & $0.74[0.47,1.16]$ \\
\hline $\begin{array}{l}2 \text { All-cause mortality up to } 100 \\
\text { days }\end{array}$ & 1 & & Risk Ratio (M-H, Fixed, 95\% CI) & Totals not selected \\
\hline $\begin{array}{l}\text { 2.1 Granulocyte dose } \\
\text { unknown }\end{array}$ & 1 & & Risk Ratio (M-H, Fixed, 95\% CI) & $0.0[0.0,0.0]$ \\
\hline 3 All-cause mortality over 100 days & 1 & & Risk Ratio (M-H, Fixed, 95\% CI) & Totals not selected \\
\hline 3.1 Low-dose granulocytes & 1 & & Risk Ratio (M-H, Fixed, 95\% CI) & $0.0[0.0,0.0]$ \\
\hline $\begin{array}{l}4 \text { Mortality due to infection up to } \\
30 \text { days }\end{array}$ & 6 & 286 & Risk Ratio (M-H, Fixed, 95\% CI) & $0.69[0.33,1.44]$ \\
\hline 4.1 Low-dose granulocytes & 3 & 144 & Risk Ratio (M-H, Fixed, 95\% CI) & $1.14[0.46,2.86]$ \\
\hline $\begin{array}{l}4.2 \text { Intermediate-dose } \\
\text { granulocytes }\end{array}$ & 3 & 142 & Risk Ratio (M-H, Fixed, 95\% CI) & $0.25[0.06,1.10]$ \\
\hline $\begin{array}{l}5 \text { Mortality due to infection up to } \\
100 \text { days }\end{array}$ & 1 & & Risk Ratio (M-H, Fixed, 95\% CI) & Totals not selected \\
\hline $\begin{array}{l}\text { 5.1 Granulocyte dose } \\
\text { unknown }\end{array}$ & 1 & & Risk Ratio (M-H, Fixed, 95\% CI) & $0.0[0.0,0.0]$ \\
\hline $\begin{array}{l}6 \text { People with localised or systemic } \\
\text { bacterial or fungal infections }\end{array}$ & 9 & & Risk Ratio (M-H, Fixed, 95\% CI) & Subtotals only \\
\hline $\begin{array}{l}\text { 6.1 Low-dose granulocyte } \\
\text { transfusions }\end{array}$ & 4 & 204 & Risk Ratio (M-H, Fixed, 95\% CI) & $0.84[0.58,1.20]$ \\
\hline $\begin{array}{l}6.2 \text { Intermediate-dose } \\
\text { granulocyte transfusions }\end{array}$ & 4 & 293 & Risk Ratio (M-H, Fixed, 95\% CI) & $0.40[0.26,0.63]$ \\
\hline $\begin{array}{l}\text { 6.3 Unknown dose of } \\
\text { granulocyte transfusion }\end{array}$ & 1 & 112 & Risk Ratio (M-H, Fixed, 95\% CI) & $0.97[0.61,1.55]$ \\
\hline $\begin{array}{l}7 \text { People with bacteraemia or } \\
\text { fungaemia }\end{array}$ & 9 & 609 & Risk Ratio (M-H, Fixed, 95\% CI) & $0.45[0.30,0.65]$ \\
\hline $\begin{array}{l}\text { 7.1 Low-dose granulocyte } \\
\text { transfusions }\end{array}$ & 4 & 204 & Risk Ratio (M-H, Fixed, 95\% CI) & $0.51[0.27,0.96]$ \\
\hline $\begin{array}{l}7.2 \text { Intermediate-dose } \\
\text { granulocyte transfusions }\end{array}$ & 4 & 293 & Risk Ratio (M-H, Fixed, 95\% CI) & $0.28[0.14,0.55]$ \\
\hline $\begin{array}{l}\text { 7.3 Unknown dose of } \\
\text { granulocyte transfusions }\end{array}$ & 1 & 112 & Risk Ratio (M-H, Fixed, 95\% CI) & $0.79[0.39,1.61]$ \\
\hline $\begin{array}{l}8 \text { People with bacteraemia or } \\
\text { fungaemia (excluding study } \\
\text { that compared prophylactic } \\
\text { granulocyte transfusions versus } \\
\text { prophylactic broad-spectrum } \\
\text { antibiotics) }\end{array}$ & 8 & 497 & Risk Ratio (M-H, Fixed, 95\% CI) & $0.37[0.23,0.59]$ \\
\hline
\end{tabular}

Granulocyte transfusions for preventing infections in people with neutropenia or neutrophil dysfunction (Review) 
8.1 Low-dose granulocyte transfusions

8.2 Intermediate-dose granulocyte transfusions

9 People with localised bacterial or fungal infection

9.1 Low-dose granulocyte transfusions

9.2 Intermediate-dose granulocyte transfusions

9.3 Unknown dose of granulocyte transfusions

10 People with localised bacterial or fungal infection (excluding study that compared prophylactic granulocyte transfusions versus prophylactic broad-spectrum antibiotics)

10.1 Low-dose granulocyte transfusions

10.2 Intermediate-dose granulocyte transfusions

\begin{tabular}{|c|c|c|c|}
\hline 4 & 204 & Risk Ratio (M-H, Fixed, 95\% CI) & $0.51[0.27,0.96]$ \\
\hline 4 & 293 & Risk Ratio (M-H, Fixed, 95\% CI) & $0.28[0.14,0.55]$ \\
\hline 6 & 296 & Risk Ratio (M-H, Fixed, 95\% CI) & $0.75[0.50,1.14]$ \\
\hline 2 & 42 & Risk Ratio (M-H, Fixed, 95\% CI) & $0.46[0.19,1.11]$ \\
\hline 3 & 142 & Risk Ratio (M-H, Fixed, 95\% CI) & $0.71[0.38,1.31]$ \\
\hline 1 & 112 & Risk Ratio (M-H, Fixed, 95\% CI) & $1.12[0.54,2.33]$ \\
\hline 5 & 184 & Risk Ratio (M-H, Fixed, 95\% CI) & $0.62[0.37,1.02]$ \\
\hline 2 & 42 & Risk Ratio (M-H, Fixed, 95\% CI) & $0.46[0.19,1.11]$ \\
\hline 3 & 142 & Risk Ratio (M-H, Fixed, 95\% CI) & $0.71[0.38,1.31]$ \\
\hline
\end{tabular}

\section{ADDITIONAL TABLES}

Table 1. Dose and frequency of granulocyte transfusions used within the studies ranked from lowest dose to highest dose, and stratified according to the frequency of granulocyte transfusions

\begin{tabular}{|c|c|c|c|c|}
\hline Study & $\begin{array}{l}\text { Mean dose of granulo- } \\
\text { cyte transfusions }\end{array}$ & $\begin{array}{l}\text { Range of doses of gran- } \\
\text { ulocyte transfusions }\end{array}$ & $\begin{array}{l}\text { Frequency of transfu- } \\
\text { sions }\end{array}$ & $\begin{array}{l}\text { Total number of trans- } \\
\text { fusions per patient } \\
\text { Mean/median and } \\
\text { range }\end{array}$ \\
\hline Strauss 1981 & $0.6 \times 10^{10 *}$ & Not reported & Daily & $\begin{array}{l}18.5 \text { (mean) } \\
\text { (3 to } 28)\end{array}$ \\
\hline Sutton 1982 & $0.9 \times 10^{10}$ & 0.2 to $2.5 \times 10^{10}$ & Daily & Not reported \\
\hline Winston 1980 & $1.2 \times 10^{10}$ & 0.3 to $3.5 \times 10^{10}$ & Daily & $\begin{array}{l}23.4 \text { mean } \\
(13 \text { to } 34)\end{array}$ \\
\hline Gomez-Villagran 1984 & $1.24 \times 10^{10}$ & 0.55 to $4.2 \times 10^{10}$ & Daily & $\begin{array}{l}6.16 \text { (mean) } \\
(5 \text { to } 11)\end{array}$ \\
\hline Clift 1978 & $\begin{array}{l}2.22 \times 10^{10} \text { (leucofiltra- } \\
\text { tion) } \\
1.57 \times 10^{10} \text { (centrifuga- } \\
\text { tion) }\end{array}$ & Not reported & Daily & $\begin{array}{l}12.4 \text { (mean) } \\
(6 \text { to } 25)\end{array}$ \\
\hline
\end{tabular}

Granulocyte transfusions for preventing infections in people with neutropenia or neutrophil dysfunction (Review) Copyright (c) 2015 The Cochrane Collaboration. Published by John Wiley \& Sons, Ltd. 
Table 1. Dose and frequency of granulocyte transfusions used within the studies ranked from lowest dose to highest dose, and stratified according to the frequency of granulocyte transfusions (Continued)

\begin{tabular}{|c|c|c|c|c|}
\hline Mannoni 1979 & $2.1 \times 10^{10}$ & 1.3 to 3.7 & Daily & $\begin{array}{l}12 \text { (mean) } \\
(8 \text { to } 15)\end{array}$ \\
\hline Petersen 1987 & Not reported & Not reported & Daily & $\begin{array}{l}12 \text { (median) } \\
\text { (6 to } 27)\end{array}$ \\
\hline Schiffer 1979 & $1.15 \times 10^{10}$ & 0.34 to $2.4 \times 10^{10}$ & 4/7 days per week & $\begin{array}{l}11 \text { (mean) } \\
(3 \text { to } 19)\end{array}$ \\
\hline Ford 1982 & $1.45 \times 10^{10}$ & 0.28 to 3.45 & Alternate days & $\begin{array}{l}7 \text { (median) } \\
(1 \text { to } 12)\end{array}$ \\
\hline Oza 2006 & $\begin{array}{l}5.9 \times 10^{10} \text { (first dose) } \\
5.2 \times 10^{10}(\text { second dose })\end{array}$ & $\begin{array}{l}0.02 \text { to } 15.5 \text { (first dose) } \\
0.02 \text { to } 21.0 \text { ( second } \\
\text { dose) }\end{array}$ & Twice & 2 \\
\hline Vij 2003 & Not reported & Not reported & Twice & 2 \\
\hline
\end{tabular}

Table 2. All-cause Mortality

\begin{tabular}{|c|c|c|c|c|}
\hline Study & $\begin{array}{l}\text { Number of participants } \\
\text { randomised }\end{array}$ & $\begin{array}{l}\text { Number of participants } \\
\text { analysed }\end{array}$ & $\begin{array}{l}\text { Prophylactic Granulo- } \\
\text { cytes }\end{array}$ & Control \\
\hline \multicolumn{5}{|l|}{ Mortality at up to 21 days } \\
\hline Clift 1978 & 86 & 69 & $0 / 29$ & $1 / 40$ \\
\hline Gomez-Villagran 1984 & 35 & 35 & $2 / 19$ & $6 / 16$ \\
\hline \multicolumn{5}{|c|}{ Mortality at up to 30 days } \\
\hline Ford 1982 & 49 & 24 & $3 / 13$ & $2 / 11$ \\
\hline Mannoni 1979 & 44 & $\begin{array}{l}44 \text { in } 50 \text { episodes of apla- } \\
\text { sia }\end{array}$ & $0 / 20$ & $4 / 26$ \\
\hline Oza 2006 & 151 & 151 & $2 / 53$ & $5 / 98$ \\
\hline Schiffer 1979 & 22 & 18 & $0 / 9$ & $2 / 9$ \\
\hline Strauss 1981 & 102 & 102 & $12 / 54$ & $6 / 48$ \\
\hline Winston 1980 & 38 & 38 & $13 / 19$ & $13 / 19$ \\
\hline
\end{tabular}


Table 2. All-cause Mortality (Continued)

Mortality at up to 100 days

\begin{tabular}{|c|c|c|c|c|}
\hline Petersen 1987 & 134 & 112 & $21 / 67$ & $11 / 45$ \\
\hline \multicolumn{5}{|c|}{ Mortality over 100 days } \\
\hline Sutton 1982 & 67 & 64 & $19 / 28$ & $25 / 36$ \\
\hline
\end{tabular}

Table 3. Mortality due to bacterial or fungal infection

\begin{tabular}{|c|c|c|c|c|}
\hline Study & $\begin{array}{l}\text { Number of participants } \\
\text { randomised }\end{array}$ & $\begin{array}{l}\text { Number of participants } \\
\text { analysed }\end{array}$ & $\begin{array}{l}\text { Prophylactic Granulo- } \\
\text { cytes }\end{array}$ & Control \\
\hline \multicolumn{5}{|c|}{ Mortality at up to 21 days } \\
\hline Clift 1978 & 86 & 69 & $0 / 29$ & $1 / 40$ \\
\hline Gomez-Villagran 1984 & 35 & 35 & $0 / 19$ & $4 / 16$ \\
\hline \multicolumn{5}{|c|}{ Mortality at up to 30 days } \\
\hline Ford 1982 & 49 & 24 & $1 / 13$ & $1 / 11$ \\
\hline Mannoni 1979 & 44 & $\begin{array}{l}44 \text { in } 50 \text { episodes of apla- } \\
\text { sia }\end{array}$ & $0 / 20$ & $2 / 26$ \\
\hline Schiffer 1979 & 22 & 18 & $0 / 9$ & $2 / 0$ \\
\hline Strauss 1981 & 102 & 102 & $8 / 54$ & $4 / 48$ \\
\hline Winston 1980 & 38 & 38 & $1 / 19$ & $2 / 19$ \\
\hline \multicolumn{5}{|c|}{ Mortality at up to 100 days } \\
\hline Petersen 1987 & 134 & 112 & $3 / 67$ & $2 / 45$ \\
\hline
\end{tabular}

Table 4. Number and type of bacterial and fungal infections

\begin{tabular}{|l|l|l|l|l|}
\hline Study & \begin{tabular}{l} 
Number of $\begin{array}{l}\text { of } \\
\text { participants } \\
\text { analysed }\end{array}$ \\
\cline { 2 - 5 }
\end{tabular} & $\begin{array}{l}\text { Total number of partici- } \\
\text { pants with an infection }\end{array}$ & $\begin{array}{l}\text { Localised infections } \\
\text { (excluding oral candida) }\end{array}$ & $\begin{array}{l}\text { Systemic infections } \\
\text { (Bacteraemia or fungaemia) }\end{array}$ \\
\cline { 2 - 6 } & $\begin{array}{l}\text { Prophylactic Control } \\
\text { Granulocytes }\end{array}$ & $\begin{array}{l}\text { Prophylactic } \\
\text { Granulocytes }\end{array}$ & Control & $\begin{array}{l}\text { Prophylactic Control } \\
\text { Granulocytes }\end{array}$
\end{tabular}


Table 4. Number and type of bacterial and fungal infections (Continued)

\begin{tabular}{|c|c|c|c|c|c|c|c|}
\hline Clift 1978 & 69 & $2 / 29$ & $17 / 40$ & $\begin{array}{l}2 \text { participants } \\
1 \text { Candidal oe- } \\
\text { sophagitis } \\
1 \text { Rhinitis due } \\
\text { to coagulase } \\
\text { positive staphy- } \\
\text { lococcus }\end{array}$ & 7 participants & 0 participants & $\begin{array}{l}10 \text { participants } \\
2 \quad \text { Escherichia } \\
\text { coli } \\
2 \text { Psendomonas } \\
\text { aeruginosa } \\
2 \text { Corynebacte- } \\
\text { ria } \\
2 \quad \text { Beta- } \\
\text { haemolytic strep- } \\
\text { tococci } \\
1 \text { Serratia } \\
1 \text { Enterobacter }\end{array}$ \\
\hline Ford 1982 & 24 & $4 / 13$ & $7 / 11$ & $\begin{array}{l}3 \text { participants } \\
1 \text { Pneumonia } \\
1 \text { Cellulitis \& } \\
\text { Abscess } \\
1 \text { Enteritis }\end{array}$ & $\begin{array}{l}5 \text { participants } \\
3 \text { Pneumonia } \\
1 \text { Cellulitis \& } \\
\text { Abscess } \\
1 \text { Enteritis }\end{array}$ & $\begin{array}{l}1 \text { participant } \\
1 \quad \text { Klebsiella } \\
\text { pneumoniae }\end{array}$ & $\begin{array}{l}3 \text { participants } \\
2 \text { Staphylococcus } \\
\text { aureus } \\
1 \text { Staphylococcus } \\
\text { alba }\end{array}$ \\
\hline $\begin{array}{l}\text { Gomez- } \\
\text { Villagran } \\
1984\end{array}$ & 35 & $4 / 19$ & $10 / 16$ & $\begin{array}{l}4 \text { participants } \\
1 \text { Pneumonia } \\
0 \text { Cellulitis \& } \\
\text { Abscess } \\
3 \text { Pharyngitis }\end{array}$ & $\begin{array}{l}6 \text { participants } \\
2 \text { Pneumonia } \\
2 \text { Cellulitis \& } \\
\text { Abscess } \\
2 \text { Pharyngitis }\end{array}$ & 0 participants & $\begin{array}{l}4 \text { participants } \\
2 \text { Escherichia } \\
\text { coli } \\
1 \text { Pseudomonas } \\
\text { aeruginosa } \\
1 \text { Staphylococcus } \\
\text { aureus }\end{array}$ \\
\hline $\begin{array}{l}\text { Mannoni } \\
1979\end{array}$ & $\begin{array}{lr}44 & (50 \\
\text { episodes } & \text { of } \\
\text { aplasia) } & \end{array}$ & $1 / 20$ & $11 / 26$ & $\begin{array}{l}1 \text { episode } \\
0 \text { Pneumonia } \\
1 \text { Cellulitis \& } \\
\text { Abscess }\end{array}$ & $\begin{array}{l}15 \text { episodes } \\
8 \text { Pneumonia } \\
4 \text { Cellulitis \& } \\
\text { Abscess } \\
3 \text { Enteritis }\end{array}$ & 0 participants & Not reported \\
\hline Oza 2006 & 151 & $7 / 53$ & $29 / 98$ & Not reported & Not reported & $\begin{array}{l}7 \text { participants } \\
\text { bacteraemia } \\
\text { (not further de- } \\
\text { fined) }\end{array}$ & $\begin{array}{l}29 \text { participants } \\
\text { bacteraemia } \\
\text { (not further de- } \\
\text { fined) }\end{array}$ \\
\hline $\begin{array}{l}\text { Petersen } \\
1987^{*}\end{array}$ & 112 & $26 / 67$ & $18 / 45$ & $\begin{array}{l}15 \text { participants } \\
0 \text { Pneumonia } \\
5 \text { Colitis } \\
1 \text { Sinusitis } \\
1 \text { Mouth/throat } \\
2 \text { Urinary tract } \\
\text { infection } \\
4 \text { RAC site } \\
4 \text { Other }\end{array}$ & $\begin{array}{l}9 \text { participants } \\
2 \text { Pneumonia } \\
1 \text { Colitis } \\
2 \text { Sinusitis } \\
2 \text { Mouth/throat } \\
1 \text { Urinary tract } \\
\text { infection } \\
1 \text { RAC site } \\
1 \text { Other }\end{array}$ & $\begin{array}{l}13 \text { participants } \\
10 \quad \text { Coagu- } \\
\text { lase -ive Staphy- } \\
\text { lococcus } \\
1 \text { Candida } \\
2 \text { Streptococcus } \\
3 \text { Gram -ive } \\
\text { bacilli }\end{array}$ & $\begin{array}{l}11 \text { participants } \\
4 \text { Coagulase - } \\
\text { ive Staphylococ- } \\
\text { cus } \\
4 \text { Candida } \\
0 \text { Streptococcus } \\
5 \text { Gram -ive } \\
\text { bacilli }\end{array}$ \\
\hline
\end{tabular}


Table 4. Number and type of bacterial and fungal infections (Continued)

\begin{tabular}{|c|c|c|c|c|c|c|c|}
\hline Schiffer 1979 & 18 & $2 / 9$ & $6 / 9$ & $\begin{array}{l}2 \text { participants } \\
1 \text { Cellulitis } \\
1 \text { Sinusitis }\end{array}$ & $\begin{array}{l}5 \text { participants } \\
2 \text { Pulmonary } \\
\text { aspergillosis } \\
2 \text { Cellulitis } \\
1 \text { Oesophagitis }\end{array}$ & 0 participants & $\begin{array}{l}1 \text { participant } \\
1 T . \text { glabrata }\end{array}$ \\
\hline Strauss 1981 & 102 & $25 / 54$ & $20 / 48$ & $\begin{array}{l}12 \text { Pneumonia } \\
5 \text { Cellulitis } \\
3 \text { Abscess } \\
3 \text { Urinary tract } \\
\text { infection }\end{array}$ & $\begin{array}{l}6 \text { Pneumonia } \\
3 \text { Cellulitis } \\
3 \text { Abscess } \\
1 \text { Urinary tract } \\
\text { infection }\end{array}$ & $\begin{array}{l}8 \text { episodes } \\
2 \text { Gram +ive } \\
\text { septicaemia } \\
3 \text { Gram -ive } \\
\text { septicaemia } \\
3 \text { fungal isolates }\end{array}$ & $\begin{array}{l}14 \text { episodes } \\
8 \text { Gram +ive } \\
\text { septicaemia } \\
8 \text { Gram -ive } \\
\text { septicaemia } \\
1 \text { fungal isolate }\end{array}$ \\
\hline Sutton 1982 & 60 & $3 / 29$ & $4 / 31$ & Not reported & Not reported & $\begin{array}{l}3 \text { episodes } \\
1 \quad \text { Escherichia } \\
\text { coli } \\
1 \text { Pseudomonas } \\
\text { aeruginosa } \\
1 \text { Klebsiella } \\
\text { pneumoniae }\end{array}$ & $\begin{array}{l}4 \text { episodes } \\
1 \text { Escherichia } \\
\text { coli } \\
1 \text { Pseudomonas } \\
\text { aeruginosa } \\
2 \quad \text { Klebsiella } \\
\text { pneumoniae }\end{array}$ \\
\hline $\begin{array}{l}\text { Winston } \\
1980\end{array}$ & 38 & $7 / 19$ & $9 / 19$ & $\begin{array}{l}7 \text { participants } \\
3 \text { Pneumonia } \\
4 \text { Cellulitis \& } \\
\text { Abscess } \\
0 \text { Urinary tract } \\
\text { infection }\end{array}$ & $\begin{array}{l}6 \text { participants } \\
3 \text { Pneumonia } \\
3 \text { Cellulitis \& } \\
\text { Abscess } \\
0 \text { Urinary tract } \\
\text { infection }\end{array}$ & 0 participants & $\begin{array}{l}3 \text { participants } \\
1 \text { Streptococcus } \\
\text { viridans } \\
1 \text { Staphylococcus } \\
\text { epidermidis } \\
1 \text { Enterococcus }\end{array}$ \\
\hline
\end{tabular}

Table 5. Number of days with fever and number of days on treatment with antimicrobials

\begin{tabular}{|c|c|c|c|c|c|c|c|c|c|}
\hline \multirow[t]{2}{*}{ Study } & \multirow{2}{*}{$\begin{array}{l}\text { Num- } \\
\text { ber of par- } \\
\text { ticipants } \\
\text { analysed }\end{array}$} & \multicolumn{2}{|c|}{$\begin{array}{l}\text { Number of days with } \\
\text { fever }\end{array}$} & \multicolumn{2}{|c|}{$\begin{array}{l}\text { Number of participants } \\
\text { receiving antibiotics }\end{array}$} & \multicolumn{2}{|c|}{$\begin{array}{l}\text { Number of days with } \\
\text { antibiotics }\end{array}$} & \multicolumn{2}{|c|}{$\begin{array}{l}\text { Number of participants } \\
\text { receiving antifungal } \\
\text { medication }\end{array}$} \\
\hline & & $\begin{array}{l}\text { Prophy- } \\
\text { lac- } \\
\text { tic granu- } \\
\text { locytes }\end{array}$ & Control & $\begin{array}{l}\text { Prophy- } \\
\text { lac- } \\
\text { tic granu- } \\
\text { locytes }\end{array}$ & Control & $\begin{array}{l}\text { Prophy- } \\
\text { lac- } \\
\text { tic granu- } \\
\text { locytes }\end{array}$ & Control & $\begin{array}{l}\text { Prophy- } \\
\text { lac- } \\
\text { tic granu- } \\
\text { locytes }\end{array}$ & Control \\
\hline Clift 1978 & $31^{*}$ & $\begin{array}{l}\text { Not } \\
\text { reported }\end{array}$ & $\begin{array}{l}\text { Not } \\
\text { reported }\end{array}$ & $9 / 16$ & $13 / 15$ & $\begin{array}{l}\text { Not } \\
\text { reported }\end{array}$ & $\begin{array}{l}\text { Not } \\
\text { reported }\end{array}$ & $\begin{array}{l}\text { Not } \\
\text { reported }\end{array}$ & $\begin{array}{l}\text { Not } \\
\text { reported }\end{array}$ \\
\hline
\end{tabular}


Table 5. Number of days with fever and number of days on treatment with antimicrobials (Continued)

\begin{tabular}{|c|c|c|c|c|c|c|c|c|c|}
\hline Ford 1982 & $19^{\#}$ & $\begin{array}{l}\text { Median } 4 . \\
5 \\
\text { (range } 0 \text { to } \\
18 \text { ) }\end{array}$ & $\begin{array}{l}\text { Median } 9 \\
\text { (range } 3 \text { to } \\
12 \text { ) }\end{array}$ & $9 / 10$ & $9 / 9$ & $\begin{array}{l}\text { Median } 8 \\
\text { (range } 0 \text { to } \\
15 \text { ) }\end{array}$ & $\begin{array}{l}\text { Median } \\
10.5 \\
\text { (range } 6 \text { to } \\
16 \text { ) }\end{array}$ & $\begin{array}{l}\text { Not } \\
\text { reported }\end{array}$ & $\begin{array}{l}\text { Not } \\
\text { reported }\end{array}$ \\
\hline $\begin{array}{l}\text { Gomez- } \\
\text { Villagran } \\
1984\end{array}$ & 35 & $5.1 \pm 3.5$ & $6 \pm 5.6$ & $11 / 19$ & $13 / 16$ & $6.7 \pm 4.4$ & $7.8 \pm 6.2$ & $\begin{array}{l}\text { Not } \\
\text { reported }\end{array}$ & $\begin{array}{l}\text { Not } \\
\text { reported }\end{array}$ \\
\hline Oza 2006 & 151 & $\begin{array}{l}\text { Median } 2 \\
\text { (range } 0 \text { to } \\
15 \text { ) }\end{array}$ & $\begin{array}{l}\text { Median } 2 \\
\text { (range } 0 \text { to } \\
17 \text { ) }\end{array}$ & $53 / 53$ & $97 / 98$ & $\begin{array}{l}\text { Median } 9 \\
\text { (range } 1 \text { to } \\
20 \text { ) }\end{array}$ & $\begin{array}{l}\text { Median } 11 \\
\text { (range } 0 \text { to } \\
26 \text { ) }\end{array}$ & $\begin{array}{l}\text { Not } \\
\text { reported }\end{array}$ & $\begin{array}{l}\text { Not } \\
\text { reported }\end{array}$ \\
\hline $\begin{array}{l}\text { Petersen } \\
1987\end{array}$ & 112 & $\begin{array}{l}\text { Not } \\
\text { reported }\end{array}$ & $\begin{array}{l}\text { Not } \\
\text { reported }\end{array}$ & $\begin{array}{l}\text { Not } \\
\text { reported }\end{array}$ & $\begin{array}{l}\text { Not } \\
\text { reported }\end{array}$ & $\begin{array}{l}\text { Not } \\
\text { reported }\end{array}$ & $\begin{array}{l}\text { Not } \\
\text { reported }\end{array}$ & 33 & 29 \\
\hline $\begin{array}{l}\text { Schiffer } \\
1979\end{array}$ & 18 & $\begin{array}{l}\text { Mean } 9 \\
\text { (range } 2 \text { to } \\
16 \text { ) }\end{array}$ & $\begin{array}{l}\text { Mean } 9 \\
\text { (range } 2 \text { to } \\
18 \text { ) }\end{array}$ & $\begin{array}{l}\text { Not } \\
\text { reported }\end{array}$ & $\begin{array}{l}\text { Not } \\
\text { reported }\end{array}$ & $\begin{array}{l}\text { Mean } 13 \\
\text { (range } 7 \text { to } \\
25 \text { ) }\end{array}$ & $\begin{array}{l}\text { Mean } 13 \\
\text { (range } 9 \text { to } \\
20 \text { ) }\end{array}$ & $\begin{array}{l}\text { Not } \\
\text { reported }\end{array}$ & $\begin{array}{l}\text { Not } \\
\text { reported }\end{array}$ \\
\hline $\begin{array}{l}\text { Winston } \\
1980\end{array}$ & 38 & $\begin{array}{l}10.1 \\
(\mathrm{SE} 1.3)\end{array}$ & $\begin{array}{l}7.7 \\
(\mathrm{SE} \mathrm{1.7)}\end{array}$ & 18 & 15 & $\begin{array}{l}10.5 \\
(S E 1.6)\end{array}$ & $\begin{array}{l}8.2 \\
\text { (SE 1.8) }\end{array}$ & 5 & 5 \\
\hline
\end{tabular}

* Participants who were not on antibiotics at the start of the study

\# Participants who did not die during the first 26 days of the study

$\mathrm{SE}=$ standard error

Table 6. Neutrophil increment after granulocyte transfusion and duration of neutropenia reversal

\begin{tabular}{|c|c|c|c|c|c|}
\hline \multirow[t]{2}{*}{ Study } & \multirow{2}{*}{$\begin{array}{l}\text { Total number of } \\
\text { granulocyte trans- } \\
\text { fusions }\end{array}$} & \multirow{2}{*}{$\begin{array}{l}1 \\
\text { hour absolute neu- } \\
\text { trophil increment }\end{array}$} & \multicolumn{2}{|c|}{1 hour corrected count increment } & \multirow{2}{*}{$\begin{array}{l}\text { Duration of neu- } \\
\text { tropenia reversal }\end{array}$} \\
\hline & & & On antibiotics & Not on antibiotics & \\
\hline Clift 1978 & 360 & Not reported & $\begin{array}{l}\text { CFC } \\
\text { Median } 0.28 \times 10^{9} / \\
\text { L } \\
\text { (Range } 0 \text { to } 1.16 \text { ) } \\
\text { LF } \\
\text { Median } 0.06 \times 10^{9} / \\
\text { L } \\
\text { (Range } 0 \text { to } 0.49 \text { ) }\end{array}$ & $\begin{array}{l}\text { CFC } \\
\text { Median } 0.38 \times 10^{9} / \\
\text { L } \\
\text { (Range } 0.1 \text { to } 1.32 \text { ) } \\
\text { LF } \\
\text { Median } 0.06 \times 10^{9} / \\
\text { L } \\
\text { (Range } 0 \text { to } 0.32 \text { ) }\end{array}$ & Not reported \\
\hline Ford 1982 & 107 & $\begin{array}{l}\text { Median } 0.32 \times 10^{9} / \\
\mathrm{L}\end{array}$ & Not reported & & Not reported \\
\hline
\end{tabular}


Table 6. Neutrophil increment after granulocyte transfusion and duration of neutropenia reversal (Continued)

\begin{tabular}{|c|c|c|c|c|c|}
\hline $\begin{array}{l}\text { Gomez-Villagran } \\
1984\end{array}$ & 254 & Not reported & $\begin{array}{l}\text { Mean } 0.41 \times 10^{9} / \mathrm{L} \\
\text { (Range } 0.04 \text { to } 1 . \\
15 \text { ) }\end{array}$ & $\begin{array}{l}\text { Mean } 0.50 \times 10^{9} / \mathrm{L} \\
\text { (Range } 0.19 \text { to } 1 . \\
14 \text { ) }\end{array}$ & Not reported \\
\hline Mannoni 1979 & Not reported & Not reported & \multicolumn{2}{|l|}{ Average $0.30 \times 10^{9} / \mathrm{L}$} & Not reported \\
\hline Schiffer 1979 & Not reported & $\begin{array}{l}\text { Most }<0.15 \times 10^{9} / \\
\mathrm{L}\end{array}$ & \multicolumn{2}{|l|}{ Not reported } & Not reported \\
\hline Winston 1980 & Not reported & Not reported & \multicolumn{2}{|l|}{$\begin{array}{l}\text { Mean } 0.12 \times 10^{9} / \mathrm{L} \\
\text { (range } 0 \text { to } 0.66 \text { ) }\end{array}$} & Not reported \\
\hline
\end{tabular}

$\overline{\mathrm{CFC}}=$ continuous flow centrifugation

$\mathrm{LF}=$ leucofiltration

Table 7. Serious adverse events to donor or recipients

\begin{tabular}{|c|c|c|c|c|}
\hline Study & $\begin{array}{l}\text { Number of participants } \\
\text { receiving granulocyte } \\
\text { transfusions }\end{array}$ & $\begin{array}{l}\text { Number of granulocyte } \\
\text { transfusions }\end{array}$ & Donor events & Recipient events \\
\hline Clift 1978 & $\begin{array}{l}29 \text { prophylactic } \\
16 \text { therapeutic }\end{array}$ & 360 & $\begin{array}{l}1 \\
1 \text { - haemodynamic com- } \\
\text { promise }\end{array}$ & 0 \\
\hline Ford 1982 & 13 prophylactic & 107 & 0 & $\begin{array}{l}1 \\
1-T A ~ G v H D\end{array}$ \\
\hline Gomez-Villagran 1984 & 19 prophylactic & 254 & Not reported & $\begin{array}{l}7 \\
1 \text { - haemolysis } \\
6 \text { - dyspnoea \& cyanosis }\end{array}$ \\
\hline Sutton 1982 & $\begin{array}{l}29 \text { prophylactic } \\
2 \text { therapeutic }\end{array}$ & Not reported & Not reported & $\begin{array}{l}3 \\
3 \text { - dyspnoea and wheeze }\end{array}$ \\
\hline
\end{tabular}

TA GvHD = Transfusion-associated Graft versus Host Disease

Table 8. Adverse events requiring permanent discontinuation of the intervention

\begin{tabular}{|c|c|c|c|c|}
\hline Study & $\begin{array}{l}\text { Number of partic- } \\
\text { ipants receiving granulo- } \\
\text { cyte transfusions }\end{array}$ & $\begin{array}{l}\text { Total number of granulo- } \\
\text { cyte transfusions }\end{array}$ & Donor events & Recipient events \\
\hline Clift 1978 & $\begin{array}{l}29 \text { prophylactic } \\
16 \text { therapeutic }\end{array}$ & 360 & $\begin{array}{l}4 \\
1 \text { - haemodynamic com- } \\
\text { promise }\end{array}$ & 0 \\
\hline
\end{tabular}

Granulocyte transfusions for preventing infections in people with neutropenia or neutrophil dysfunction (Review) 
Table 8. Adverse events requiring permanent discontinuation of the intervention (Continued)

\begin{tabular}{|c|c|c|c|c|}
\hline & & & $\begin{array}{l}1 \text { - abdominal cramps } \\
2 \text { - recurrent blocking of } \\
\text { port }\end{array}$ & \\
\hline Petersen 1987 & $\begin{array}{l}67 \text { prophylactic } \\
4 \text { therapeutic }\end{array}$ & Not reported & $\begin{array}{l}6 \\
1 \text { - low platelet count } \\
1 \text { - bleeding from arterio- } \\
\text { venous shunt } \\
4 \text { - obstruction of lumen of } \\
\text { shunt or catheter }\end{array}$ & $\begin{array}{l}13 \\
5 \text { - transfusion reactions } \\
3 \text { - no increment in granu- } \\
\text { locyte count } \\
5 \text { - donor required for } \\
\text { platelet transfusions }\end{array}$ \\
\hline Schiffer 1979 & $\begin{array}{l}10 \text { prophylactic } \\
0 \text { therapeutic }\end{array}$ & Not reported & Not reported & $\begin{array}{l}1 \\
1 \text { - diffuse pulmonary infil- } \\
\text { trate }\end{array}$ \\
\hline Strauss 1981 & 54 prophylactic & 987 & Not reported & $\begin{array}{l}6 \\
\text { (not further defined) }\end{array}$ \\
\hline Sutton 1982 & $\begin{array}{l}29 \text { prophylactic } \\
2 \text { therapeutic }\end{array}$ & Not reported & Not reported & $\begin{array}{l}5 \\
\text { (not further defined) }\end{array}$ \\
\hline Winston 1980 & $\begin{array}{l}19 \text { prophylactic } \\
6 \text { therapeutic }\end{array}$ & Not reported & Not reported & 0 \\
\hline
\end{tabular}

\section{WHAT'S NEW}

Last assessed as up-to-date: 20 April 2015.

\begin{tabular}{|c|c|c|}
\hline Date & Event & Description \\
\hline 20 April 2015 & New search has been performed & $\begin{array}{l}\text { New search, two new citations added, one completed } \\
\text { study was identified in the updated search (Vij 2003), } \\
\text { and one ongoing study was identified (NCT01204788) } \\
\text { ' } \\
\text { 'Risk of bias' assessment of all included studies updated. } \\
\text { gummary of findings' table added. PRISMA flow dia- } \\
\text { gram added (Stovold 2014). }\end{array}$ \\
\hline 20 April 2015 & New citation required but conclusions have not changed & One new study added but conclusions not changed. \\
\hline 27 March 2014 & Amended & Contact details updated. \\
\hline
\end{tabular}




\section{H I S T O R Y}

Protocol first published: Issue 3, 2005

Review first published: Issue 1, 2009

\begin{tabular}{lll}
\hline Date & Event & Description \\
\hline 14 May 2008 & Amended & Converted to new review format. \\
\hline 29 November 2007 & New citation required and conclusions have changed & Substantive amendment \\
\hline
\end{tabular}

\section{CONTRIBUTIONSOFAUTHORS}

- Lise Estcourt: searching, selection of studies, eligibility and methodological quality assessment, data extraction and analysis, and content expert.

- Simon Stanworth: protocol development, data extraction and analysis and content expert.

- Edwin Massey: protocol development and content expert.

- Carolyn Doree: protocol development, searching; selection of studies; final report.

- Patricia Blanco: searching; selection of studies and data extraction.

- Sally Hopwell: methodological expert

- Marialena Trivella: methodological expert

\section{DECLARATIONSOF INTEREST}

- Lise Estcourt is partly funded by an NIHR Cochrane Programme Grant.

- Edwin Massey is involved in the design of clinical trials of granulocytes for transfusion.

- Carolyn Doree: none to declare

- Simon Stanworth is involved in the design of clinical trials of granulocytes for transfusion.

- Patricia Blanco is funded by an NIHR Cochrane Programme Grant.

- Sally Hopwell is partly funded by an NIHR Programme Grant

- Marialena Trivella is partly funded by an NIHR Programme Grant 


\section{SOURCES OF SUPPORT}

\section{Internal sources}

- National Blood Service, Research and Development, UK.

\section{External sources}

- Department for International Development (DFID), UK.

\section{DIFFERENCES BETWEEN PROTOCOLANDREVIEW}

We did not pre-specify in the protocol how we would deal with any unit of analysis issues. There were unit of analyses issues. In Mannoni 1979, participants were randomised more than once, 44 participants were included within the study but six participants were re-randomised. Data for the first randomisation could not be extracted from the report, and further information from the authors was not available. Data from this study were therefore not incorporated into any meta-analyses.

The methodology of the review has changed in this update of the review to conform to current Cochrane Collaboration recommendations.

We used GRADE to build a 'Summary of findings' table as suggested in the Cochrane Handbook for Systematic Reviews of Interventions (Schünemann 2011. A GRADE assessment had not been pre-specified in the protocol.

For time-to-event outcomes, we planned to extract the hazard ratio (HR) from published data according to Parmar 1998 and Tierney 2007. However, no time to event data were reported.

We did not perform a formal assessment of potential publication bias (small trial bias) by generating a funnel plot and statistically test using a linear regression test (Sterne 2011) as no meta-analysis contained 10 or more studies.

We planned to use the random-effects model for sensitivity analyses as part of the exploration of heterogeneity. However, none of the analyses performed reported heterogeneity, as expressed by the $\mathrm{I}^{2}$ above $50 \%$, therefore only the fixed-effect model was reported.

We did not perform a sensitivity analysis including only those studies at low risk of bias because none of the studies were at low risk of bias.

No study reported the duration of neutropenia reversal.

\section{INDEX TERMS}

\section{Medical Subject Headings (MeSH)}

Anti-Bacterial Agents [therapeutic use]; Antifungal Agents [therapeutic use]; Bacterial Infections [* prevention \& control]; Glucocorticoids [therapeutic use]; Granulocyte Colony-Stimulating Factor [therapeutic use]; Granulocytes [*transplantation]; Leukocyte Disorders [complications; therapy]; Leukocyte Transfusion [ ${ }^{*}$ methods]; Mycoses [ ${ }^{*}$ prevention \& control]; Neutropenia [complications; *therapy]; Randomized Controlled Trials as Topic 


\section{MeSH check words}

Humans Copyright $\odot 2015$ The Cochrane Collaboration. Published by John Wiley \& Sons, Ltd. 